\title{
Composition and proliferation of normal human tracheobronchial mucosa
}

Citation for published version (APA):

Boers, J. E. (1997). Composition and proliferation of normal human tracheobronchial mucosa. [Doctoral Thesis, Maastricht University]. Datawyse / Universitaire Pers Maastricht. https://doi.org/10.26481/dis.19971107jb

Document status and date:

Published: 01/01/1997

DOI:

10.26481/dis.19971107jb

Document Version:

Publisher's PDF, also known as Version of record

\section{Please check the document version of this publication:}

- A submitted manuscript is the version of the article upon submission and before peer-review. There can be important differences between the submitted version and the official published version of record.

People interested in the research are advised to contact the author for the final version of the publication, or visit the DOI to the publisher's website.

- The final author version and the galley proof are versions of the publication after peer review.

- The final published version features the final layout of the paper including the volume, issue and page numbers.

Link to publication

\footnotetext{
General rights rights.

- You may freely distribute the URL identifying the publication in the public portal. please follow below link for the End User Agreement:

www.umlib.nl/taverne-license

Take down policy

If you believe that this document breaches copyright please contact us at:

repository@maastrichtuniversity.nl

providing details and we will investigate your claim.
}

Copyright and moral rights for the publications made accessible in the public portal are retained by the authors and/or other copyright owners and it is a condition of accessing publications that users recognise and abide by the legal requirements associated with these

- Users may download and print one copy of any publication from the public portal for the purpose of private study or research.

- You may not further distribute the material or use it for any profit-making activity or commercial gain

If the publication is distributed under the terms of Article $25 \mathrm{fa}$ of the Dutch Copyright Act, indicated by the "Taverne" license above, 
Composition and proliferation of normal human tracheobronchial mucosa 
The author of this thesis is highty indebted to the following organizations for their financial suppont:

Stichting Kinische Pathologie Zuid-Limburg Stichting ter Bevordering van de Continuiteit van de Gezondheidszorgverlening Nederlands Astma Fonds

Leica

Colofon

Uitgever: Datawyse / Universitaire Pers Mastricht

Drukker: Krips Repro, Meppel

Gezet in Humanst521 L. BT Light 11 pos

Composition and proliferation of nomal human tracheobronchial mucosa

Boers. James Evan

Matastricht Universitaire Pers, - H.

Thesis Maastricht. - With ref. - With sumpmary in Dutch

ISBN $90-9010950-1$

NUGI 743

(1) . E. Boers, Maastricht 1997

All rights reserved. No part of this book may be reproduced, stored in a retrieval system, or transmitted, in any form or by any means, electronic, mechanical, or otherwise without the prior written permission of the holder of the copyright. 


\title{
Composition and proliferation of normal human tracheobronchial mucosa
}

\author{
Proefschrift
}

ter verkrijging van de graad van doctor aan de Universiteit Maastricht,

op gezag van de Rector Magnificus, Prof. Mr. M. J. Cohen, volgens besluit van het College van Decanen, in het openbaar te verdedigen, op vrijdag 7 november 1997 om 14.00 uur,

door

James Evan Boers

geboren te Calgary (Canada) op 20 april 1959 
Promotor:

Prof. Dr. J.W. Arends

Co-promator:

Dr. F.B.J.M. Thunnissen

Beoordelingscommissie:

Prof. Dr. E.F.M. Wouters (woorzitter)

Prof. Dr. J. Drukker

Prof. Dr. W.J. Mooi (Erasmus Universiteit Rotterdam)

Prof. Dr. F.C.S. Ramaekers

W. D. Travis, MD (American Forces Institute of Pathology, Washington, D.C., USA) 
En la forest de Longue Attente chevauchant par divers sentiers m'en voys, ceste année présente où voyage de Desiriers

In het Woud der Lang Verwachten te paard op pad, dolenderwijs zie ik mijzelf dit jaar bij machte tot Verlangens' verre reis

Charles d'Orléans (1394-1465) (vertaling: Hella $S$. Haasse)

Ter nagedachtenis aan

Gerard H.J. Tegelaar, SMI

(1959-1989) 



\section{Contents}

Chapter One. General introduction ................... 9

1. Introduction ............................... 10

2. Organisation of the lower conducting airways $\ldots \ldots \ldots \ldots \ldots \ldots \ldots$ |

3. Composition of the normal tracheobronchial mucosa $\ldots \ldots \ldots \ldots \ldots \ldots 12$

3.1. Short historical overview \& microscopical techniques $\ldots \ldots \ldots \ldots 12$

3.2. Morphology and function of individual cell types $\ldots \ldots \ldots \ldots \ldots \ldots$

3.2.1. Neuroendocrine cells

3.2.2. Basal cells

3.2.3. Goblet cells

3.2.4. Ciliated Cells

3.2.5. Clara cells

3.2.6. Intermediate (or parabasal) cells

3.2.7. Other tracheobronchial epithelial cell types

3.2.8. Nonepithelial cells

3.3. Quantitative data of the tracheobronchial mucosal composition $\ldots \ldots, 17$

4. Proliferation of tracheobronchial epithellial cells . . . . . . . . . . . . 19

4.1. Concepts ............................... 19

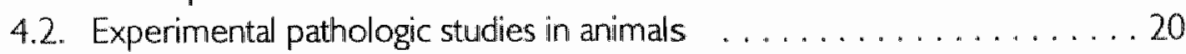

4.3. Proliferation in human tracheobronchial epithelium $\ldots \ldots \ldots \ldots \ldots 2$.

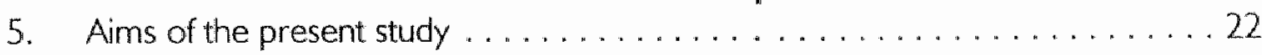

Chapter Two. Neuroendocrine cells $\ldots \ldots \ldots \ldots \ldots \ldots . . \ldots 25$

Chapter Three. Goblet and ciliated cells ............... 35

Chapter Four. Basal and parabasal cells $\ldots \ldots \ldots \ldots \ldots \ldots . \ldots 9$

Chapter Five. Clara cells .......................6 61

Chapter Six. An example of abnormal proliferation in human tracheobronchial epithelium: squamous metaplasia . . . . . . . . . . 73

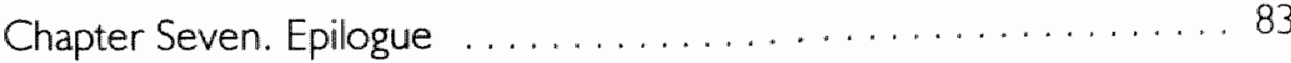

1. Introduction ................................. 84 
2. Reproducible and efficacious quantification of the tracheobronchial mucosa . . 84

2.1. Reproducibility .......................... 84

2.2. When is the composition of the human tracheobronchial epithelium

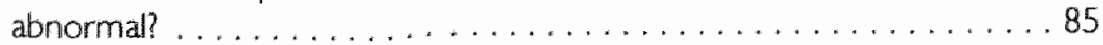

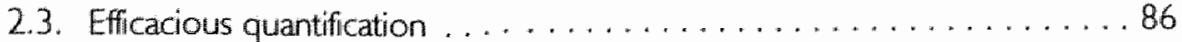

3. Composition of the normal human tracheobronchial mucasa . . . . . . . . . 87

3.1. The normal human tracheobronchial mucosa: a comprehensive account 87

3.2. Cell typing of tracheobronchial mucosa: electron microscopy or

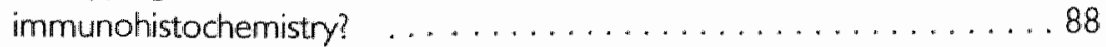

3.3. The complex composition of the human tracheobronchial mucosa: can structure explain function? . . . . . . . . . . . . . . . . . . . 89

4. Proliferation of tracheobronchial epithelial cells in man . . . . . . . . . . .91

4.1. The proliferation compartment of normal human tracheobronchial mucosa: a comprehensive account ............................

4.2. Proliferation in the lower conducting airway epithelium: two separate stern cell compartments? ........................... 93

4.3. An example of proliferation in abnormal tracheobronchial mucosa:

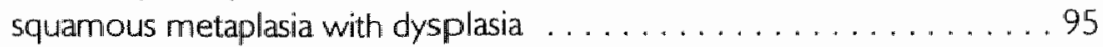

5. Conduding remarks . . . . ...................... 96

Appendix to Chapter Seven. Cell type composition and the overall proliferation compartment of the normal human tracheobronchial epithelium. Mean values and $90 \%$ confidence intervals.

Chapter Eight. Summary / Samenvatting . . . . . . . . . . . . . . . 103

Dankwoord

Color plates

Figure 2, Chapter Two

Figure 2, Chapter Three

Figure 1, Chapter Four

Figure 1, Chapter Five

Bibliography

Curriculum vitae 


\section{One}

General Introduction 


\section{Introduction}

The human lung accomplishes the intake of oxygen and the elimination of carbon dioxide. Air is continuously transported into and out of the respiratory portion, which consists of alveoli and is directly involved in gas exchange, through the conducting airways '. These air passages consist of the upper conducting airways (the nose, pharynx and the larynx) and of the trachea, bronchi and bronchioles known as the lower conducting airways. The mucosal surface of the lower conducting airways is exposed to a considerable number of airborne pathogens ${ }^{2,3}$. Consequently, primary pulmonary diseases induding COPD, asthma and bronchogenic carcinoma are extremely common and account for a high world-wide mortality ${ }^{4-6}$.

In the study of disease, pathology focuses on the structural and functional consequences of injurious stimuli on organisms ${ }^{7}$; morphologic alterations are one of the aspects of a disease process caused by changes in the cellular ${ }^{8}$ and extra-cellular composition. Prerequisites for an adequate description of structural deviations are a comprehensive study of normal histology, and an analytical method which allows definition of normal ${ }^{9}$ and abnormal in statistical terms.

The microscopic anatomy of the surface mucosa lining the lower conducting airways in adult humans has been the subject of extensive research. The heterogenous epithelium consists of at least five principal types of cells ${ }^{10-34}$, namely neuroendocrine ${ }^{35-55}$, goblet and ciliated ${ }^{56-70}$, basal ${ }^{71,72}$ and Clara cells ${ }^{73-82}$; the composition of the tracheobronchial epithelium varies depending on airway level. While the results of cumulative research efforts appear to be without significant lacunae, no definition is offered of normal human conducting airway epithelium comprising all important cell types at all airway levels. Also, most researchers have employed sophisticated techniques (i.e., electron microscopy or plastic tissue sections) which predudes simple comparison of the presented data with archival lung tissues of other institutions.

Surface epithelial cells proliferate relatively slowly in the conducting airways of normal laboratory animals ${ }^{72},{ }^{83-112}$; the stem cells of the tracheobronchial lining epithelium appear to be basal cells and Clara cells. Cellular proliferation increases enormously in response to injury, and plays a major role in tissue repair ${ }^{12.84-110,113,114}$ and in the development of various disease states induding COPD and lung cancer ${ }^{86,91,113.115}$. Information about the proliferation of human tracheobronchial mucosa is virtually absent, presumably due to technical constraints ${ }^{116.118}$. As the organization of the conducting airways shows speciesspecific variations in addition to a highly diverse epithelial cell composition, extrapolation of data obtained from animal models concerning epithelial proliferation to the human lung is highly questionable ${ }^{119,120}$.

In the present study, a comprehensive approach to the determination of the composition and proliferation of the human tracheobronchial mucosa is described employing relatively 
simple immunohistochemical techniques. Normal values of the cell type distribution and proliferation of the normal airway lining epithelium are established corresponding to various airway levels using an efficacious quantification procedure. As the described methods can be carried out on routinely processed archival lung tissues, comparison of data obtained in future studies with the presented normal values is now feasible. Such studies may reveal vital information on the biology and pathogenesis of lung disease in man.

\section{Organisation of the lower conducting airways}

The lower conducting airways are a branching system of tubes lined by a ciliated pseudostratified epithelium 1. 13. 121. The pattern of airway branching pattern can described by a model of irregular bifurcations ${ }^{12.1}$ in which the trachea divides into a new generation of two smaller airways with two different diameters and lengths along two different axes. The tracheobronchial 'tree', a metaphorical name of the lower conducting airways 1,13 , extends from the trachea down to the respiratory zone by an average of 11 to 24 successive generations ${ }^{121}$. Considerable variation is present in the total number of airway generations ${ }^{a}$ and in the airway path lengths ${ }^{b}$ between different parts of the tracheobronchial tree as a result of branching asymmetry; in addition, the range of internal airway diameters of a particular airway generation is substantial ${ }^{13,121}$.

The basic morphology of the trachea and the larger branching airways (or bronchi) is similar and consists of the mucosa, submucosa, smooth muscle and plates or irregular plaques of supporting cartilage ${ }^{13,122,123}$. Submucosal seromucous glands open by ducts at the mucosal surface ${ }^{123}$. The submucosal glands and supporting cartilage gradually disappear after an average of 12 airway generations; the subsequent conducting airways are termed bronchioles (or small airways) ${ }^{122-124 .}$.

By definition, the distal boundary of the tracheobronchial tree is positioned at the junction between the terminal nonalveolarized bronchiole and the respiratory bronchiole 1. 121. ${ }^{125}$. The terminal bronchiolar wall differs from proximal (or membranous) bronchioles primarily by its juxtaposition to the respiratory zone, but their wall morphology is similar. The respiratory bronchioles in man comprise three generations of alveolarized airways lined by three different epithelia: (1) ciliated pseudostratified epithelium extending from the terminal bronchioles, (2) alveolar lining consisting of type I and type 2 pneumocytes and (3) a transitional zone between (I) and (2) uniformly composed of cuboidal nonciliated cells ${ }^{73,79}$. The traditional distinction between the conducting zone and the respiratory zone is evidently based on a simple anatomical dichotomy (i.e., alveolarized versus non-alveolarized airways) but has no functional meaning. For the purpose of the present study, the lower conducting airway mucosa will include not only the pseudostratified lining epithelium

\footnotetext{
The range of generation numbers between the trachea and the terminal bronchioles is 8 to 21 "

"The average airway path length between the laryngeo tracheal junction and the respiratiory zone is $27 \mathrm{~cm}$, with a range of 20 to $35 \mathrm{~cm}^{171}$.
} 
of the tracheobronchial tree but also the (histologically similar) extension of this cillated epithelium in the respiratory bronchioles up to the transitional zone.

\section{Composition of the normal tracheobronchial mucosa ${ }^{a}$}

\subsection{Short historical overview \& microscopical techniques}

By 1938, the composition of the human tracheobronchial epithelium was already elucidated in considerable detail using light microscopy combined with histochemical staining techniques. The basic structure of the human pseudostratified epithelium, containing ciliated cells, goblet and basal cells was described in late nineteenth century ${ }^{16}$; later on, Clara $^{73}$ and neuroendocrine cells ${ }^{126}$ were also recognized. Important new histochemical stains (e.g., periodic acid-Schiff and Alcian Blue) ${ }^{127}$ developed shortly after the Second World War made elaborate study of goblet cell mucins possible $25,27,57,60,61,65,98-101,105,128$ 139

The adoption of transmission electron microscopy disclosed the ultrastructural characteristics of previously identified human tracheobronchial cells ${ }^{16,28,29,34,41,42,58,70,76,74.77,102,140-}$ ${ }^{143}$ and facilitated the recognition of new epithelial cell types in laboratory animals ${ }^{144}$. In addition, considerable interspecies heterogeneity in the cell type ultrastructure $e^{77,144.146}$ and the distribution along the tracheobronchial tree ${ }^{17,120,144,145,147-149}$ was revealed by detailed qualitative and quantitative studies. Identification of cytoplasmic secretory granule contents of Clara ${ }^{150}$ and neuroendocrine cells ${ }^{15 \|}$ was made with the use of immuno-electron microscopy. The scanning electron microscope proved particularly useful in the study of the various cell types at the junction between the conducting and respiratory zones in the respiratory bronchiole ${ }^{79,122}$.

Application of plastic embedding techniques resulting in semithin tissue sections with distinct histologic quality facilitated the assessment of individual cell type $\mathrm{e}^{71.76}$ distribution and comprehensive tracheobronchial cell type quantification ${ }^{34.98-101,144,148}$. The combination of plastic tissues sections with autoradiography following ${ }^{3} \mathrm{H}$-thymidine infusion became the standard experimental pathologic research tool in the studly of airway cell proliferation (see section 4.2) ${ }^{89,888,92-96,104}$.

The introduction of immunohistochemistry revolutionized both clinical and experimental pathology ${ }^{152}$. In the conducting airway epithelium, neuroendocrine secretory granule constituents were studied extensively ${ }^{35}$, 40, 47, 49-52, 153-166; quantitation of human pulmonary neuroendocrine cells was carried out using several different antibodies ${ }^{37.39,48,50,53,55,167.170}$. Qualitative studies were performed on Clara cells ${ }^{81.171-174}$ and basal cells ${ }^{175}$, while the expression of different cytokeratin types ${ }^{31,176,177}$ and other less well defined cell type

\footnotetext{
"The submukosal glandular epithelum will not be considered further as the epithelial composition differs from the mucosa lining the lower conducting ainways.
} 
markers $^{178}$ was also elucidated. In man, the immunohistochemical detection of a proliferation-associated marker has been reported only rarely ${ }^{17}$. The concomitant use of immunohistochemical markers of both cell type and proliferation was performed in one study in which rat neuroendocrine cells were studied ${ }^{112.179}$ (see section 4.2).

\subsection{Morphology and function of individual cell types}

The adult human tracheobronchial tree is lined with a pseudostratified ciliated epithelium which contains five well defined cell types ${ }^{16,17}$. In addition, an intermediate or parabasal cell has been recognized by several researchers ${ }^{16,17}$. A brief morphological description followed by some remarks about possible function will be provided for each of the six different cell types. Subsequently, other cell types that could be present in the human tracheobronchial mucosa are briefly mentioned. Studies regarding the quantitative assessment of the epithelial cell types will be considered in the next section (3.3).

\subsubsection{Neuroendocrine cells}

Solitary pulmonary neuroendocrine cells (PNECs), also known by many other names including $K$ [ultschitsky] cells, are triangular or bipolar fusiform shaped cells ${ }^{180}$. At the apex

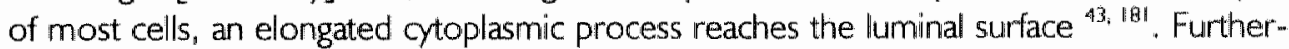
more, the cells possess dendrite-like processes that protrude over a long distance into the intercellular spaces among other epithelial cells ${ }^{43}$. Innervated clusters of PNECs called neuroepithelial bodies (NEBs) are invariably found in fetal lungs ${ }^{42,181.183}$; NEBs are also reported to be present in the adult tracheobronchial tree ${ }^{36,39,182}$.

Ultrastructurally, PNECs contain membrane-bound dense-core granules (DCGs) ${ }^{36,41,44}$. One of the constituents of all DCGs is chromogranin $A^{153,154,184,185}$, a potentially useful general neuroendocrine marker ${ }^{186}$. In addition, secretory products are found in DCGs including gastrin releasing peptide (or 'mammalian bombesin'), calcitonin generrelated protein and calcitonin ${ }^{51,52.151 .168 .189}$.

Within a PNEC, there is a clear partitioning of DCGs towards the base of cell ${ }^{181}$ and the dendrite-like cytoplasmic processes also contain DCGs ${ }^{43}$. Therefore, the polarity of secretion is directed towards adjacent epithelial cells and structures rather than towards the airway lumen, indicating a paracrine function of these cells ${ }^{181}$. That the neuroendocrine cell exerts its influence by releasing locally active humoral substances was already suggested by its discoverer Feyrter in $1938^{126}$. Though the definitive role of PNECs in the adult human lung remains to be established, several possibilities have been proposed including involvement in the inflammatory response, in stimulating cell growth and in bronchial smooth muscle tone ${ }^{188}$. 


\subsubsection{Basal cells}

Basal cells occur in a variety of shapes ranging from columnar to flat ${ }^{71,72}$. Basal cells with an avoid or columnar morphology form a single row along the basement membrane in the upper tracheobronchial tree and are responsible for the pseudostratified appearance of the epithelium ${ }^{16}$. Scattered flat-shaped basal cells are found in the bronchioles ${ }^{16.72}$.

Ultrastructurally, basal cells are the only cell type that are firmly attached to the basement membrane by hemidesmosomes; in all but the smaller airways, cillated or nonciliated columniar cells make minimal contact to the basal lamina but form desmosome attachments with basal cells ${ }^{16,17,72,189.190}$. Basal cells contain an extensive keratin filament network interconnecting desmosomes and hemidesmosomes ${ }^{17}$.

Immunohistochemical studies performed on the conducting airway epithelium have shown that keratins 5 and $\| 4$ are preferentially expressed by basal cells $31,175,176,191.196$. Keratins 5 and 14 may form a resilient network that is particularly tough and elastic ${ }^{191}$.

Basal cells probably perform other functions apart from having a role in the adhesion of the tracheobronchial epithelium to the basement membrane. In stratified squamous epithelium, keratin 5 and/or 14 immunoreactive basal cells are characteristic of the proliferation compartment ${ }^{175,197}$ "Experimental pathologic studies have suggested that the basal cell is one of the stem cells of the lower conducting airway epithelium ${ }^{90,92,94,104,198-200}$.

\subsubsection{Goblet cells}

Typical goblet cells have a cup-shaped apical aspect with a tapering base; the cytoplasm is distended by large coalescing mucous granules ${ }^{16,64}$. The shape of a goblet cell changes after (partial) mucous discharge into an elongated cell, containing a few mucous granules protruding into the airway lumen ${ }^{16.64}$; the change in morphology is sometimes reflected by a different name, i.e., small mucous gramule cell ${ }^{29}$.

Using standard electron microscopical techniques, the mucous granules of human goblet cells appear as large structures with varying electron-lucency which in some instances contain electron-dense cores ${ }^{16,143}$. A considerable interspecies variation in mucous granule ultrastructure has been described ${ }^{145}$, in addition, certain fixatives can change the appearance of the mucous granules into uniformly electron-dense structures ${ }^{64,145}$. Ultrastructural identification of cell type can be problematic at times as a number of different secretory cell types exist with predominantly electron-derise granules (e.g., Clara celis) ${ }^{145}$.

The main constituent of mucous are mucins, a broad family of complex molecules that consist of high molecular weight glycoproteins ${ }^{64,139}$. A variety of mucin genes located on different chromosomes are implicated in the synthesis of the peptide skeleton ${ }^{139}$. In the human respiratory tract, mucins contain are either neutral or acidic carbohydrate side chains, staining red with the periodic acid-Schiff (PAS) histochemical procedure and blue with the Alcian Blue $(\mathrm{pH}=2.5)$ stain, respectively ${ }^{65 .}$.

Mucous droplets secreted by goblet cells form a high-viscosity protective layer overlying the ciliary tips of ciliated cells ${ }^{70,443,201}$. Muco-ciliary clearance is an important defence 
mechanism responding to the inhaled irritants ${ }^{20,143,201}$. The extraordinary diversity of the carbohydrate chains most probably plays an important role in the defence of the mucosa ${ }^{139}$ by facilitating adherence prior to mucociliary clearance ${ }^{64}$. An elevation in goblet cell secretory activity is noted following inhalation of many airway irritants, and the number of goblet cells is increased in a considerable variety of pulmonary diseases ${ }^{32,56.57 .60,64.66-69.76,}$ 90, 104-106, 110, 131, 202-207.

\subsubsection{Ciliated Cells}

The ciliated cell is a columnar cell with 100 to 250 cilia found at the luminal surface ${ }^{16,208}$. A cilium contains an axoneme composed of 2 single microtubuli surrounded by nine microtubular doublets ${ }^{70}$. The axoneme originates in the basal body, located in the apical region of the cell cytoplasm ${ }^{70}$. In the respiratory tract, $\beta$-tubulin is the major protein of microtubules which can detected immunohistochemically ${ }^{209}$.

The main role of the ciliated cell is the propulsion of fluid lining the surface epithelium towards the larynx ${ }^{149.210}$. The cilia are bathed in a periciliary sol layer; on top of the cillia lies the mucous gel which may be continuous or consists of discrete islands ${ }^{70,201,211}$. Normal cilia beat at a frequency of 10 to $25 \mathrm{~Hz}^{201}$. The function of the mucociliary 'escalator' is impaired in certain congenital syndromes (i.e., Kartagener syndrome and cystic fibrosis) ${ }^{70.212}$, following inhalation of irritants ${ }^{129.149 .212}$, in squamous metaplasia and in many acquired pulmonary diseases ${ }^{70,201,211,213}$.

\subsubsection{Clara cells}

A Clara cell is a dome-shaped non-ciliated cell bulging into the airway lumen ${ }^{73.74,214}$. Ultrastructurally, granular endoplasmic reticulum and mitochondria are the dominant cytoplasmic organelles ${ }^{77}$. A small number (e.g., six) membrane-bound electron-dense ovoid granules with an average diameter of $300 \mathrm{~nm}$ are located in the luminal part of the cell ${ }^{74,77,80}$. Only small patches of glycogen are infrequently present in the basal cytoplasm 77

As nonciliated columnar cells in other species have no common ultrastructural features " 102. 146. 214, it appears appropriate to preserve the eponym "Clara cell' to the human lung, and to refer to a more or less similar cell type in non-human species as "Clara-like cell"

Clara cells are thought to have three major functions ${ }^{78.119 .214 .215}$ : (1) synthesis and secretion of protein components (e.g. Clara cell $10 \mathrm{kd}$ protein or CCl0) of the extracellu-

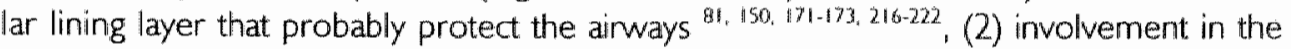
metabolism of xenobiotic compunds ${ }^{219} .223 .225$, and (3) propagation of new Clara cells and ciliated cells ${ }^{86,87,99,103,226,227}$. Antibodies raised against human $\mathrm{CClO}^{82,171}$ and a similar secretory protein $\mathrm{PI}{ }^{222}$ can be used as immunohistochemical marker of Clara cells.

\footnotetext{
"In most papers, Clara-like cetls are referred to as 'nonciliated columnar' cells, which is a rather elurive terminology.
} 


\subsubsection{Intermediate (or parabasal) cells}

After electron microscopical identification of the 5 major epithelial cell types in the human conducting arrway epithelium, a number of cells remain yet undassified. Some cells are of epithelial nature which lack sufficient cytoplasmic characteristics for proper categorization ${ }^{17}$. 29. 33. 143, and are known as indeterminate cells. Some researchers recognize a poorly defined layer of cells located just above the basal cells. which they resemble electron microscopically ${ }^{16,17}$, i.e. the cytoplasm of these 'intermediate' cells contains a dense keratin filament network. Because of the striking similarity of cytoplasmic differentiation to basal cells and of intermediate (or parabasal) cells, an interrelation of these two cell types is not inconceivable. However, epithelial cells are present in the tracheobronchial epithelium with a position between the basal and luminal cell rows that do not correspond ultrastructurally with basal cells.

\subsubsection{Other tracheobronchial epithelial cell types}

Breeze and Wheeldon ${ }^{16}$ have reported the presence of 6 other cell types present in the human tracheobronchial lining epithelium in addition to the six major epithelial cell types (i.e., neuroendocrine, basal, goblet, ciliated, Clara and intermediate cells).

Serous cells have ultrastructural similarities to Clara(-like) cells and are the major secretory cells of the rat. These cells are also present in the human fetal conducting airway muco$\mathrm{sa} ;$ in addition, one study reported the occurrence of a few serous cells in the bronchiolar epithellium of lung cancer patients ${ }^{80,144}$.

The brush cell, a nonciliated cell with a prominent tuft of microvilli ${ }^{13}$, is present in tracheal mucosa of rats. After being described in some early electron microscopical studies in man ${ }^{16}$ "no positive identification has been reported since ${ }^{143}$.

Special Type cells with numerous intracytoplasmatic membrane-bound inclusions, infrequently found in dogs, have been identified in the tracheal epithelium of 2 smoking laryngeal cancer patients ${ }^{16}$.

Oncocytes " cells with a deeply eosinophilic cytoplasm due to an abundance of mitochondria, are degenerative phenomena sometimes present in man $^{16}$.

Nonciliated columnar cell is a descriptive term reserved for inclassifiable columnar cells.

Finally, squamous cells are metaplastic cells; by definition, metaplasia is an abnormal finding, and does not occur in the normal human tracheobroncial mucosa. Other transitional cell forms (i.e., Clara-mucous cell) have been described as metaplastic phenomena ${ }^{143}$.

As the cell types discussed in this subsection are only infrequently (if at all) described in the normal human tracheobronchial mucosa, the present study will focus on the six major epithelial cell types adressed to in the sections 3.2.1. to 3.2.6. In addition, squamous metaplasia is considered further in Chapter 6 . 


\subsubsection{Nonepithelial cells}

Some cells in the tracheobronchial lining mucosa are not epithelial but migratory cells, e.g. lymphocytes ${ }^{24,30,69,133,137,206,228-232}$, mast cells ${ }^{143}$ or Langerhans cells ${ }^{233}$.

\subsection{Quantitative data of the tracheobronchial mucosal composition}

The morphology and function of the cell types in the adult human tracheobronchial mucosa has been studied in considerable detail, as the previous section indicates. Quantitative assessment of the epithelial composition has been carried out much less frequentlly. A comprehensive review of the present body of knowledge concerning the numerical data of the major epithelial cell types is shown in the table.

Table. Quantitative assessment of adult human tracheobronchial mucosal cell types.

\begin{tabular}{|c|c|c|c|c|c|}
\hline $\begin{array}{l}\text { cell } \\
\text { type }\end{array}$ & ref. & units & $\begin{array}{l}\text { quantity } \\
\text { (ainway level/ diameter) }\end{array}$ & technique & $\begin{array}{l}\text { sub- } \\
\text { jects }\end{array}$ \\
\hline $\begin{array}{l}\text { neuro- } \\
\text { endo- } \\
\text { crine }\end{array}$ & 39 & cells $/ 10 \mathrm{~cm} \mathrm{Bm}$ & 2-3 (all levels)" & $\mathrm{H} H \mathrm{C}[\mathrm{CgA}]$ & $\begin{array}{l}n= \\
14\end{array}$ \\
\hline
\end{tabular}

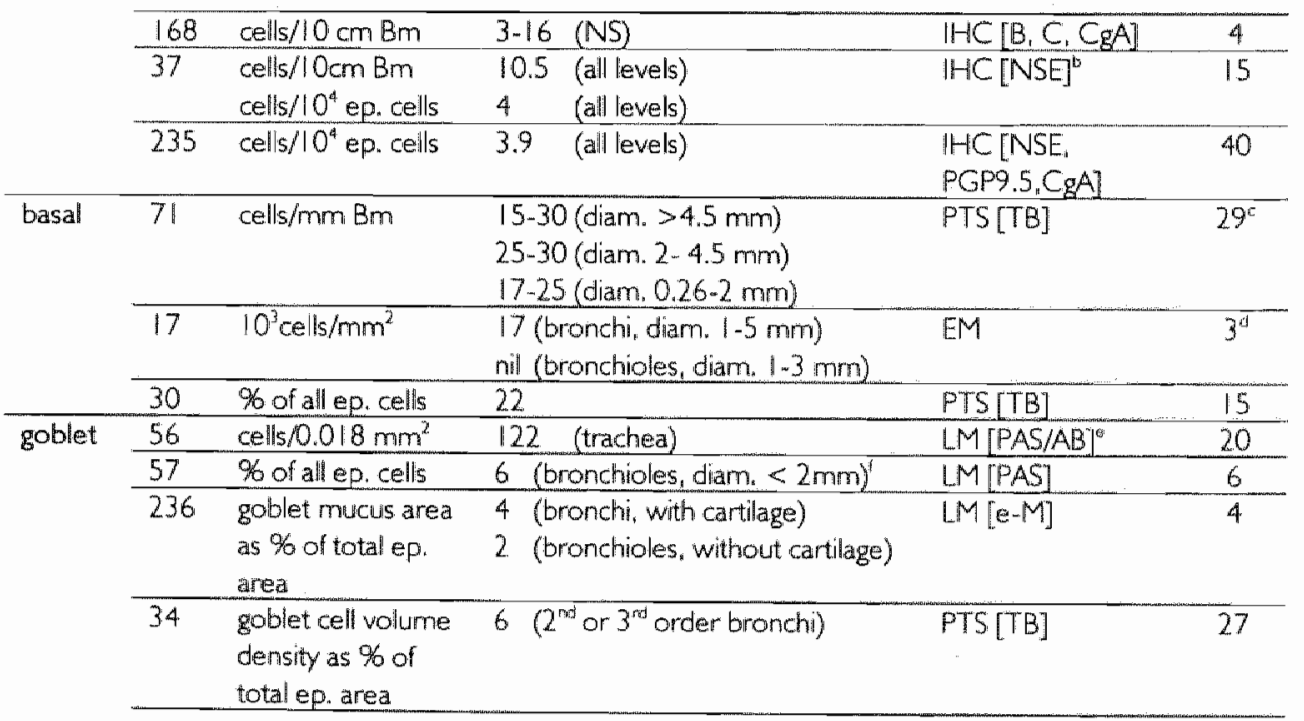

\footnotetext{
Many NEBs were in the bronchioles and are not taken into account in this table.

- Two-thirds of neuroendocrine cells. GRP/bombesin positive, one-third C positive.

"Mainly lung resection specimens for primary bronchogenic carcinoma.

'One patient with primary ademocarcinoma.

"Whole-mount technique of tissue strips.

"Respiratory bronchioles not taken into account.
} 


\begin{tabular}{|c|c|c|c|c|c|}
\hline $\begin{array}{l}\text { cell } \\
\text { type }\end{array}$ & rel. & units & $\begin{array}{l}\text { quantity } \\
\text { (airway level/ diameter) }\end{array}$ & technique & $\begin{array}{l}\text { sub- } \\
\text { jects }\end{array}$ \\
\hline \multirow[t]{3}{*}{$\begin{array}{l}\text { goblet } \\
\text { cont'd }\end{array}$} & 76 & $\%$ of all ep. cells & $\begin{array}{l}0.1 \text { (tem \& resp, bronchioles) } \\
1.2 \text { (all bronchioles, < } 3 \mathrm{~mm} \& \\
\text { no cartilage) }\end{array}$ & PTS [TB] & 4 \\
\hline & 17 & $10^{3}$ cells/mm & $\begin{array}{l}5 \text { (bronchi, diam. } 3-5 \mathrm{~mm}) \\
8 \text { (bronchi, diam. } 1-3 \mathrm{~mm}) \\
0 \text { (bronchioles, diam. } 0.4-1 \mathrm{~mm} \text { ) }\end{array}$ & $E M$ & 3 \\
\hline & 30 & $\%$ of ail ep. cells & 15 (bronchi) & PTS [TB] & 15 \\
\hline \multirow[t]{2}{*}{ ciliated } & 17 & $10^{3} \mathrm{cells} / \mathrm{mm}^{2}$ & $\begin{array}{l}18 \text { (bronchi, diam. } 3.5 \mathrm{~mm} \text { ) } \\
18 \text { (bronchi, diam. } 1-3 \mathrm{~mm} \text { ) } \\
14 \text { (bronchioles, diam. } 0.4-1 \text { mum) }\end{array}$ & $E M$ & 3 \\
\hline & 30 & $\%$ of all ep. cells & 48 (bronchi) & PTS [TB] & 15 \\
\hline \multirow[t]{3}{*}{ Clara } & 76 & $\%$ of aill ep. cells & $\begin{array}{l}15 \text { (term \& resp bronchioles) } \\
8 \text { (all bronchioles " }<3 \mathrm{~mm} \& \text { no } \\
\text { cartillage) }\end{array}$ & PTS [TE] & 4 \\
\hline & 80 & \% of all ep. cells & $\begin{array}{l}12 \text { (terninal bronchioles) } \\
25 \text { (respiratory bronchioles) }\end{array}$ & PTS [TE] & 5 \\
\hline & 82 & $\%$ of all ep cells & 30 ('bronchioles') & $1 H C[T Y 5]$ & 10 \\
\hline $\begin{array}{l}\text { "Secre- } \\
\text { tory"a }\end{array}$ & $1 \overline{7}$ & $10^{3} \mathrm{cells} / \mathrm{mmm}^{2}$ & $\begin{array}{l}2 \text { (bronchi, diam. } 3-5 \mathrm{~mm} \text { ) } \\
2 \text { (bronchi, diam. } 1-3 \mathrm{~mm} \text { ) } \\
11 \text { (bronchioles diam. } 0.4-1 \mathrm{~mm} \text { ) }\end{array}$ & $E M$ & 3 \\
\hline
\end{tabular}

Abbreviations: Bm, basement membrane; $N S$, not specified; $H \mathrm{HC}$, immunohistochemistry of paraffin tissue slides: CgA, chromogranin $A_{*} B$, antibombesin; $C$, calcitonin; GRP, gastrin releasing peptide (or 'mammalian" bombesin): NSE, neuro-specilic enolase; PTS, plastic tissue sections: TB, toluidine blue; EM, electron microscopy: e-M, elastic-Masson; TrS, a monodomal anti-CC10 antibody.

The fourteen papers that have been published used a variety of histological techniques ${ }^{b}$ which have been carried out on lung specimens obtained by autopsy 37, 39, 57, 235, 236, lobecto -my/ pneumonectomy 17,71,76,80,82, 168, open lung biopsy or bronchial biopsy ${ }^{30,34.56}$. The lining epithelium of different airway levels (or diameters) were examined. The upper tracheobronchial epithelium has been taken into account in some studies, the distal conducting airways in others. Comprehensive assessment of all airway levels was performed in three papers focused on the neuroendocrine cell type, and the only report concerning almost all cell types ${ }^{\mathrm{c}}$ at virtually all conducting airway levels ${ }^{\mathrm{d}}$. used electron microscopy. The considerable variation in study design is also reflected in the method of quantitative assessment and in the manner of reporting the results. The total number of epithelial cells counted is mentioned in only three reports ${ }^{17.5 \%, 76}$. The quantity of cell types studied are

\footnotetext{
"Comprising the combined neuroendocrine and Cara cell population

"In addition to a histologicat evaluation of bronchial biopsy material, Danel and colleagues ${ }^{33}$ report data of a quantitative cytological assessment using nasal and bronchial brushings and conpare the data of the histological and cytological materials. In bronchial brushes, $64 \%$ are ciliated cells, $11 \%$ are basal cells, and $6 \%$ are 'secretory' cells. These findings. indicating an underrepresentation of basal celis in cytological brush material relative to histological samples, are corrobo. rated by Korn and colleagues ${ }^{234}$.

"Neuroendocrire and Clar cells were combined into one single cell type category.

"Lobectomy specimens were used, preduding assessmert of the trachea or principal bronchi.
} 
expressed in units which differ considerably, namely as a proportion of all airway epithelial cells, numbers of cells per unit of basement membrane (one or two dimensionally) or as a proportion of total epithelial area. Reproducibility of cell type enumeration, an important aspect in quantitative assessment, is not discussed but in one study ${ }^{17}$. Finally, the subjects whose specimens were the basis of the studies performed varied between large groups of young, healthy volunteers ${ }^{34}$ and a few lung cancer patients ${ }^{17.80}$.

Obviously, the wide dissimilarity in study design of the quantitative assessment of tracheobronchial cell types combined with the considerable variations in the units in which the results were published precludes straightforward comparison of the hitherto acquired data with future studies of other institutions.

\section{Proliferation of tracheobronchial epithelial cells}

\subsection{Concepts}

The growth and renewal of the tissues of the body depend upon cellular proliferation, the process of chromosomal duplication followed by cell division ${ }^{237-239}$. Proliferating cells in non-embryonic tissues go through four distinguishable phases of the cell cycle, namely the Gl-phase (a period of cell growth), the S-phase (a period of DNA replication), the G2. phase (a period of preparation for mitosis), and the M-phase (mitosis). The postmitotic cells may stay in the proliferative cycle (i.e., entry into GI-phase, and so forth), may become terminally differentiated (i.e., unable to divide with eventual cell death) or may enter a resting state termed the G0-phase. The quiescent cells in the G0-phase may reenter the GI-phase after the appropriate stimuli ${ }^{86,238-242}$.

In general, tissues may be divided into three broad groups on the basis of their proliferative characteristics ${ }^{83.86,89,107.243 .245}$ : (1) static tissues without any proliferative activity" "(2) continually renewing tissues and (3) expanding (or conditional renewing) tissues. Continually renewing tissues exhibit a relatively high rate of constant cell division facilitating the study of cell kinetics under normal conditions. An example of a continually renewing tissue is the $\mathrm{skin}^{\mathrm{b}}$, composed of a stratified epithelium that is anatomically divided into a proliferative, a maturation and a functional compartment. The proliferative compartment of the skin is located in the germinative layer which is composed of basal cells adherent to the basement membrane. Some basal cells are slowly cycling cells thought to possess extensive selfreplicating capacity (i.e., stem cell properties ${ }^{246}$ ), and produce a transit amplifying cell population. This committed population contains several generations of rapidly proliferating basad cells with finite self-renewal capacity. Postmitotic cells migrate upwards into the maturation compartment made up of the spinous and granular llayers, where differentiation

\footnotetext{
"E.g., nerve tissue.

"Other examples are the bone marrow, the testis and the intestine.
} 
of keratinocytes occurs into the tightly interconnected keratinized layer. This horny layer represents the functional compartment ${ }^{241,244,246,247}$.

Most adult tissues proliferate very slowly under normal conditions but are able to increase cell proliferation manyfold conditional on the need to replace cells in response to injury or other stimuli. The study of cell-kinetics of these expanding (or conditional renewing) tissues is not only complicated by a low proliferative rate in the steady state, but also by a complex histological structure with different co-existing cell components and cell-lineages. As a consequence, the proliferative compartment may not be anatomically evident, and the existence of cell-kinetically distinct subpopulations (e.g., stem cell and transit-amplifying compartments) may be obscured by possible de-differentiation or metaplastic phenomena $241,244,246,247$

\subsection{Experimental pathologic studies in animals}

Experimental pathologic studies indicate that the tracheobronchial epithelium is a conditional renewal system ${ }^{89}, 107.108,248$. Proliferation in lower conducting airway epithelium is difficult to study due to the very low proliferative rate in the steady state ${ }^{86,89.90,107}$, and because the three compartments ${ }^{x}$ are not anatomically distinct. Therefore, the determination of the tracheobronchial proliferation compartment requires a combination of two methods, namely a method that will identify proliferative cells, and a second approach that will classify a particular proliferative cell as one of the major epithelial cell types. Assessment of relatively large quantities of epithelium is a prerequisite for reliable cell population estimates.

A common approach in experimental research of tracheobronchial epithelial proliferation has been in vivo metabolic labeling of ${ }^{3} \mathrm{H}$-thymidine followed by autoradiography of plastic lung tissue sections. When laboratory animals are examined shortly after ${ }^{3} \mathrm{H}$-thymidine administration ${ }^{104}$, the labeling index (LI) will be indicative of the proportion of active cycling cells at any given time (i.e., the proliferative state ${ }^{249.250}$ ). Using this approach in rats under normal conditions, the overall $\mathrm{LI}$ of the upper tracheobronchial epithelium is approximately $2 \%{ }^{83}, 92.94$. The cell type distribution of the proliferation compartment is: basal cells, between $28 \%$ and $66 \%$, serous or Clara-like cells ('secretory cells'), between $10 \%$ and $45 \%$, indeterminate or intermediate cells (see section 3.2 .6 ), between $6 \%$ and $28 \%,{ }^{88,92}$. 94. 104. The overall $\mathrm{L} /$ in hamster bronchial epithelium in the steady state is $0.16 \%$ with a proliferative cell type distribution not unsimilar to rats, but with a signilicant labeling of ciliated cells as well ${ }^{93}$. These studies suggest that the basal cell is the predominant cell type of the proliferation compartment of the upper tracheobronchial epithelium in normal rodents despite their relatively low frequency. The contribution of the secretory cell to cell renewal is also significant, but to a lesser extent than the basal cell.

\footnotetext{
Q.e., the prolferation, naturation and functional compartments.
} 
A labeling index obtained shortly after ${ }^{3} \mathrm{H}$-thymidine administration can only indicate size of the the proliferation compartment ${ }^{249,250}$, and does not provide specific information about cell proliferative rate, cell cycle time or pathways of cell differentiation (or cell lineage) ${ }^{86,242,249,250}$. Some facts about cell lineage can be inferred from studies using pulsechase techniques, which has been performed in normal rodents. If the animals are killed shortly after a single ${ }^{3} \mathrm{H}$-thymidine injection, the predominantly labeled cell type of the upper tracheobronchial epithelium is the basal cell. At some time after the ${ }^{3} \mathrm{H}$-thymidine pulse, an increase is seen of labeled intermediate cells followed by a peak of ciliated and secretory cells. These studies strongly suggest that basal cells may have stem cell features, i.e., they have self-renewal capacity and act as a source of other cell types ${ }^{92.94,104}$. However, the contribution of secretory cells to cell renewal is not insignificant in these studies of the upper tracheobronchial tree. And while the distal conducting airway epithelium in the steady state (where basal cells are scarce or absent) has not been the subject of detailed study, considerable evidence has accumulated that secretory cells ${ }^{\mathrm{a}}$ are important progenitor cells of both themselves and of ciliated cells ${ }^{86,87,90,91,95,96,104,200,251}$ in these airways. Thus, the tracheobronchial epithelium appears to have two cell lineages, with the basal cell and the secretory cell as two separate progenitor cells. Whether these cells possess stem cell properties or that there is a population of more primitive stem cells is still a matter of debate ${ }^{252}$.

Application of a thymidine analogue 5'-bromodeoxyuridine (BrdU) can be used as an alternative to the slow and costly autoradiography technique. BrdU incorporation into the DNA can be detected immunohistochemically ${ }^{253}$, allowing simultaneous immunolabeling of BrdU and a specific cell type in routinely fixed paraffin-embedded tissue slides ${ }^{254}$. 255. This method has been carried out in rat tracheobronchial epithelium for the detection of proliferative neuroendocrine cells ${ }^{112}$. A possible explanation for the infrequent employment of this method could be the complicated immunostaining protocol ${ }^{179}$.

The composition of the tracheobronchial epithelium and the differentiation of cell type populations is extremely diverse between all mammalian species hitherto examined ${ }^{120}$. In addition, virtually all cell-kinetic studies have been carried out in young laboratory animals whose lungs are still growing ${ }^{89}$. As significant decreases have been noted in the proportion of proliferating tracheobronchial epithelial cells of aging rats ${ }^{90,1088}$, extrapolation of results obtained by the study of the proliferation of the non-human mammalian tracheobronchial epithelium to the human lung should be done with extreme caution.

\subsection{Proliferation in human tracheobronchial epithelium}

In man, ethical considerations severely limit the in wivo administration of ${ }^{3} \mathrm{H}$-thymidine or $\mathrm{BrdU}^{\mathrm{t}}$. Incubation of fresh and viable biopsy specimens with BrdU (i.e., ex vivo labeling) is

\footnotetext{
"Oar a-like cells and/or serous cells, not goblet cells.

- Though studies regarding endobronchial biopsy specimens of car cinomas have been reported ${ }^{256.25 \%}$.
} 
theoretically possibie but fraught with technical difficulties ${ }^{258}$. As a relatively recent alternative, antibodies directed against endogenous prolfferation-associated antigens have become available. A simple immunohistochemical procedure allows the detection of the proliferative state of cells in paraffin-embedded tissues ${ }^{259-264}$. Three studies have been performed in routinely processed ${ }^{a}$ tracheobronchial epithelium using anti-proliferating cell nuclear antigen (PCNA) antibodies. Pendleton and colleagues ${ }^{116}$ examined histologically normal resection margins of 32 pneumonectomy / lobectomy specimens, and report a mean PCNA-labeling of $2 \%$. Lee and Hong ${ }^{265}$ mention a $0.7 \%$ PCNA labeling percentage in 59 bronchial biopsies. Demoly and coworkers 117 used PCNA immunolabeling on bronchial biopsies; only one of II biopsies taken from normal volunteers demonstrated PCNA immunoreactivity. However, technicall constraints concerning PCNA-immunostaining should be paid attention. The detectability of PCNA is strongly dependent on the type and duration of fixation ${ }^{257,266,267}$, In addition, PCNA-immunoreactive percentages in routinely processed tissues obviously overestimates the proliferation compartment when compared with ${ }^{3} \mathrm{H}$ thymidine or BrdU labeling ${ }^{262,268}$.

Assessment of an another proliferation-associated antigen $\mathrm{Ki}-67^{249.260 .269-277}$ in routinely processed tissues has been made accessible by recent technical advances. Application of MIB-11, a new antibody directed against recombinant parts of the Ki-67 antigen ${ }^{261 .}{ }^{263}$, in combination with new antigen retrieval methods ${ }^{264 .} 278.290$ allows reasonably reliable determination of the proliferation compartment ${ }^{262,268,291-293}$ in routinely processed tissues. Simultaneous immunostaining of MIB-I with cell type-specific markers could now be feasible in order to establish the identity and number of human proliferating tracheobronchial cells, without any prerequisite other than good laboratory practise.

\section{Aims of the present study}

An adequate description of structural deviations of the lower conducting airway epithelium depends on a clear understanding of the composition of the normal human tracheobronchial mucosa. Although previous quantitative studies of the lower conducting airway epithelium have been conducted, published results do not provide a comprehensive insight of the norrnal human tracheobronchial mucosa. In addition, comparison of hitherto acquired data of cell type distribution with future studies of other institutions is virtually impossible due to wide disparity in study design of prior reports.

Morphologic alterations of the tracheobronchial mucosa, caused by an aberrant cell cycle regulation of epitheliall cell types, are linked with a wide range of pulmonary diseases. Information about the proliferative cell type distribution of the normall conducting airway epithelium may reveal which cell types are involved in the maintenance of the human tracheobronchial mucosa, and may indicate which cell types are probable target cells of

"i.e. fixed in $4 \%$ buffered formaldehyde for approximately $24 \mathrm{~h}$ and paraffin-emuedded. 
injurious stimuli in the pathogenesis of human airway disease. To date, no data is available of the cell type distribution of the proliferation compartment of the lower conducting ainway epithelium in man.

The aims of the present study are to develop (immuno-)histochemical techniques that allow the identification and enumeration of the major cell types lining the human tracheobronchial tree (i.e., cell type composition), to analyse the proliferation compartment and the proliferative cell type distribution, to establish an efficacious quantification procedure and to employ these methods to normal human lung tissue. The focus of the study will concentrate on neuroendocrine cells (Chapter 2), goblet and ciliated cells (Chapter 3), (para)basal cells (Chapter 4) and Clara cells (Chapter 5). In Chapter 6, the overall proliferation compartment of squamous metaplastic lesions is examined as an example of histologically abnormal mucosa, and is compared with normal values. In the epilogue (Chapter 7), airway dassification systems and statistical approaches for efficacious quantification will be discussed, as these procedures were developed gradually during the study period. Results of the quantification procedures will be combined into several figures containing the cell type composition of normal human tracheobronchial mucosa and the cell type distribution of the proliferation compartment (detailed data are presented in the Appendix to Chapter 7). The presented data can be used for comparison with future studies of the lower conducting ainway epithelium of patients with pulmonary disease. In addition, this chapter will review the individual airway epithelial cell types in respect to the maintenance of the normal lower conducting airway mucosa, and the role of the basal cell in the genesis of squamous metaplasia with dysplasia is discussed. A chaptenwise résumé is given in the Surnmary (Chapter 8). 



\section{Two}

\section{Neuroendocrine cells}

Published as

Number and distribution of neuroendocrine cells in normal human airway epithelium James E Boers, Jan LM den Brok, Joh Koudstall, jan Willem Arends and

Frederik BMM Thunnissen

American Journal of Respiratory and Critical Care Medicine

1996; Volume 154; pages 758-63 


\section{Introduction}

The epithelium of the conducting airways can be divided into three biological compartments: the proliferation, maturation and the functional compartment ${ }^{86}$. The three compartments are not anatomically distinct; a particular cell can be in more than one compartment at the same time. The kinetics of the mammalian airway epithelium are presently classified as a conditional renewal system, i.e. proliferating very slowly in adults under normal conditions, but able to increase proliferation in response to injury. The proliferation compartment has been thoroughly investigated in rodents using either ${ }^{3} \mathrm{H}$-Thymidine or $5^{3}$ bromodeoxyuridine (BrdU) incorporation techniques ${ }^{90}$. In normal rodent airway epitheli$u m$, the labelling percentages reported are between $0.3 \%$ to $1.6 \%$. From proximal to distal airways a decrease has been noted; this decrease is less pronounced in older animals. In human airways average labelling percentages between $0.18 \%$ and $2 \%$ have been reported with very high variability in normal airway epithelium using anti-proliferating cell nuclear antigen (PCNA) immunohistochemistry on small bronchial biopsies 116, 117. 265. 294 . Because anti-PCNA is sensitive to heat and fixation time ${ }^{249.295}$ this antibody can be used only in carefully controlled conditions. Moreover, only small bronchial biopsies were investigated with a presumed maximum of about 1,000 epithelial cells. As the observed proliferation compartment is very low in normal human adult airway epithelium, this cell number may be too low for a reliable estimation of proliferation.

The existence of pulmonary neuroendocrine cells (PNECS) is well established in human

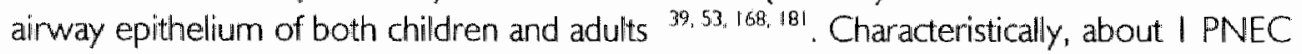
per $1 \mathrm{~cm}$ basement membrane has been reported using various immunohistochemical techniques and many different antisera ${ }^{39,42,53,168,181}$. Antiserum raised against chromogra$\operatorname{nin} \mathrm{A}(\mathrm{CgA})$, a constituent of the matrix of neurosecretory granules ${ }^{153.154,185,296}$, is regarded as one of the most specific of the general neuroendocrine markers. However, insufficient sensitivity has been reported using anti- $\mathrm{CgA}$ in formalin-fixed lung tissues ${ }^{153,297}$. The development of specific and sensitive detection methods of PNECs is important, as PNEC hyperplasia has been reported in bronchial biopsies of cigarette smokers, and in a great number of pulmonary diseases $50.53,181.298$.

It is still a question whether neuroendocrine cells proliferate after the early fetal period. In fetal hamsters, mitotic division of PNECs have been noted ${ }^{299}$. According to Hoyt "', division of PNECs stops at an early stage of fetal lung development; in later stages PNECs are regarded as terminally differentiated cells like ciliated cells. Using a double immunohistochemical detection method in adult rats $7 \%$ of PNECs were reported to be in wivo labeled for BrdU, a thymidine analogue ${ }^{112}$. These PNECs were hypothesized as being terminally differentiated cells arising from adjacent non-neuroendocrine precursor cells. Apart from fragmentary data, reporting dividing neuroendocrine cells in fetal lung 42,300 , no 
data exists on the proliferation of human PNECs. Data collected from growing animals like rats and hamsters may prove impossible to extrapolate to adult humans.

In view of these fragmentary data, the aim of our study was to quantify in normal-appearing adult human airway epithelium: the proliferation compartment; the number of PNECS; and the proliferation fraction of PNECs. These data, generated with simple standard techniques, could then be used as reference to future comparisons with disease states. To this end, cross-sections from central to peripheral airways were sequentially stained with an antibody to the proliferation-associated protein $\mathrm{Ki}-67$ (MIB-1) and a neuroendocrine (CgA.) marker.

\section{Methods}

\section{I. Material}

In De Wever Hospital, Heerlen, and the Hospital of Maastricht University, the Netherlands, perfusion fixation of lungs was performed if deceased patients were available for autopsy within $6 \mathrm{~h}$ of death. In total, perfusion fixation of 250 cases was carried out. A canula was inserted in the trachea. The lungs were placed in a large container filled with $4 \%$ buffered formaldehyde, and through the canula perfusion fixation was performed during $24 \mathrm{~h}$ under a constant pressure of $3 \mathrm{kPa}\left(30 \mathrm{~cm} \mathrm{H}_{2} \mathrm{O}\right){ }^{301}$. After fixation, seven samples were taken from trachea down to peripheral lung tissue of the left upper lobe (modified from ${ }^{43}$ ), and routinely processed. We cut $3 \mu \mathrm{m}$ sections from paraffin blocks. A standard haematoxylin-eosin stain was carried out for histologic assessment. In order to obtain a more or less normal population, all cases with primary or secondary pulmonary diseases including bronchitis were excluded except for minor anthracosis (presumably due to air pollution) or minor pulmonary congestion (without ederna or extravasation of erythrocytes). In addition, the airway epithelium had to be attached to the basement membrane. Only nine cases fulfilled these criteria and were used for further study.

\subsection{Immunohistochemistry}

Pretreatment. We placed $3 \mu \mathrm{m}$ sections on 3-amino propyltriethoxysilane (APES)-coated slides (Sigma Chemical Co., St. Louis, MO) and dried them overnight in a convection oven $\left(56^{\circ} \mathrm{C}\right)$. Slides were dewaxed in xylene, rehydrated in graded alcohols, and rinsed in distilled water. Subsequently, slides were placed in plastic jars containing $500 \mathrm{ml}$ of $10 \mathrm{mM}$ citrate buffer in distilled water, $\mathrm{pH}=6$, and tightly closed with a lid. Two jars were placed in a Philips $650 \mathrm{~W}$ microwave oven, and irradiated until boiling point. Then, $15 \mathrm{~min}$ of uninterrupted boiling was performed using full power irradiation ${ }^{264}$. After removing the jar from the microwave oven, cooling down until room temperature (RT) was achieved in 20 $\min$. 
Selection of a neuroendocrine marker out of several antibodies. Immunohistochemical staining using several antibodies known to be quite specific for neuroendocrine differentiation (listed in table 1) was performed.

After pretreatment, slides were rinsed in phosphate-buffered saline (PBS), and if polyclonal antiserum was used, incubated with diluted normal swine serum (1:5 dilution in PBS; Dako, Glostrup, Denmark). Then serial slides of a particular tracheal block containing 10,000 epithelial cells were incubated with the antisera as mentioned in table I for 45 min at RT.

Table 1. Quantitative immunoreactivity of antisera used for the detection of pulmonary neuroendocrine cells.

\begin{tabular}{|c|c|c|c|}
\hline $\begin{array}{l}\text { Antiserum } \\
\text { (dilution, company) }\end{array}$ & $\begin{array}{l}\text { Monoclonal/ } \\
\text { Polyclonal }\end{array}$ & $\begin{array}{l}\text { PNECs per } 10,000 \\
\text { Ainway cells }\end{array}$ & $\begin{array}{c}\% \text { of } \mathrm{CgA} \\
\text { immunoreactivity }\end{array}$ \\
\hline $\begin{array}{l}\text { Chromogranin } A \\
(1: 2,500 ; \text { Immunotech) }\end{array}$ & Monoclonal & 40 & $100 \%$ \\
\hline $\begin{array}{l}\text { Gastrin Releasing Peptide } \\
\left(1: 1,000^{\circ} \text { Dako }\right)\end{array}$ & Polyclonal & 27 & $59 \%$ \\
\hline $\begin{array}{l}\text { Calcitonin } \\
(1,1,000 ; \text { Dako })\end{array}$ & Polyclonal & 15 & $30 \%$ \\
\hline $\begin{array}{l}\text { Protein Gene Product } 9.5 \\
\left(1.250^{\prime} \text { Uthraclone }\right)\end{array}$ & Polyclonal & 6.2 & $14 \%$ \\
\hline
\end{tabular}

Immunotech, Marseille, France; Dako, Glostrup, Denmark; Ultraclone, Isle of Wright, England.

Slides were washed thrice with PBS, and incubated with biotinylated rabbit-anti-mouse (Dako; 1:500) for the monodonal antibody, and biotinylated swine-anti-rabbit (Dako; 1:1000) for the polyclonal antibodies. After rinsing twice in PBS, slides were incubated with the peroxidase-conjugated streptavidin label (Dako; 1:1000) for $30 \mathrm{~min}$ at RT, rinsed again in PBS, and incubated with diaminobenzidine (DAB; Sigma) for 5 to $15 \mathrm{~min}$.

As depicted in table 1, CgA provided the most sensitive immunohistochemical staining for the detection of neuroendocrine differentiation, and was therefore used for the quantification of neuroendocrine cells in subsequent sequential immunohistochemistry.

Sequential immunohistochemical staining. After pretreatment, all slides were incubated with MIB-I ${ }^{263}$ (Immunotech, Marseille, France; dilution 1:25) for 45 min at RT. Slides were thrice washed in PBS, and incubated with biotinylated rabbit-anti-mouse, and subsequently with peroxidase-conjugated streptavidin label; finally incubated with DAB (Sigma) for 5 min. Subsequently, slides were incubated with CgA for 45 min at RT. Then, biotinylated rabbit-anti-mouse (as previously described) and alkaline phosphatase-conjugated streptavidin label (Dako, 1:200) were used as subsequent layers. After rinsing in PBS slides were incubated with New Fuchsine (Biogenex, San Ramon, CA, USA). Then, slides were rinsed in PBS, counterstained in Mayer's hematoxylin, placed in tap water for $15 \mathrm{~min}$, allowed to dry, and mounted in Entellan (Merck, Darmstadt, Germany). 


\subsection{Controls including fixation delay and dilution studies}

Negative control slides were stained with the omission of the primary antibodies MIB-1 and/or $\mathrm{LK} 2 \mathrm{H} 1 \mathrm{O}(\mathrm{CgA})$. As an additional negative control for $\mathrm{CgA}, \mathrm{LK} 2 \mathrm{HIO}$ antibody was preincubated with a suspension of neurosecretory granules for ih at RT, and after centriffugation of the suspension the slides were incubated with supernatant, invariably producing a negative immunoreaction. As positive controls, human pancreas, colon and adrenal tissue were used.

For the studies of the impact of microwave irradiation in citrate buffer on slides on CgA immunoreactivity, a particular tracheal tissue block (with positive controls) was incubated with several dilutions of $\mathrm{LK} 2 \mathrm{HIO}$ with or without prior microwave treatment. This study was repeated with DAK-A3 EPOS (Dako), another monoclonal antibody against CgA. At least 10,000 cells were counted on each slide. Microwave irradiation yielded 12 times more immunoreactive PNECs.

To examine the specificity of this procedure the following was considered: (1) the morphology of all CgA immunoreactive cells was typical of PNECs; (2) the control slides, consisting of human pancreas, colon, and adrenal, showed specific immunoreaction; (3) after preincubation of $\mathrm{LK} 2 \mathrm{H} 1 \mathrm{O}$ antiserum with a suspension of neurosecretory granules, no positive cells were found in the control slides (4) all tests including the morphology " controls and pre-incubation were identical when DAK-A3 EPOS was used instead of LK2HIO.

In order to assess the impact of autolysis on MIB-I and CgA immunoreactivity a fixation delay study was performed. Fixation delay up to $24 \mathrm{~h}$ did not affect MIB-I immunoreactivity. For CgA, up to $12 \mathrm{~h}$ fixation delay had no effect on PNEC counts. In our autopsy material with a fixation delay of $6 \mathrm{~h}$ maximum, autolysis is not a confounding factor for this study.

\subsection{Airway diameters}

For the purpose of comparison between airway diameters internal diameter of airway was measured and divided in three groups: 'large', internal diameter $>4.5 \mathrm{~mm}$, representing trachea and large bronchi; 'intermediate', internal diameter between $1.2 \mathrm{~mm}$ and $4.5 \mathrm{~mm}$, and 'small', internal diameter $<1.2 \mathrm{~mm}$, representing bronchioles down to respiratory bronchioles ${ }^{i 21}$.

\subsection{Image analysis and measurements}

An interactive image analysis system consisting of the Quantimet $570 \mathrm{C}$ and a microscope ( $40 x$ objective, numerical aperture 0.65 ) was used. Epithelium of the 63 slides was assessed as follows: first, the internal diameter of the airway was measured with a measuring rule at low power. Then, using the $40 x$ objective, a video image was made, typically showing $60-70$ epithelial cells on $\pm 180 \mu \mathrm{m}$ basement membrane. Only normal-appearing, well oriented epithelium was evaluated. A line was manually drawn over the image of 
the basement membrane with a computer mouse, and the luminal side of the epithelium was marked. The length of basement membrane was automatically determined. Next, immunoreactive nuclei $(=\mathrm{MIB}-1)$ and/or cytoplasm (= CgA) were manually scored. Only unequivocally stained nuclei were counted, and a cell was considered a PNEC only if at least half the perimeter of a nucleus was brightly immunolabeled. Finally, automated segmentation analysis of epithelial area was performed with the drawn line of the basement membrane. Subsequently, the nuclei were automatically segmented and the total number of epithelial nuclei counted. Data were stored after interactive control of this count.

For studies of reproducibility sequential immunostained slides were compared with either MIB-I or CgA stained slides and counted thrice.

As the expected percentages of either $\mathrm{MBB}-1$ or $\mathrm{CgA}$ immunoreactive cells were very low, all available epithelium of all slides was counted. Reproducibility of MIB-I between single and double immunohistochemical staining procedures, as well as repeated quantification of particular slides was $>90 \%$. Reproducibility of CgA was $>95 \%$.

\section{Results}

After a rigorous selection procedure, nine of 250 autopsies were considered to have

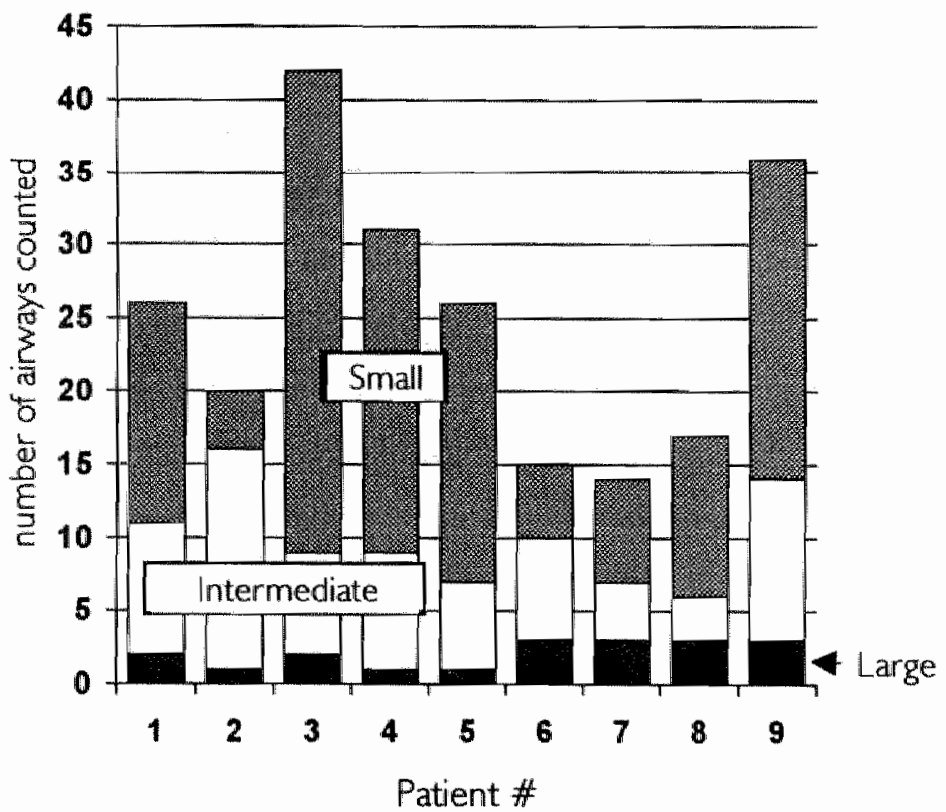

Figure 1. The amount of aimays counted per patient divided per airway diameter group. 
airway epithelium without visible disease. Four patients were male, five female. Ages were between 23 and 76 years. The causes of death were: myocardial infarction (five patients); cerebral infarction (one); aortic stenosis with sudden death (one); sick sinus syndrome with sudden death (one) and ruptured abdominal aortic aneurysm (one).

In total, 326,500 cells and $105 \mathrm{~cm}$ of basement membrane were counted; the mean number of epithelial cells expressed per $\mathrm{cm}$ basement membrane was $3,101 \pm 623$ (mean \pm SD). The amount of airways counted, total length of basement membrane and total number of epithelial cells in relation to internal arway diameter are presented in Figure I and Table 2.

\subsection{Proliferation compartment}

The proliferation compartment was quantified using the MIB- 1 antibody, which recognizes a part of the Ki-67 epitope ${ }^{263}$. Only (para) basal located nuclei were immunoreactive (Figure 2 on p. 114); no mitoses were seen. Immunoreactive nuclei were scattered throughout the epithelium; only infrequently dustering of positive nuclei was seen. The mean number of MIB-I immunoreactive cells was $0.76 \% \pm 0.53 \%$. Only one out of 227 airways counted showed more than $2 \%$ MIB-I immunoreactivity. The relation between internal airway diameter and proliferation compartment (MIB- $\mid$ immunoreactivity) is shown in Table 2. The airways were clustered in three groups: 'large' (diameter $>4.5 \mathrm{~mm}$ ), 'small' (diameter $<1.2 \mathrm{~mm})$ and 'intermediate'. No statistically significant difference $(p=0.6)$ was seen in the number of MIB-1 immunoreactive nuclei between the three groups of airway diameters (table 2).

Table 2. Number of airways, length of basement membrane, amount of epithelial cells, proliferation compartment of all epithelial cells, and the proportion of PNECs in relation to internal airway diame-

ter.

\begin{tabular}{lcccc}
\hline & Large $(>4.5 \mathrm{~mm})$ & airway & $\begin{array}{c}\text { diameter } \\
\text { Intermediate }\end{array}$ & Small $(<1.2 \mathrm{~mm})$ \\
\hline Total number of airways counted in & 19 & 70 & 138 \\
nine patients & 36 & 38 & 32 \\
Total length of $\mathrm{BM}$, cm & 125.539 & 115.645 & 85,306 \\
Total amount of epithelial cells & $3.526 \pm 335$ & $3.056 \pm 553$ & $2.681 \pm 730$ \\
Epithelial cells/cm & $0.89 \pm 0.38$ & $0.71 \pm 0.56$ & $0.62 \pm 0.62$ \\
Proliferation compartment, \% & $0.49 \pm 0.17$ & $0.39 \pm 0.16$ & $0.33 \pm 0.15$ \\
PNECs, \% & & & \\
\hline
\end{tabular}

\subsection{Pulmonary Neuroendocrine cells (PNECs)}

The number of PNECs was quantified in sections immunostained for chromogranin A (CgA). The mean number of PNECs was $0.41 \% \pm 0.17 \%$, or an average of 12.5 cells per 
$\mathrm{cm}$ basement membrane. No statistically significant differences $(p=0.3)$ were seen between the number of PNECs in the respective airway diameter groups (Table 2). All CgAimmunoreactive cells had the typical morphology ${ }^{53}$ of PNECs (Figure 2); apart from nucleated cells, many immunoreactive dendritic cell processes were seen parallel and adjacent to the basement membrane (Figure 2). Only four clusters of PNECs $\geq 2$ cells were seen. No PNECs were noted in the alveoli.

\subsection{Proliferation fraction of PNECs}

Immunohistochemical staining for MIB-I (= proliferation compartment) and CgA (= PNECs) was performed sequentially on the slides. Fourteen of 326,500 cells were double immunolabeled with MIB-1 and anti-CgA (Figure 2). Although proliferation of PNECs is a rare phenomenon, these results show that approximately I\% of PNECs are in the proliferation compartment. This proliferation fraction is simillar to the average proliferation fraction of all epithelial cells. In addition, several MIB-I immunoreactive nuclei were noted in the vicinity of PNECs, but this phenomenon was not quantified.

\section{Discussion}

The proliferation compartment of normal-appearing human conducting airway epithelium using MIB-I immunoreactivity is $0.76 \%$ of total epithelial cell count. No mitoses were seen arnong 326,500 cells. The mean number of pulmonary neuroendocrine cells. (PNECs) using Chromogranin A (CgA) monoclonal antiserum is $0.41 \%$ of total epithelial cell count; the sensitivity of $\mathrm{CgA}$ immunoreactivity is significantly enhanced by microwave pretreatment of slides. Virtually all PNECs were solitary. The proliferation fraction of PNECs was proportional to the proliferation fraction of all epithelial cells.

Data on the proliferation compartment of epithelial cells of the conducting airways is almost exclusively based on still growing rodents ${ }^{107}$. Labeling percentages using ${ }^{3} \mathrm{H}$-Thymidine or $\mathrm{BrdU}$ incorporation are between $0.3 \%$ and $1.6 \%{ }^{90}$. Only three studies on adult human airway epithelium have been published, using PCNA antiserum on small bronchial biopsy specimens. Labeling percentages between $0.18 \%$ and $2 \%$ have been reported ${ }^{116}$. $117,265,294$. Pendleton and coworkers ${ }^{116}$ found a mean PCNA-labeling percentage of $2 \%$ in bronchial epithelium taken from resection margins of lung resection specimens. However, the range of PCNA labeling percentages was $0-19 \%$, and up to 11 mitoses per 1,000 cells were counted. Demoly and coworkers ${ }^{17}$ used PCNA immunolabeling on bronchial biopsies, and claim a PCNA labeling percentage of $0.18 \%$ in healthy non smokers (only 1 out of II biopsies PCNA immunoreactive). These data show a very high variability of the size of the proliferation compartment in small bronchial biopsies. Finally, Lee mentions a PCNA labeling percentage of $0.7 \%$ in 59 bronchial biopsies without statistical details ${ }^{265}$. In asthma, cigarette smoking, and squamous metaplasia, an increase of the proliferation 
compartment up to $60 \%$ has been noted 116, 117,265.2\%\%. PCNA has been a widely applied antibody for the detection of cell cycle related antigens, but is sensitive to heat and fixation time ${ }^{249}$. We have used MIB-I, an antibody against the Ki-67 antigen which can be used on paraffin material after antigen retrieval. The MIB-I labeling percentage of human conducting airway epithelium was $0.76 \%$ in our study based on autopsy material was similar to the PCNA labeling percentage of Lee's biopsy specimens ${ }^{265}$. The MIB-I labeling percentages in epithelium of the trachea and large bronchi did not differ from the labeling percentages of the small bronchi. Thus, baseline proliferation compartment in lower airway epithelium is similar to the epithelial from the central airways. Our data thus validates the use of proliferation associated antigens in biopsy material for the determination of the average proliferation compartment.

PNECs in human adult lungs are well established by immunohistochemistry; using several 'general' antibodies against all types of neuroendocrine cells a consistent quantity of PNECs of about I cell per $1 \mathrm{~cm}$ of basement membrane has been reported untill now ${ }^{39.53}$. 168. Using the current antigen retrieval technique employing microwave irradiation of slides immersed in citrate buffer, in the present study the mean number of PNECs is 12.5 cells per centimeter basement membrane, twelve times more than previously reported. As shown in table I, the other 'general' neuroendocrine markers were disappointing: PGP9.5 yielded $14 \%$ of $\mathrm{CgA}$ immunoreactivity. In contrast, gastrin releasing peptide (GRP) (or mammalian bombesin) and calcitonin antisera stained about two-thirds and one-third of the CgA immunoreactive neuroendocrine cells, respectively. This staining pattern was already reported by Gosney ${ }^{53}$. Laitinen reports even higher PNEC counts with quantitative electron microscope analysis ${ }^{302}$. Sufficient information of this procedure was lacking not allowing further discussion here. In addition, many dendritic neuroendocrine cell processes could be seen between epithelial cells at dose proximity to the basement membrane. The combination of the dendritic process and the relative high density of PNECs (one of every 240 epithelial cells) could imply that every non-neuroendocrine cell of the pseudostratified airway epithelium is in close proximity to PNECs. Adult human PNECs contain neuropeptides like calcitonin, calcitonin gene-related peptide (CGRP), or GRP/mammalian bombesin ${ }^{53}$. Possible targets for the secreted peptides are the conducting airway epithelium, but also the mesenchymal tissues surrounding the airways. Both in vitro and in vivo studies suggest a 'trophic' effect of neuropeptides on epithelial cells, fibroblasts and smooth muscle cells, as well as a role as chemotactic factor for inflammatory cells, 51. 53.160.298. In addition, PNECs play a role in fetal lung development. Our data, showing relative high PNEC numbers as well as many dendritic cell processes underscore the importance of neuroendocrine cells in pulmonary physiology and pathology.

Whether PNECs in adult mammalian airways proliferate is an unresolved question. Hoyt performed several studies on hamsters. In the fetal hamster, occasional mitosis were seen 11'; by means of continuous ${ }^{3} \mathrm{H}$-Thymidine infusion, Hoyt observed that most PNECs arose from cells that stopped dividing long before the surrounding endoderm. Morituenga and coworkers ${ }^{1 / 2}$ studied adult rat lung tissue with $7 \mathrm{~d}$ of continuous BrdU infusion, a thymidine analogue. They reported a 7\% BrdU immunolabeling of PNECs. They concur- 
red with Hoyt's observation in hypothesizing that differentiation of PNECs took place after proliferation of non-neuroendocrine precursor cells. These data are on lung tissue of still growing rodents, in which PNECs are present in innervated dusters called neuroepithelial bodies (NEBs). To our opinion, NEBs are very rarely present in the normal adult human lung, which is in agreement with Gosney ${ }^{53}$. Our study differs also from these previous studies of the proliferation fraction of PNECs because we employed MIB-I antiserum raised against the Ki-67 epitope ${ }^{263}$ which labels nuclei of cells in mid $G \mid$ through $M$ phase of the cell cycle, rapidly disappearing after mitosis. In contrast to in vivo labeling agents like ${ }^{3} \mathrm{H}$-Thymidine or BrdU, no post mitotic immunolabeling is seen. Although the number of proliferative PNECs counted is relatively small, the fact that approximately $1 \%$ of these PNECs are also immunoreactive with MIB-I demonstrates that adult human PNECs may occasionally be in both the proliferation and differentiation compartment. Many pathological pulmonary conditions are accompanied by neuroendocrine (NE) cell hyperplasia $50,53$. ${ }^{29: 4}$. The question whether NE cell hyperplasia is a result of either NE cell proliferation or postmitotic differentiation of nonneuroendocrine cells needs still to be resolved.

In conclusion, in histologically normal adult human conducting airway epithelium, the average proliferation compartment is $0.76 \%$. The proliferation fraction of PNECs is equal to the overall proliferation fraction. The proportion of PNECs is $0.41 \%$, using anti-CgA antiserum after microwave pretreatment of slides, twelve times more than previously reported. Many dendritic neuroendocrine cell processes were seen between non-neuroendocrine epithelial cells adjacent to the basement membrane. The widely held belief that neuroendocrine cells are of little importance in the adult lung is contradicted by the relative high density of PNECS and its cytoplasmic processes. 


\section{Three}

\section{Goblet and ciliated cells}

Submitted for publication as

Number and proliferation of goblet and ciliated cells in normal human airway epithelium

James E Boers, Mischa A Selis, Anton W Ambergen and Frederik B/M Thurnissen 


\section{Introduction}

Mucus-producing goblet cells are one of the major secretory cell types in mammalian airway epithelium ${ }^{120}$. The quantity of goblet cells in humans is known to vary substantially even between comparable aimays in a particular individual ${ }^{73 .}{ }^{7 \%}$. In spite of this considerable variation in goblet cell number, studies performed on human lungs ${ }^{17,57.76}$ have not taken in account the minimum quantity of ainway epithelial cells required for the determination of a reliable goblet cell count. This may partly explain the differences in the proportion of goblet cells reported in normal human airways.

The cominant cell type in the mammalian respiratory epithelium is the ciliated cell which is responsible for respiratory mucokinesis ${ }^{120}$. The only report of the number of ciliated cells in human airways is of Mercer and colleagues ${ }^{17}$. In their electron microscopic study they found that cliated cells constituted about $33 \%$ in the epithelial cells of the large bronchi, and $47 \%$ in the smallest airways. No quantitative study on this important cell type has been performed to date using conventional light microscopic techniques.

Proliferation of mammalian airway epithelium has been the subject of many investigations (reviewed in ${ }^{12,86,90}$ ). The traditional concept that basal cells are the progenitor cells of the airway epithelial cells has been challenged by several observations. During fetal lung development of the Rhesus monkey basal cells are the last cell type to appear in tracheal epithelium ${ }^{303}$. Experimental studies performed on rodent airways after chemical ${ }^{88,95,104}$ or mechanical injury ${ }^{98}$ showed an increase in proliferation activity of secretory cells but not of basal cells. On the other hand, investigations of adult rat airway epithelium in the resting state have suggested that both basal and secretory cells proliferate, showing the highest proliferative intensity in basal cells ${ }^{93}$. Contrary to other previous findings, this study also showed that $6 \%$ of the ${ }^{3} \mathrm{H}$-thymidine labeled epithelial cells were ciliated cells, suggesting that at least some ciliated cells are in the proliferative compartment. Marked interspecies heterogeneity of the airway epithelium ${ }^{120}$ precludes direct application of data obtained in rodents to the human lung.

In studies reponting on the proliferation compartment of human airway epithelium ${ }^{117.304}$, (para) basal cells were thought to represent the major part of the proliferative compartment. To date, no systernatical quantitative study has been performed on the proliferative activity of goblet and ciliated cells in normal human lungs.

The purpose of our study was to determine in normal appearing human ainway epithellium: the number and proliferation fraction of goblet and ciliated cells; the proliferation compartment; the minimum number of epithelial cells required for a relliable estimate of both the proliferation compartment and the number of goblet and ciliated cells. To this end, human lungs obtained by autopsy were fixed by tracheal perfusion of formalin and stained sequentially with an antibody to the proliferation-associated protein Ki-67 (M||B-1) and a standard histochemical technique. 


\section{Methods}

\subsection{Material}

In De Wever Hospital, Heerlen, and Maastricht University Hospital, the Netherlands, perfusion fixation of lungs was performed if deceased patients were available for autopsy within 6 h after death (for details see chapter 2). Perfusion fixation of 275 cases was carried out. After fixation, seven samples taken from trachea down to peripheral lung tissue and routinely processed. A standard H\& E stain was used for histological assessment. In order to obtain a more or less normal population all cases with primary or secondary pulmonary diseases were excluded. After these selection procedures, a total pathologic score (TPS) was established for each slide according to Berend and colleagues 228 . Four variables: inflammatory cellular infiltrate, pigmentation, fibrosis and muscle hypertrophy were scored in small airways with an internal diameter of two mm or less using both $H$ \& $E$ and Elastica - von Gieson stained sections. The four variables were graded from 0 (= normal) to 3 ( $=$ severely abnormal) for each airway; then an average score was calculated for each variable for each slide. Slides of patient material were independently assessed by two observers (I.E.B. and F.B.I.M.T. The calculated Cohen's kappa score ${ }^{305}$ between these two observations was +0.77 (95\% confidence limits +0.52 to +1.02$)$. From the average scores of the slides, a TPS score was calculated as follows: the average score of each variable was expressed as a percentage of the maximum score. Next, the four percentages were added. The maximum theoretical TPS was 400. Seven patients (six non-smoking, one with unknown smoking status) with a TPS score of less than 100 remained for further study.

\subsection{Sequential immunohistochemical / histochemical staining}

We placed $3 \mu \mathrm{m}$ tissue sections on 3-amino propyltriethoxysilane coated slides (Sigma Chemical Co, St. Louis, MO) and dried them overnight in a convention oven. Slides were dewaxed in xylene, rehydraded in graded alcohols and rinsed in distlled water. Subsequently, the slides were placed in plastic jars containing $500 \mathrm{ml}$ of $10 \mathrm{mM}$ citrate buffer in distilled water, $\mathrm{pH}=6$. Two jars were placed in a $650 \mathrm{~W}$ microwave oven, and irradiated untill boiling point. Then, 15 min of uninterrupted boiling was performed using full-power irradiation. After remowing the jar from the microwave oven cooling until room temperature was achieved in $20 \mathrm{~min}$. Slides were incubated for 45 min at room temperature with the MIB-I antibody ${ }^{263}$ (Immunotech, Marseille, France; dilution 1:25). Slides were washed thrice with phosphate buffered saline, incubated with biotinylated rabbit-anti-mouse and subsequently with peroxidase-conjugated streptavidin label. The slides were finally incubated with diaminobenzidine (Sigma) for 10 min. Subsequently, a periodic acid-Schiff (PAS) stain ${ }^{57,65}$ was carried out which stains neutral glycoproteins. 
Negative controls were stained with the omission of the primary antibody MIB-1. As a positive control tissue sections were used representing lung tissue with bronchus-associated lymphoid tissue (BALT). For the detection of goblet cells, additional slides containing both large and small airways were stained with the following histochemical stains: PAS, staining neutral mucins red; Alcian Blue ( $\mathrm{pH}=2.5$ ), staining acidic mucins blue; both PAS and Alcian Blue (AB-PAS). In a pilot study comprising 2 large (internal diameter $>4 \mathrm{~mm}$ ) and 2 small (internal diameter 1 to $2 \mathrm{~mm}$ ) airways the three histochemical methods were compared. Since the differences in assessed goblet cell numbers were less than $5 \%$ between the different methods, the PAS stain with the red color was used for further study.

\subsection{Image analysis and measurements}

An interactive image analysis system consisting of the Quantimet $570 \mathrm{C}$ and a microscope was used as described in chapter 2 . Only nucleated epithelial cells were counted manually and divided in six categories: the total number of epithelial cells; the number of goblet and ciliated cells; the total number of MIB-I immunoreactive nuclei; goblet and ciliated cells possessing $M \mid B-I$ immunoreactive nudei. The following criteria were used for identifying cell types (see Figure 2 on p. 116): (a) goblet cells: flask shaped cell with large PAS-positive cytoplasmic vacuoles, ovoid nuclei below the cytoplasmic vacuole; (b) ciliated cells: cilia at apical surface, large pale nucleus; (c) MIB-I positive cells: nuclei stained unequivocally brown with diaminobenzidine.

\subsection{Data handling and statistics}

During assessment of each airway, the number of cells divided in the six categories and the length of basement membrane were added until 10 successive epithelial areas were counted. This aggregated data was recorded on file and referred to as a 'field'. For each airway all suitable epithelial areas were counted. In small airways with an internal diameter of less than two mm only a few successive epithelial areas were present because of their small size. In order to obtain aggregated 'fields' of these small airways, data of several different small airways were added when present in a particular slide if the internal diameter of these airways were closely similar (i.e., if the difference in internal diameters was less than $0.2 \mathrm{~mm}$ ). In this manner, two or three 'fields' could be assessed for the small airways in most patients.

Reproducibility of cell number measurements was $>90 \%$ between observers (I.E.B. and M.A.S.) as well as after repeated observations by one observer (J.E.B.). Reproducibility of the number of MIB-I positive airway epithelial cells was further attempted by comparing data of five patients who were also part of the study described in chapter 2. For this purpose, data of these five patients were recalculated according to the present procedure.

Cumulative proportions were calculated for each successive 'field' for each airway for five cell types, namely the proportion of goblet cells, ciliated cells, MIB-I positive cells, goblet 
and ciliated cells with MIIB-I positive nuclei. The airways were divided into four groups depending on the internal airway diameter: $\geq 4 \mathrm{~mm}, \geq 2 \mathrm{~mm}$ but less than four $\mathrm{mm}, \geq 1$ $\mathrm{mm}$ but less than two $\mathrm{mm}$, and $<\| \mathrm{mm}$. The data presented are percentages calculated as follows: the mean percentage of a particular cell type was calculated per patient and per airway diameter group. This resulted in $7 \times 4=28$ means (in total there were 69 assessed ainways), as table 2 shows for the goblet cells. These percentages were used to determine a mean per patient and a mean per airway diameter group. The overall mean was assessed using the patient mean percentages. The standard deviation was calculated with the nested ANOVA procedure ${ }^{306}$; this approach not only detects variance between patient means but also between the different observations comprising a particular mean of the $7 \times$ 4 table. The standard deviation was established as the total SD per airway diameter group, but also calculated separately for the data obtained between patients, and within patients. $90 \%$ confidence intervals per airway diameter group were calculated as the mean \pm 1.645 times the SD. For obtaining the SD of the overall mean, only the SD calculated between patient means were used as variance within patient data were large because of the different airway diameter groups.

A feasibility study was performed regarding the reduction of the number of epithelial cells required for establishing reliable estimation of the proportion of goblet cells, ciliated cells and MIB-I positive cells. Two different statistical approaches were used to analyse the data.

The first method used a standard error of cumulative proportion which was calculated for each successive 'field' using the formula $S E_{\text {prop }}=\operatorname{sqrt}(p(1-p) / n)$ in which $p=$ cumulative proportion and $n=$ cumulative number of all airway epithelial cells ${ }^{307}$. When the $\mathrm{SE}_{\text {prop }}$ of three cell categories (i.e. goblet cells, ciliated cells and MIB-I positive cells) was $<0.025$, then the cumulative data of these cell types and length of basement membrane obtained of the 'fields' so far for this airway were used for subsequent analysis. Using $\mathrm{SE}_{\text {prop }}=0.025$ as a cut-off point, the corresponding $95 \%$ confidence interval is $p \pm 0.05$. The length of the $95 \%$ interval is 0.10 , irrespective of the magnitude of the proportion.

The second method used the relative standard error as advocated by Going ${ }^{308}$ using the formula: $\mathrm{RSE}=S \mathrm{E}_{\text {prop }} / \mathrm{p}$. In this method the length of the $95 \%$ confidence interval is related to the magnitude of the proportion. For example, when a RSE of $20 \%$ is chosen the length of the $95 \%$ confidence interval of a proportion of 0.01 will be $\pm 1.96 \times 0.002$, whereas the length of the $95 \%$ confidence interval of a proportion of 0.5 will be $\pm 1.96 \times 0.1 \%$. Analysis of the data of goblet cell proportions yielded the result that a $\operatorname{RSE}_{\text {godile }}$ was less than $20 \%$ was reached in about $90 \%$ of all assessed airways. Subsequently, cumulative data of each airway was obtained in a similar manner as described for the previous statistical method if a RSE $_{\text {goblet }}<20 \%$ was reached.

\section{Results}

After rigorous selection lungs of only seven of 275 patients appeared to be 'normal'. The last selection criterium was the total pathologic score (TPS). Data of the patients regarding 
Tabie I. Age of patients, cause of death, total pathologic score (TPS), number of ainways and airway epithelial cells assessed per individual patient.

\begin{tabular}{lcclccc}
\hline patient & age sex cause of death & TPS & $\begin{array}{c}\text { number of } \\
\text { assessed } \\
\text { airways }\end{array}$ & $\begin{array}{c}\text { total number } \\
\text { of assessed } \\
\text { epithelial cells }\end{array}$ \\
\hline 1 & 58 & $f$ & cerebral infarction & 30 & 11 & 10,300 \\
2 & 75 & $f$ & myocardial infarction & 33 & 7 & 5,700 \\
3 & 73 & $m$ & aortic stenosis & 67 & 12 & 13,300 \\
4 & 77 & $f$ & myocardial infarction & 50 & 7 & 27,300 \\
5 & 24 & $f$ & sick sinus syndrome & 70 & 14 & 22,300 \\
6 & 84 & $f$ & saddle embolus of lung & 20 & 11 & 11,400 \\
7 & 51 & $m$ & possible myocardial infarction & 95 & 7 & 5,000 \\
total & & & & 69 & 95,400 \\
\hline
\end{tabular}

age, sex, cause of death and TPS are presented in table I. In total, 95,400 cells and $34 \mathrm{~cm}$ of basement membrane were counted in 69 airways.

The number of airway epithelial cells per millimeter of basement membrane was $280 \pm$ 55 (mean \pm SD). The number of epithelial cells assessed per airway was 1,382 $\pm 1,657$ (range, 67 to 9,798 ; median 879).

\subsection{Goblet and ciliated cells}

A total number of 7,192 goblet cells were counted. Table 2 shows the number of goblet cells expressed as the cumulative percentage of airway epithelial cells per patient and per airway diameter group. The overall goblet cell percentage was 10\% $\pm 6 \%$. In the airways with an internal diameter of one mm or more, ten to thirteen percent of epithelial cells were goblet cells but in the airways with a diameter of less than one mm corresponding to

Table 2. Calculation of mean percentages of goblet cells per patient and per ainway diameter group.

\begin{tabular}{|c|c|c|c|c|c|}
\hline patient & $24 \mathrm{~mm}$ & $\begin{array}{r}\text { ainway } \\
<4,22 \mathrm{~mm} \\
\end{array}$ & $\begin{array}{l}\text { diameter } \\
<2,21 \mathrm{~mm}\end{array}$ & $<1 \mathrm{~mm}$ & mean \\
\hline 1 & 21 & 18 & 19 & 4 & 15 \\
\hline 2 & 7 & 20 & 23 & $N A$ & 17 \\
\hline 3 & 14 & 14 & 10 & 6 & 11 \\
\hline 4 & 3 & 3 & 3 & 4 & 3 \\
\hline 5 & 2 & 13 & 17 & 2 & 8 \\
\hline 6 & 6 & 2 & 2 & 0 & 2 \\
\hline 7 & 17 & 20 & 11 & 4 & 13 \\
\hline mean $( \pm S D)$ & $10( \pm 8)$ & $13( \pm 7)$ & $12( \pm 9)$ & $3( \pm 7)$ & $10( \pm 6)$ \\
\hline $\begin{array}{l}\text { Total number } \\
\text { of epithelial cells }\end{array}$ & 50,427 & 11,209 & 21.123 & 12.613 & 95.372 \\
\hline
\end{tabular}


terminal and respiratory bronchioles only three percent goblet cells were present. Figure I shows the mean percentage of goblet cells per aimay diameter with the lower and upper $90 \%$ confidence intervals based on the calculations of the column means and standard deviations of table 2 and 3 . The quantity of goblet cells is known to vary between the large and small airways, with lower goblet cell numbers is the bronchioles. Four patients ( $\mathrm{pa}$ tients \# 1,3,6 and 7) had indeed a relatively high percentage of goblet cells in airways of one $\mathrm{mm}$ or more but a much lower number of goblet cells in the smallest airways. Two patients (\# 2 and \# 5) showed a different distribution in goblet cell numbers in the larger airways, namely a low percentage of goblet cells in the airways with a diameter of four $\mathrm{mm}$ of more, and a much higher percentage of goblet cells in the airways with diameter of one $\mathrm{mm}$ to four $\mathrm{mm}$. One patient (\# 4) had a low percentage of goblet cells in the airways of all sizes, with no decrease in goblet cell numbers in the smallest airways. Expressed as the SD of the mean, variability of goblet cell numbers between airways of similar diameters within a patient were apparent but of smaller magnitude than the variance between airways of equal diameters between patients (see table 3). When these two separate SDs are combined, this results in a relatively large $90 \%$ confidence interval depicted in Figure 1 .

A total number of 45,346 ciliated cells were counted. The cumulative percentage ciliated cells were calculated per patient and per airway diameter group similar to the procedure followed for goblet cells. The overall cillated cell percentage was $48 \% \pm 8 \%$. Figure 1 shows the mean percentage ciliated cells per airway diameter group with the $90 \%$ confi-

Table 3. Standard deviation (SD) of the mean percentage of ciliated cells, goblet cells and the proliferation compartment calculated with the nested ANOVA procedure. SDs are given as percentages.

\begin{tabular}{|c|c|c|c|c|c|}
\hline & $\geq 4 \mathrm{~mm}$ & $\begin{array}{r}\text { airway } \\
<4, \geq 2 \mathrm{~mm}\end{array}$ & $\begin{array}{l}\text { diameter } \\
<2, \geq 1 \mathrm{~mm}\end{array}$ & $<1 \mathrm{~mm}$ & total \\
\hline $\begin{array}{l}\text { Number of assessed } \\
\text { airways }\end{array}$ & 18 & 12 & 18 & 21 & 69 \\
\hline \multicolumn{6}{|l|}{ Ciliated cells } \\
\hline Within patients & 4.7 & 8.7 & 5.9 & 13.1 & \\
\hline Between patients & 5.0 & 7.9 & 12.2 & 12.5 & 8.1 \\
\hline Total & 6.9 & 11.8 & $13: 6$ & 18.1 & \\
\hline \multicolumn{6}{|l|}{ Goblet cells } \\
\hline Within patuents & 2.1 & 2.8 & 5.6 & 4.0 & \\
\hline Between patients & 7.3 & 6.8 & 7.2 & 6.0 & 5.2 \\
\hline Total & 7.9 & 7.4 & 9.1 & 7.2 & \\
\hline \multicolumn{6}{|l|}{$\begin{array}{l}\text { Proliferation compart- } \\
\text { ment }\end{array}$} \\
\hline Within patjents & 0.5 & 0.6 & 0.4 & 0.6 & \\
\hline Between patients & 0.0 & 0.2 & 0.8 & 0.6 & 0.4 \\
\hline Total & 0.5 & 0.6 & 0.9 & 0.9 & \\
\hline
\end{tabular}


dence intervals. The wide confidence intervals are a result of variance of ciliated cell number between patients, but also because high variance of cell numbers between the airways. of similar diameter within a patient (see table 3). A linear regression function was obtained between the percentage of goblet and ciliated cells. A regression line was obtained with the formula: [ciliated cell percentage $=64-(1.3 \times$ goblet cell percentage)], with $r=0.71$. This shows that the number of ciliated cells is inversely related to the number of goblet cells. The percentage of ciliated cells increased with diminishing airway diameter. This corresponds to a decrease in goblet cell number (see figure I).

\subsection{Proliferation compartment}

The proliferation compartment of the airway epithelium was quantified using the MIB-1 antibody ${ }^{263}$. 940 of 95,372 airway epithelial cells were MIB-I immunoreactive. Most MIB1 positive cells were located near the basement membrane, sometimes pairs of MIB-1 positive cells were seen. On one occasion, a MHB-I positive basal cell was seen adjacent to a MIB-I positive goblet cell (Figure 2, upper panel). The proliferation compartment expressed as the percentage of aimay epithelial cells immunoreactive for MIB-I was calculated per patient and per airway diameter group, similar to the percentages of goblet and ciliated cells. The mean proliferation compartment was $0.95 \% \pm 0.4 \%$. Figure 1 shows the mean proliferation compartment per airway diarneter group with $90 \%$ confidence intervals.

Five patients (patient \#I to \#5) were part of the study described in chapter 2 , in which the proliferation compartment was defined as the total number of epithelial cells immunoreactive for MIB-I divided by the total number of all ainway epithelial cells times $100 \%{ }^{304}$. The proliferation compartment of these five patients was $0.81 \% \pm 0.60 \%$ in this previous study and $0.80 \% \pm 0.71$ in the present study, showing good reproducibility of quantification of the proliferation compartment.

Nine of 7,192 goblet cells were MIB-1 immunoreactive (Figure 2, upper panel on $p$. 116). Thus, the fraction of goblet cells in the proliferation compartment is $0.13 \%$. Of all airway epithelial cells in the proliferation compartment, $1 \%$ of cells are goblet cells $(9 / 940)$. Of 45,346 ciliated cells, 112 or $0.27 \%$ were MIB-1 positive (Figure 2, lower pane)). Twelve percent of proliferating airway epitheilial cells were ciliated cells. Thus, the overwhelming majority of the proliferating airway epithelial cells are neither goblet nor ciliated cells, while these two cell types comprise $52 \%$ to $64 \%$ of the airway epithelial cells.

\subsection{Feasibility study of reduction the required number of epithelial cells using two alternative statistical approaches}

Data obtained after assessment of all suitable airway epithelial cells was compared with the data after two statistical approaches were used. The first statistical method was to disregard all subsequent data obtained from a particular airway if the standard error $\left(\mathrm{SE}_{\text {prop }}\right)$ of the 

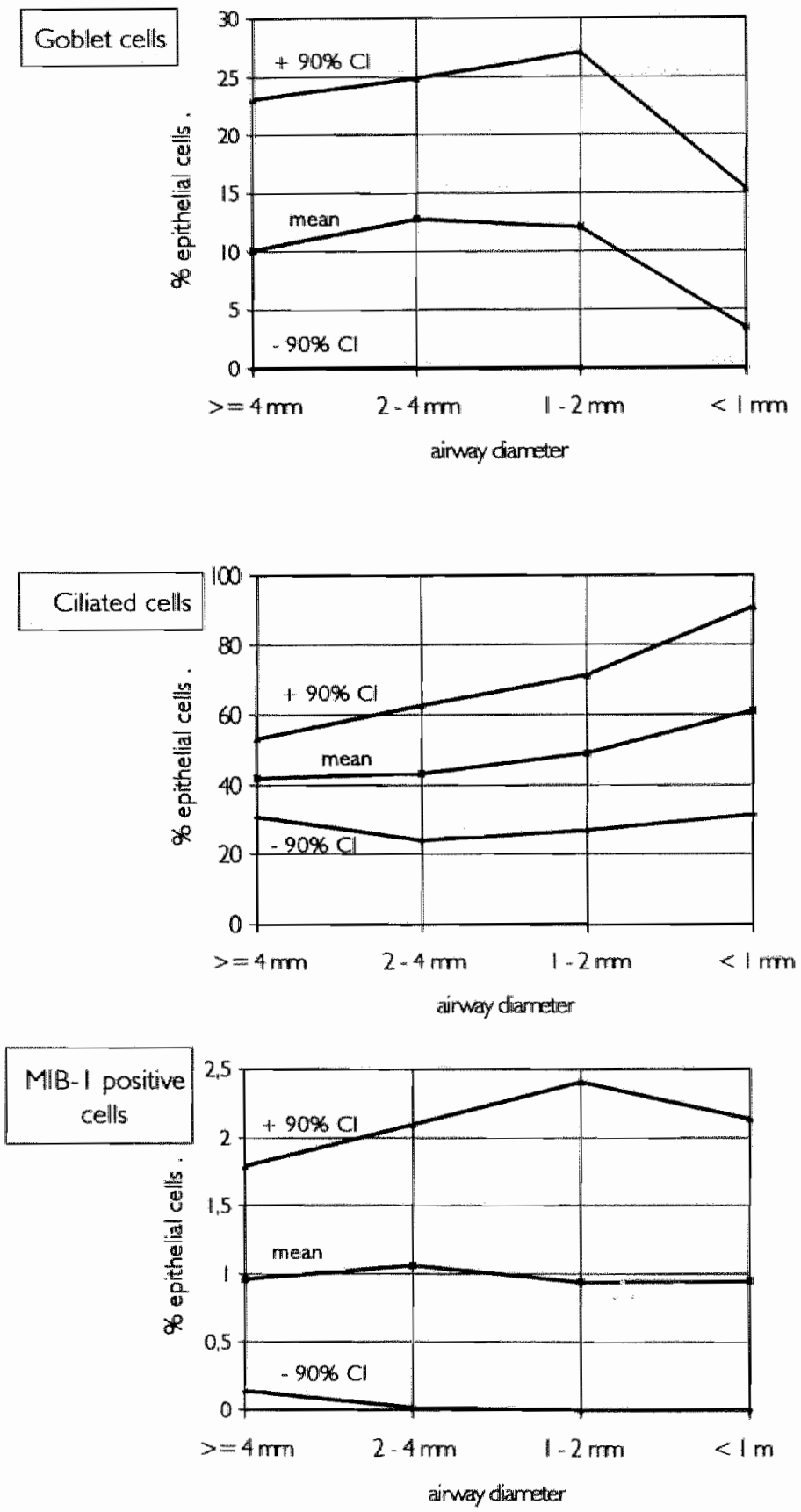

Figure I. The mean percentages of goblet, ciliated and MIB-I positive cells (proliferation compartment) with the $90 \%$ confidence intervals $(\mathrm{Cl})$ per diameter group. 
cumulative proportion of three cell types (i.e., goblet cells, ciliated cells, and MIB-1 positive cells) was less than 0.025 . In 65 of 69 airways these conditions were fulfilled. A mean ( \pm SD) of $489 \pm 120$ epithelial cells were counted in each of these 65 airways, which means that when 724 cells were counted per airway, in $95 \%$ of the airways the condition that $S E_{\text {pros }}<0.025$ was fulfilled. In total, 31,787 airway epithelial cells were taken into account or one-third of the epithelial cells assessed originaly (table 4 ). The mean percentage of goblet and ciliated cells after this data selection were identical to the data obtained after all epithelial cells were assessed. The mean proliferation compartment was slightly higher in the data selection group in comparison with the original data set (table 4). In total, 165 epithelial cells were MIB-I positive, one goblet cell $(0.6 \%$ of proliferating cells) and 18 ciliated cells ( $11 \%$ of proliferating cells).

The second method was to disregard data if the relative standard error ( $\mathrm{RSE}_{\mathrm{gablet}}$ ) of the cumulative proportion of goblet cells was less than $20 \%$. This condition was reached in 61 of 69 airways. A total of 30,516 epithelial cells were taken in to account, with a mean of $509 \pm 711$ cells per airway. Up to 1,902 epithelial cells had to be counted per airway to reach the upper $95 \%$ confidence interval (table 4). The mean percentage of goblet and ciliated cells, and the mean proliferation compartment was almost identical to the first statistical approach. In total, 156 epithelial cells were MIB-1 immunoreactive, two goblet cells and 14 ciliated cells.

The second statistical approach (RSE $E_{\text {goblet }}$ ) required analysis of acquired data before implementation, and regards the variation in goblet cell numbers only. Furthermore, up to 1,902 epithelial cells had to be assessed for a reliable goblet cell number estimate. The first statistical approach ( $S E_{\text {prop }}$ ) yielded reliable cell number estimates of all three parameters which were obtained after assessment of up to 724 epithelial cells, and without the need of prior data analysis. The calculation of the standard error of proportion is the more comprehensive and faster statistical approach.

Table 4. Comparison of the results of the two statistical approaches ( $S E_{\text {prop }}$ and $R S E_{\text {gowled }}$ ) with the original data set obtained after assessment of all available ainway epithelial cells.

Total number of airways

Total number of aimwa epithelial cells counted

Mean number of cells per aimway countead ( \pm SD)

$95 \%$ confidence interval of aimay cell number

Mean $\$ 6$ of goblet ceils ( $\pm 5 D$ )

Mean 96 of ciliated cells ( \pm SD)

Mean proliferation compantment, \%( $\%$ SD)

\begin{tabular}{ccc} 
All data & SE $_{\text {prop }}$ & RSE $_{\text {gowlat }}$ \\
\hline 69 & 65 & 61 \\
95,372 & 31,787 & 30,516 \\
$1.382 \pm 1.657$ & $489 \pm 120$ & $509 \pm 711$ \\
$0 \pm 4,629$ & 254 to 724 & $0 \pm 1,902$ \\
$10 \pm 5$ & $11 \pm 5$ & $12 \pm 5$ \\
$48 \pm 8$ & $47 \pm 7$ & $46 \pm 7$ \\
$0.95 \pm 0.4$ & $1.06 \pm 0.48$ & $1.12 \pm 0.51$
\end{tabular}




\section{Discussion}

The purpose of this study was to determine in normal human ainway epithelium the number and proliferation compartment of goblet and ciliated cells, and to evaluate statistical approaches in order to establish the required number of epithelial cells to be assessed for a reliable estimate of these cell numbers and the proliferation compartment. The mean number of goblet and ciliated cells in normal appearing human airways is $10 \%$ and $48 \%$, respectively. In the airways with a diameter of less than one millimeter, relatively few goblet cells are present, with many ciliated cells. The proliferation compartment of airway epithelium as defined by MIB-I immunoreactivity was $0.95 \%$. Twelve percent of proliferating airway cells are ciliated cells, and one percent are goblet cells. A reliable estimate of goblet and ciliated cell numbers as well as proliferation compartment can be established by counting approximately 400 epithelial cells per airway.

The mean number of goblet cells is ten to twelve percent of all epithelial cells in the conducting airways with an internal diameter of one millimeter or more. This finding corresponds with previous reports of goblet cell numbers in cartilaginous airways it. However, large differences in goblet cell numbers were present not only between airways of similar diameter groups of the seven patients, but also between different airway diameter groups within a particular patient. This wide range of goblet cell numbers was already noted by Clara in $1937^{73}$, and is reflected by the relatively large $90 \%$ confidence intervals of goblet cell percentages of the different ainway diameter groups. Fewer goblet cells were found in airways with a diameter of less than one millimeter corresponding to terminal and respiratory bronchioles. The presence of goblet cells in these small airways is regarded as an abnormality by several researchers ${ }^{204,309}$. Two studies of three ${ }^{17}$ and four ${ }^{76}$ nonsmoking subjects did not show any goblet cells in the noncartilaginous airways. In contrast, another study reported a low but detectable goblet cell number in presumably normal control subjects ${ }^{57}$.

The number of goblet cells is known to increase after administration of tobacco smoke to animal models ${ }^{64}$ and in asthma and COPD in humans ${ }^{309}$. We tried to rule out the influence of environmental hazards as well as disease states on epithelial morphology as much as possible by selection of patient material using the total pathologic score (TPS) as applied by Berend and associates ${ }^{228}$, after prior rigorous selection of autopsy lungs. In this study, the airways with an internal diameter of less than two $\mathrm{mm}$ were scored for smooth muscle hypertrophy, fibrosis, pigmentation, and most importantly, inflammation. The application of histopathological classification systems to human lungs do not preclude the presence of a fair number of goblet cells in the smallest airways in virtually all patients with the lowest pathology scores ${ }^{133.309}$. We propose a definition of goblet cell hyperplasia as an abnormality in human airway epithelium when these airways contain a percentage of goblet cells higher than the upper $90 \%$ confidence interval limits as depicted in Figure I. In 
the case of the smallest airways (i.e., diameter less than one $\mathrm{mm}$ ) the upper $90 \%$ confidence interval limit was $12 \%$ goblet cells which is almost identical to the findings of Thurbeck and associates ${ }^{5 \%}$.

Secretory cell types can also be defined by electron microscopical criteria of the secretory granules. The appearance of these granules varies widely between species ${ }^{145}$, giving rise to a great diversity in cell counts of goblet cells, serous cells and Clara cells of the respective airway epithelia. The electron microscopical criteria for goblet cells are quite simple, as these cells contain large electron-lucent granules in rats and humans ${ }^{17}$. Clara cells and serous cellis on the other hand, contain electron-dense granules ${ }^{17,145}$. However, when a particular species like the hamster is examined, important secretory cell types are sometimes classified as mucous cells (goblet cells) by some authors and Clara cells by others, presumably due to variations in fixation procedures yielding variable morphology of the cellular granule ${ }^{64.145}$. Thus, extrapolation of experimental data concerning airway secretory cell counts and proliferative abilities of these cells to the human situation should be done with great caution.

The mean number of ciliated celis in the conducting airways with a diameter of four $\mathrm{mm}$ or more is $42 \%$ of all airway epithelial cells, increasing to $61 \%$ of the epithelia of the smallest airways with an internal diameter of less than one $\mathrm{mm}$. Lower percentages of ciliated cells were reported by Mercer and colleagues ${ }^{17}$ in their study of human lung tissue with electron microscopical techniques. The distinction between light and electronmicroscopical techniques may be responsible for this difference in ciliated cell percentages.

The compartment of proliferating epithelial cells as defined by MIB-I immunoreactivity of nuclei was $0.95 \%$ of all airway epithelial cells. No differences were present between the large and small airways. This finding confirms our previous report (see chapter 2). After computing the mean proliferation compartment per airway separately, upper $90 \%$ confidence interval limits per airway diameter group could be calculated. Since the upper $90 \%$ confidence interval limits were $2.2 \%$ or less, we propose as a definition of hyperproliferativity in human airway epithelium a proliferation compartment of more than $2.2 \%$, as detected by the MIB-I antibody in formalin-fixed, paraffin embedded lung tissue.

One percent of all proliferating cells were goblet cells. The low proliferative activity of goblet cells is at first sight in contradiction with the concept that secretory cells are regarded by some authors as the primary progenitor cell in the lower and upper airways ${ }^{2}$. This relatively new concept has challenged the traditional view that basal cells are the stem cells of the respiratory epithelium, and is based on experimental studies of the large airways after mechanical ${ }^{98}$ or chemical ${ }^{89}$ injury. Moreover, these studies describe 'secretory cells' in the harnster, a cell compartment with a problematic cell type definition (see above). Our condusion is that goblet cells are not one of the major cell types comprising the proliferation fraction of the epithelium of normal human conducting airways. In the next chapters, these cell types will be identified however.

Proliferation of airway epithelium in the steady state has been investigated in the large airways of both hamster ${ }^{93}$ and rat ${ }^{88.92,94,1041}$ lungs. Breuer and colleagues ${ }^{93}$ quantified hamster bronchial epithelial cells using light microscopy of semithin tissue sections after ${ }^{3} \mathrm{H}$ - 
thymidine pulse-labeling. They found that in the steady state the contribution to cell renewal was $51 \%$ for basal cells and $37 \%$ for secretory cells, each cell type having a major share of the proliferation compartment. In upper airway of rats, three studies report on proliferation of normal epithelium. Ayers and Jeffery quantified cell types and the prolife. ration compartment of pathogen free rat epithelial cells after ${ }^{3} \mathrm{H}$-thymidine pulse-labeling on semithin toluidine blue stained slides. Only $3 \%$ of all epithelial cells were goblet cells, with nil contribution to the cell renewal. In contrast, 30\% of cells were serous cells and $22 \%$ were basal cells contributing $27 \%$ and $66 \%$ to cell renewal, respectively. After exposure to cigarette smoke, goblet cells did proliferate with a sharp increase in the number of goblet cells. Evans and colleagues ${ }^{99}$ used normal control rats versus rats exposed to nitrous oxide. With electron microscopical criteria, about $2 \%$ of the bronchial epithelial cell population were cells with electron-lucent granules, probably presenting goblet cells. The overall proliferation compartment was $1.6 \%$ with a $2.5 \%$ contribution of goblet cells to cell renewal. The third report is from Donnelly and associates ${ }^{92}$, also performing ${ }^{3} \mathrm{H}$-thymidine pulse-labeling in rats. About ten percent of labeled cells were non-ciliated luminal cells, which were referred to as "goblet" cells while mentioning that classic goblet cells were hardly encountered during evaluation of rat airway epithelium in semithin toluidine stained tissue sections. Bindreiter and colleagues ${ }^{94}$ identified goblet cells. as one of the five major cell types in rat tracheal epithelium using identical tissue section techniques as Donnelly. After 40 min of ${ }^{3} \mathrm{H}$-thymidine pulse-labeling they did not identify any labeled goblet cells. In summary, the only data available on the proliferative capacity of goblet cells in respiratory epithelium in the steady state to date were derived from rodents in which few if any of the classic goblets cells are part of the respiratory cell population. Our finding that a low proliferative fraction of human goblet cells in normal airway epithelium is not at variance with experimental work in rodents. Classic goblet cells rarely take part in the proliferation of the normal human conducting airway epithelium.

The low proliferation fraction of human goblet cells in the steady state does not predict the proliferative potential of these cells when acute or chronic disease states are present. Apart from the finding that goblet cells increase in cell number in asthma and severe COPD ${ }^{57,309}$, we do not know whether these cells increase by enhanced proliferation of the goblet cells or by differentiation of other cell types to goblet cells.

Twelve percent of proliferating cells were ciliated cells. The proliferation fraction of ciliated cells is very low (0.27\%), but the size of the cillated cell population is very large. Most reports on proliferation of airway epithelium in animals take the ciliated cell a the classic example of a terminally differentiated cells incapable of cell division ${ }^{86,98,90,92,94,98,104}$ " One of the few reports to the contrary are of Brewer and associates ${ }^{23}$. who found with their ${ }^{3} \mathrm{H}$-thymidine pulse-labeling experiments in hamsters that six percent of labeled airway epithelial cells were ciliated cells one hour after injection of ${ }^{3} \mathrm{H}$-thymidine. As misciassification of labeled cell types was unlikely, Breuer hypothesized that some cliated cells had undergone cilliogenesis but had not yet completely lost their proliferative abilities. Another possibility was that postmitotic cells had taken up ${ }^{3} \mathrm{H}$-thymidine labeled metabolic DNA fragments. If so, misclassification of these cells as being proliferative would ensue. In 
our study the proliferation compartment was defined by immunoreactivity of the MIB-1 antibody, raised against recombinant parts of the nuclear $\mathrm{Ki}-67$ antigen ${ }^{263}$. Present only in proliferating cells, this antigen is maximally expressed during mitosis. The $\mathrm{Ki}-67$ antigen rapidly disappears in the later stages of the mitotic phase of the cell-cycle ${ }^{272}$. Misclassification of $\mathrm{M} \| \mathrm{B}-1$ positive cillated cells, representing $0.27 \%$ of the large ciliated cell population, is therefore unlikely. The present study indicates that a small proportion of ciliated cells proliferate in normal human airway epithelium.

Counting large numbers of cells is a cumbersome procedure. Evaluation of statistical approaches which estimates population proportions correctly can be quite useful to reduce the assessment effort. If random sample sizes are sufficiently large the normal approximation can be used for statistical purposes ${ }^{30 \%}$. We calculated a standard error of cumulative proportion of goblet and ciliated cells and the proliferation compartment. A standard error of less than 0.025 was taken as a arbitrary cutoff point, reached theoretically for all cell types proportion of 0.5 and less at a sample size of 400 cells. We calculated the standard error of proportion for goblet cells, ciliated cells and the proliferation compartment after assessment of the epithelium, which was done in quantities called 'fields', representing 10 successive epithelial areas. As we regarded these "fields" as indivisible quanta, many airways required a higher number of assessed epithelial cells than the theoretical 400 cells. The average amount of cells required was 489 cells (table 4); even with this approach only one-third of the epithelial cells of the original data set were taken into account, thus reducing the required numbers of assessed cells significantly. With this procedure, the advantage is that no prior knowledge is required for the expected proportions. When only the data per airway was considered gathered up to the point that all standard errors of proportions are less than 0.025 and compared with the original data set, no differences were found in goblet and ciliated cells numbers or the proliferation compartment. As an alternative statistical approach, the relative standard error as proposed by Going ${ }^{308}$ was calculated for goblet cellis. A relative standard error of $20 \%$ or less was reached in about $90 \%$ of the airways of the original data set. This rellative standard error was taken as a cutoff point and subsequent calculations were identical to the first statistical approach. The mean number of goblet and ciliated cells and the proliferation compartment estimates by this method were similar to both the first statistical approach and the original data set. In contrast to the first statistical approach, the relative standard error method required prior knowledge of cell type numbers and the required number of cells to be assessed per airway varied widely. Thus the method using calculation of standard error of population proportion seems to be the most rapid and reliable method while reducing cell counting effort significantly.

In conclusion, in normal adult airway epithelium the mean number of goblets cells and ciliated cells is $10 \%$ and $48 \%$, respectively. The proliferation compartment is $0.95 \%$. Only a minor part of the proliferation compartment consists of either ciliated cells or goblet cells.

\section{Acknowledgments}

The authors appreciate the collaboration with the Department of Pathology, De Wever Ziekenhuis, Heerlen, the Netherlands for collecting part of the lung samples. 


\section{Four}

\section{Basal and parabasal cells}

Submitted for publication as

Distribution and proliferation of basal and parabasal cells in normal human airway epithelium

James E Boers, Anton W Ambergen and Frederik B/M Thunnissen 


\section{Introduction}

The lower conducting airway epithelium is lined by a pseudostratified epithelium which is a complex epithelium composed of ciliated, secretory and basal cells ${ }^{16}$. Epithelial cells contain keratin filaments which are a family of more than 20 different cytoskeletal proteins 194; different cell types express different pairs of keratin proteins ${ }^{192}$. In the tracheobronchial mucosa, basal cells are the only cell type that are firmly attached to the basement membrane with hemidesmosomes ${ }^{72}$. Keratins 5 and 14 are preferentially expressed in basal cells $175,176,191$ and may form a resilient filament network ${ }^{191}$ attached to hemidesmosomes. Basal cells are ubiquitous in the human conducting airway epithelium though cell numbers are reduced in the peripheral airways 16.71 . The number of basal cells is related to the thickness of the columnar epithelium ${ }^{72}$, underscoring their role in anchoring the pseudostratified respiratory epithelium to the basement membrane.

In the epidermis, keratins 5 and 14 are faithful markers of the mitotically active basal cells 197. In analogy to the skin, the basal cell has been suggested by many researchers to be the stem cell in the tracheobronchial epithelium ${ }^{90,92.94,104,198 . ~ I n ~ t h e ~ b r o n c h i o l a r ~ e p i t h e l i u m, ~}$ where basal cells are sparse or absent, nonciliated columnar cells (i.e., the Clara cell) are thought to be the sitem cells ${ }^{36}$. However, the concept that the basal cell is the stem cell of the tracheobronchial epithelium of the major airways has been challenged by several studies. Basal cells are the last cell type to appear in fetal lung development ${ }^{31.120}$. Work performed in animal models has demonstrated that the nonciliated columnar cell is the predominant proliferative cell type in response to chemical injury ${ }^{n}$. Application of concepts obtained from experimental models to the human lung has to be done with great caution since the composition of epithelial cell populations varies markedly between different species ${ }^{120}$.

Intermediate cells form a poorly defined layer located just above the basal cells which they resemble electron microscopically ${ }^{16.17}$. In addition to the suprabasal location of nuclei, intermediate cells have been defined by the absence of morphological characteristics of ciliated, neuroendocrine and secretory cell types ${ }^{17.92 .94}$. Defined as such, intermediate cells have been shown to contribute to cell renewal in rodent conducting aimay epithelium ${ }^{92-94}$. Though Donnelly and colleagues ${ }^{92}$ tend to establish the intermediate cell as a legitimate cell compartment composed of differentiating basal cells, other authors hesitate to attribute a role of this category to cell renewal ${ }^{93}$ for lack of positive identification criteria of this cell type. If intermediate cells are defined not only by morphological criteria but also by a positive immunoreactivity of keratins 5 and 14 shared with basal cells, then these 'parabasal' cells could represent a reasonably demarcated and thus quantifiable cell compartment.

The proliferation compartment of the human airway epithelium has been the subject of three recent studies (described in the chapters 2,3 and 6). According to these reports less 
than one percent of airway epithelial cells were proliferating; cycling cells were predominantly located in the proximity of the basement membrane. These findings suggest that the basal cell represents the major cell type of the proliferative compartment in the human tracheobronchial epithelium, but detailed quantification is lacking.

The aim of this study was to quantify in normal human airway epithelium: the number of basal and parabasal cells as defined by cell nucleus position and expression of the keratins 5 and 14; the proliferation compartment; and the contribution of (para)basal cells to the proliferative compartment. To this end, human lungs, obtained by autopsy and by rigorous criteria considered to be normal, were fixed by tracheal infusion of formalin and crosssections from central to peripheral ainways were stained sequentially with an antibody to the proliferation-association protein Ki-67 (MIB-1) and the anti-keratin antibody $34 \beta \mathrm{E} / 2$ as a marker for (para)basal cells.

\section{Methods}

\subsection{Material}

In De Wever Hospital, Heerlen, and Maastricht University Hospital, the Netherlands, perfusion fixation of lungs was performed if deceased patients were available for autopsy within $6 \mathrm{~h}$ after death (for details see chapter 2). Perfusion fixation of 275 cases was carried out. After fixation, seven samples taken from trachea down to peripheral lung tissue and routinely processed. A standard haematoxylin \& eosin stain was used for histological assessment. In order to obtain a more or less normal population all cases with primary or secondary pulmonary diseases were exduded. After these selection procedures, a total pathologic score (TPS) was established for each slide according to Berend and colleagues 228 using both haematoxylin and Elastica - von Gieson stained sections (for details see chapter 3). Seven patients (six non-smoking, one with unknown smoking status) with a TPS score of less than 100 remained for further study. This patient group is identical to the group described in chapter 3 .

\subsection{Immunohistochemistry}

$3 \mu \mathrm{m}$ tissue sections were placed on 3-amino propyltriethoxysilane-coated slides (Sigma Chemical $\mathrm{CO}$., St. Louis, $\mathrm{MO}$ ) and dried overnight in a convection oven $\left(56^{\circ} \mathrm{C}\right)$. Slides were dewaxed in xylene, rehydrated in graded alcohols, and rinsed in distilled water. Subsequently, the slides were placed in plastic jars containing $500 \mathrm{ml}$ of $10 \mathrm{mM}$ citrate buffer in distilled water, $\mathrm{pH}=6$. Two jars were placed in a $650 \mathrm{~W}$ microwave oven, and irradiated until boiling point. Then, 15 min of uninterrupted boiling was performed using full-power irradiation. After removing the jar from the microwave oven, cooling until room temperature was achieved in about 20 min. Slides were incubated with the MIB-I antibody 
263 (Immunotech, Marseille, France; dilution 1:25) for 45 min at room temperature. Slides were washed thrice with phosphate buffered saline (PBS), incubated with biotinylated rabbit-anti-mouse (Dako, Glostrup, Denmark; 1:500) and subsequently with peroxidlaseconjugated streptavidin label (Dako" 1:1000). The slides were then incubated with diaminobenzidine (Sigma) for $10 \mathrm{~min}$. Subsequently, slides were incubated with $0.0025 \%$ pepsine in $0.1 \mathrm{~N} \mathrm{HCl}$ for 10 min at room temperature. After rinsing twice with $\mathrm{PBS}$, the slides were incubated with the monodonal antibody $34 \beta E 12$ (Dako; 1:400) for $45 \mathrm{~min}$ at room temperature. The antibody $34 \beta E 12$ is specific for high-molecular-weight keratin pair $1 / 10$, only present in keratinized squamous epithelium, and intermediate-molecular-weight keratin pair $5 / 144^{192.311}$. After incubation with the $34 \mathrm{BE} / 2$ antiserum, biotylinated rabbitanti-mouse (Dako; 1:500) and alkaline phosphatase-conjugated streptavidin label (Dako; 1:200) were used as subsequent layers. After rinsing in PBS, slides were incubated with New Fuchsine (Biogenex, San Ramon, CA). Then, slides were rinsed in PBS, counter stained in Mayer's haematoxylin and placed in tap water for 15 min. Three drops of $1 \mathrm{~m}$ sol/Mount (Klinipath, Zevenaar, the Netherlands) were applied to the tissue section. Slides were then allowed to dry, and mounted in Entellan (Merck, Darmstadt, Germany).

Negative control slides were stained with the omission of the monodonal antibodies MIB- $\|$ and/or 34BEI2. As positive control a slide was used from a bronchial resection margin of a pneumonectomy specimen. A fixation delay study was performed on a pneulmonectomy specimen, showing no impact of fixation delay up to $12 \mathrm{~h}$ on either MIB-I or $34 \beta E 12$ immunoreactivity.

\subsection{Image analysis and measurements}

An interactive image analysis system consisting of the Quantimet $570 \mathrm{C}$ and a microscope was used as described in chapter 2. Epithelial thickness was defined as the distance between the basement membrane and the luminal cell membrane excluding the cilia ${ }^{\text {. }}$ Only epithelium with a orientation perpendicular to the basement membrane was evaluated. Subsequently, only nucleated epithelial cells were counted manually and divided in six categories: the total number of epithelial cellis; the number of basal and parabasal cells; the number of MIB-1 immunoreactive cells; the number of $M I B-1$ positive basal and parabasal cells. The total number of epithelial cells was assessed by counting all nuclei located at the luminal site of the basement membrane. A cell was identified as a basal cell when the cytoplasm surrounding an airway cell nucleus was brightly immunostained with the monoclonal antibody $34 \mathrm{BE} 12$ and the nucleus was adjacent to the basement membrane. A parabasal cell was defined as a cell with a brightly immunolabeled cytoplasm without cytoplasmic projections to the luminal surface and a nucleus positioned superiorly to the nuclei of basal cells and inferiorly to the nuclei of luminal columnar cells. Occasionally, a ciliated or non-ciliated columnar cell was $34 \beta E 12$ immunopositive. These cells were easily recognized as luminal cells and not included in the parabasal cell category. Epithelial cell nuclei stained unequivocally with diaminobenzidine were regarded as MIB-I positive cells. 
Reproducibility of the number of all airway epithelial cells, basal and parabasal cells, and MIB-I positive cells was $>90 \%$.

\subsection{Data handling and statistics}

During assessment of each airway, the number of cells divided in the six categories (i.e., total number of airway epithelial cells, basal cells, parabasal cells, total number of MIB-I positive cells, basal and parabasal cells with MIB-I positive nuclei) and the length of basement membrane were added until 10 successive epithelial segments (i.e., one videa image of the epithelium) were counted. These aggregated data were recorded on file with the internal diameter and epithelial thickness added manually and referred to as a "field", constituting 250 to 500 cells and $1.4 \mathrm{~mm}$ of basement membrane. Assessment of the epithelium of an airway was discontinued when three 'fields' were assessed. For the small airways

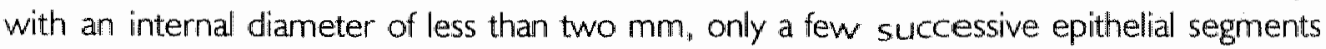
are present because of their small size. The data of these small airways were added in a particular slide when the difference in internal diameters was less than $0.2 \mathrm{~mm}$. In this manner, two or three 'fields' could be assessed in the small airways.

In the previous chapter two statistical approaches were examined in order to establish the minimum number of cells required for a reliable estimate of cell type proportions. In this study, the standard error of proportion method was repeated to find out whether similar results are obtained.

Cumulative percentages were calculated for each successive 'field' for each airway for five cell types, namely the percentage of basal cells, parabasal cells. MIB-I positive cells, basal and parabasal cells with MIB-I positive nuclei. The airways were divided into four groups according internal airway diameter: $\geq 4 \mathrm{~mm}, \geq 2 \mathrm{~mm}$ but less than four $\mathrm{mm}, \geq 0.5$ $\mathrm{mm}$ but less than two $\mathrm{mm}$, and $<0.5 \mathrm{~mm}$. The data presented are the cumulative percentages calculated as follows: the mean cumulative percentage of a particular cell type was calculated per patient and per airway diameter group. This resulted in $7 \times 4=28$ means (in total there were 92 assessed airways), as tabie I shows for basal cells. Then, the mean percentage of a cell type was obtained per airway diameter group by calculating the mean of the individual patient data of this airway diameter group (column mean in table 1). Also, the overall mean was obtained by calculating the mean of the 28 individual patient means. The standard deviation was calculated with the nested ANOVA procedure ${ }^{306}$; this approach not only detects variance between patient means but. also between the different observations within a patient and within an airway group. The standard deviation was established as the total SD per airway diameter group, but also calculated separately for the data obtained between patients, and within patients. For obtaining the SD of the overall mean, only the SD calculated between patient means were used as wariance within patient data were large because of the different airway diameter groups. 


\section{Results}

In total, 101,800 cells and $375 \mathrm{~mm}$ of basement membrane were counted; the number of assessed ainways and epithelial cells per ainway diameter group are presented in table 2. The mean number of airway epithelial cells expressed per millimeter of basement membrane was 338 cells/mm in the airways with the largest diameter ( $\geq 4 \mathrm{~mm}$ ), and 173 cells/mm in the smallest airways $(<0.5 \mathrm{~mm})$. Per airway, a mean of 1107 epithelial cells were assessed.

Table 1. Calculation of mean percentages of basal cells per patient and per airway diameter group.

\begin{tabular}{|c|c|c|c|c|c|}
\hline patient & $\geq 4 \mathrm{~mm}$ & $\begin{array}{r}\text { airway } \\
\leq 4, \geq 2 \mathrm{~mm} \\
\end{array}$ & $\begin{array}{l}\text { diameter } \\
<2, \geq 0.5 \mathrm{~mm}\end{array}$ & $<0.5 \mathrm{~mm}$ & mean \\
\hline 1 & 21 & 23 & 22 & 4 & \\
\hline 2 & 26 & 25 & 25 & 8 & \\
\hline 3 & 35 & 35 & 14 & 2 & \\
\hline 4 & 36 & 36 & 36 & NA & \\
\hline 5 & 35 & 25 & 17 & 10 & \\
\hline 6 & 33 & 33 & 22 & 5 & \\
\hline 7 & 30 & 31 & 23 & 4 & \\
\hline mean $( \pm 5 D)$ & $31( \pm 7)$ & $30( \pm 7)$ & $23( \pm 7)$ & $6( \pm 4)$ & $23( \pm 11)$ \\
\hline
\end{tabular}

$\mathrm{NA}=$ not available

\section{I. Basal and parabasal cells}

A total number of 25,075 basal cells (Figure I on p. 117) were counted. Table I shows the number of basal cells expressed as the mean percentage of airway epithelial cells per patient and per airway diameter group. In the airways with a diameter of two $\mathrm{mm}$ or more, $30 \% \pm 7 \%$ (mean \pm SD) of epithelial cells are basal cells. Basal cells were present in the smallest airways with a diameter $<0.5 \mathrm{~mm}$, but the percentage basal cells $(6 \% \pm$ 4\%) was considerably lower than in the larger airways. Comparing the number of basal cells expressed per $\mathrm{mm}$ of basernent membrane with the total thickness of the airway epithelium revealed a strong correlation $(r=0.83)$.

A total number of 3.774 parabasal cells were counted, predominantly in the airways with a diameter of two $\mathrm{mm}$ or more (Table 2). Parabasal cells were absent in the smallest airways with a diameter of less than $0.5 \mathrm{~mm}$. The combined number of basal and parabasal cells per millimeter of basement membrane is strongly correlated with the total thickness of the airway epithelium $(r=0.84)$.

\subsection{Proliferation compartment}

The proliferation compartment was defined by the immunoreactivity of airway cell nuclei of the MIB-1 antibody ${ }^{263} .844$ of 101,840 airway epithelial cells were immunoreactive. 
The proliferation compartment expressed as the percentage MIB-I positive epithelial cells was calculated per patient and per airway diameter group (Table 2). The overall mean proliferation compartment was $0.87 \% \pm 0.30 \%$.

Table 2. Number of assessed ainways, total number of epithelial cells per mm of basement membrane (bm); basal, parabasal and MIB-I positive cells expressed as percentage of epithelial cells per ainway diameter group.

\begin{tabular}{|c|c|c|c|c|c|}
\hline & $=4 \mathrm{~mm}$ & $\begin{array}{rl} & \text { aiirway } \\
<4 & 4 \\
\geq 2 \mathrm{~mm}\end{array}$ & $\begin{array}{c}\text { diameter } \\
<2 . \\
\geq 0.5 \mathrm{~mm}\end{array}$ & $<0.5 \mathrm{~mm}$ & $\begin{array}{l}\text { total } / \\
\text { mean }\end{array}$ \\
\hline Assessed airways & 24 & 24 & 23 & 21 & 92 \\
\hline Assessed epith. cells & 36,093 & 30,619 & 19,011 & 16,117 & 101.800 \\
\hline Epithelial celis $/ \mathrm{mm}$ bm & 338 & 271 & 223 & 173 & 266 \\
\hline Basal cells ${ }^{\mathrm{a}}$ & $31 \pm 7$ & $30 \pm 7$ & $23 \pm 7$ & $6 \pm 4$ & $23 \pm 5$ \\
\hline Parabasal cells" & $7 \pm 4$ & $3 \pm 2$ & $1 \pm 2$ & 0 & $3 \pm 1$ \\
\hline MIB-I positive cells ${ }^{a}$ & $1.02 \pm 0.41$ & $0.85 \pm 0.50$ & $0.87 \pm 0.43$ & $11.01 \pm 0.98$ & $0.87 \pm 0.30$ \\
\hline
\end{tabular}

Mean $\% \pm S D$

Of 25,075 basal cells, 423 cells of the basal cell compartment were MIB-I immunoreactive (Figure I on p. 117); thus, the proliferative fraction was $1.6 \%$. On average, basal cells represented $48 \%$ of the proliferation compartment of the conducting airway epithelium. In the airways with a diameter of $0.5 \mathrm{~mm}$ or more, over $50 \%$ of the airway epithelial cells constituting the proliferation compartment were basal cells (Figure 2). In the smallest airways (diameter $<0.5 \mathrm{~mm}$ ) $30 \%$ of proliferative cells were basal cells. Of 3.774 parabasal cells, 198 cells (proliferative fraction $5.25 \%$ ) of the parabasal cell compartment were MIB-I immunoreactive (Figure I) constituting $15 \%$ of the proliferation compartment. 33\% of proliferating epithelial cells in the largest airways (diameter $\geq 4 \mathrm{~mm}$ ) were parabasal cells (Figure 2).

3.3. Feasibility study of reducing the required number of epithelial cells using calculation of the standard error of proportion

The standard error of proportion ( $\mathrm{SE}_{\mathrm{prop}}$ ) was calculated for each individual airway after obtaining 10 successive epithelial segments (recorded as a 'field' or data record) for the proportion of basal cells, parabasal cells and MIB-I positive cells. When the SE $E_{\text {prop }}$ was less than 0.025 , the cumulative data of the individual airway was taken into account, ignoring subsequent data acquisition. 39,422 epithelial cells and $150 \mathrm{~mm}$ of basement membrane (263 cells $/ \mathrm{mm}$ basement membrane) were used for data analysis, representing $39 \%$ of the original data set. Per airway a mean of 429 epithelial cells were taken into account. The number of basal cells, parabasal cells, MIB-I positive cells, MIB-I positive basal and parabasal cells calculated after using the $\mathrm{SE}_{\text {prop }}$ method were compared with the original data presented in table 2 . The difference in the number basal cells, parabasal cells and MIB-I positive cells was less than $3.5 \%$; the difference in the number of MIB-I positive basal cells and parabasal cells was less than $10 \%$. Therefore, the use of the calculation of the standard 
error of proportion seems to be validated in the quantitation of (para)basal cells and MIB-1 positive cells in the human conducting airway epithelium.

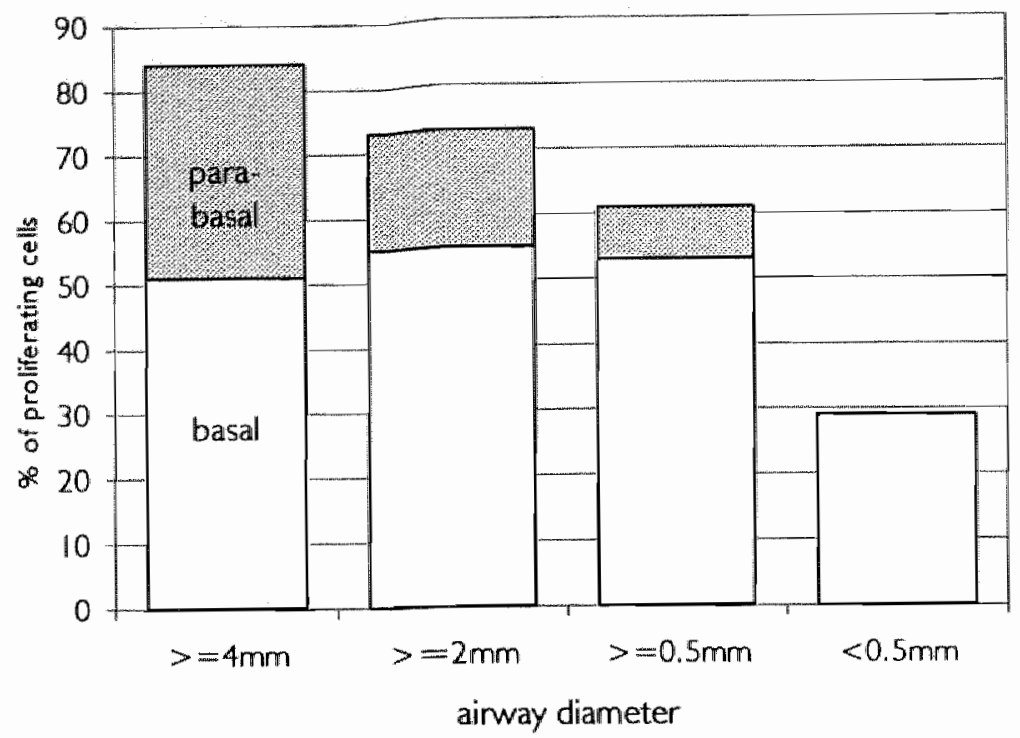

Figure 2. The contribution of (para) basal cells to the proliferation compartment of the tracheobronchial epithelium per airway diameter group

\section{Discussion}

The purpose of this study was to determine the distribution of basal and parabasal cells in normal human airway epithelium using the anti-keratin antibody $34 \beta \mathrm{E} 12$, and to establish the contribution of basal and parabasal cells to the proliferation compartment. The mean percentages of basal and parabasal cells were $23 \%$ and $3 \%$, respectively. The overall proliferation compartment as defined by MIB-I immunoreactivity was $0.87 \% ; 48 \%$ of proliferating epithelial cells were basal cells and $15 \%$ were parabasal cells.

The number of basal cells expressed per $\mathrm{mm}$ of basement membrane was strongly correlated to the thickness of the respiratory epithelium $(r=0.83)$. This anatomic relationship corresponds to the findings of Evans and associates ${ }^{109}$ who studied the airway epithelium in several species. The plausible role of basal cells in the attachment to the basement membrane of complex epithelia in general has also been discussed by Purkis and colleagu- 
es ${ }^{191}$. They hypothized that the keratins 5 and 14 may form a fillamentous network which is tough and elastic. In our view, basal cells with a resilient cytoskeleton could play a useful supportive role where the airways are relatively rigid. In the more dellicate and elastic terminal and respiratory bronchioles such tough supportive cells seem to be less needed.

Intermediate cells are a poorly defined cell population ${ }^{16}$ located between basal cells and columnar cells. Using electron microscopical techniques, morphological similarities have been noted between of intermediate cells and basal cells ${ }^{16,17}$ apart from the position of the cytoplasm relative to the basement membrane. Because of these similarities, such intermediate cells could be named 'parabasal' cells. On a light microscopical level, intermediate cells have been defined negatively: nuclei positioned neither basally nor luminally, cytoplasm having neither cilia nor secretory granules ${ }^{92-94}$. The intermediate cell population defined as such could comprise not only 'parabasal' cells, but also secretory cells without readily discernible granules. In addition to the morphological criteria concerning cell nucleus position and cell differentiation, we have defined the parabasal cell population by their immunoreactivity of the anti-keratin antibody $34 \beta \mathrm{E} / 2$; the combined criteria allow for distinction from both basal cells and columnar cells (Figure I).

Proliferation of the respiratory epithelium has been studied predominantly in the large airways of laboratory animals. The basal cell is the dominant cell type of the proliferation compartment of normal airway epithelium when plastic tissue sections of rodent lungs are assessed shortly after ${ }^{3} \mathrm{H}$-thymidine pulse-labeling ${ }^{86,92-94,104}$. Nonciliated columnar ceils (i.e., Clara cells) do contribute to the proliferation compartment of the rodent respiratory epithelium in the steady state, but to a lesser extent than basal cells. The question remains whether basal cells are the stem cells of the mammalian conducting airway epithelium.

The concept of stem cells is derived from studies performed on tissues with rapidly renewing cell populations including blood and skin ${ }^{107,241,277}$. In these tissues, certain cells are thought to have an almost unlimited capacity for self-renewal. These putative stem cells are considered to be slowly cycling (if at all) in a specific micro-environment ${ }^{27}$, and to produce a transit amplifying cell population. This committed cell population comprises several generations of rapidly proliferating cells with a finite self-renewal capacity; as progressive differentiation of cell generations ensue the self renewal capacity eventually ceases 248. 277. Direct identification of stem cells is virtually impossible as specific markers for these cells are absent ${ }^{27}$.

Examination of lung tissue sections obtained from laboratory animals at various times after pulse-labeling with ${ }^{3} \mathrm{H}$-thymidine can be used to establish the temporal and spatial relationships of the dividing airway epithelial cell population ${ }^{99,90,104}$. Donnelly and associates ${ }^{92}$ studied plastic tissue sections of rat tracheal epithelium up to 10 days after a ${ }^{3} \mathrm{H}$-thymidine pulse-label. The compartment of ${ }^{3} \mathrm{H}$-thymidine labeled basal cells peaked at one day after pulse-labeling followed by a peak of intermediate cells at two days, and both secretory cells and ciliated cells at three days. They concluded that basal cells are the progenitor cells of the tracheal epithelium, and divide to intermediate cells which in turn give rise to luminal epithelial cells (ciliated and non-ciliated). Other researchers using identical techniques described a more complex picture of cell proliferation and differentiati- 
on in rats ${ }^{94,104}$ and hamsters ${ }^{43}$. In these studies, basal cells appear to be the most important progenitor cells in the conducting epithelium of the large airways in the steady state, with the capacity of self-renewall ${ }^{93}$ suggesting stem cell properties. Secretory cell types (in particular Clara and serous cells) also contribute to cell renewal and in fact appear to be the stem cells of the small airways where basal cells are sparse or even absent ${ }^{87}$. The complexity of airway epithelial cell proliferation and differentiation becomes even more acute when rat epithelium is studied after the exposure of tobacco smoke ${ }^{104}$ or nitrogen dioxide ${ }^{88}$. Secretory cells are the dominant cell type in the proliferative response to airway epithelial injury in these studies, which have led Evans and associates to conclude that the basal cell is not a primary progenitor cell at all but plays an adhesive role only.

In humans, sequential tissue sampling after injection of label is virtually impossible in the study of the conducting airway epithelium in the steady state. Alternatively, immunohistochemical detection of naturally occurring cell proliferation-associated nuclear proteins such as Ki-67 can identify proliferative cells reliably ${ }^{249,270}$. These methods can not reveal the temporal relationships of the dividing and differentiating cell populations, but do demonstrate those cells that are part of the proliferation compartment. When the number of the various epithelial cell types of the conducting airway epithelium are correlated with their respective shares of the proliferation compartment, insight could be gained into the role of these different cells in the maintenance of the normal human airway epithelium. In the present study, basal cells represent over $50 \%$ of the proliferation compartment of the conducting respiratory epithelium of the airways with an internal diameter of $0.5 \mathrm{~mm}$ and more (table 2 and figure 2) while these cells comprise up to $31 \%$ of the epithelial cell population. Thus, the proliferative fraction of basal cells in these large airways is $1.6 \%$. If the relative percentage of a cell type which contributes to the proliferation compartment (i.e., the percentage contribution to the proliferation compartment of a cell type divided by the percentage of a cell type contributing of the airway epithelium) termed proliferative fraction is $>1 \%$, this may be defined as 'overrepresentation' of this cell type in the proliferation compartment. Overrepresentation might indicate that the two roles suggested for basal cells (adhesive and proliferative) are not incompatible but a typical phenomenon in cells expressing keratins 5 and $\| 4$, as described in several tissues other than the lung. The expression of the 'basal' type keratins 5 and 14 is characteristic of the compartment of proliferating cells in cornifying and non-comitying stratified squamous epithelia ${ }^{175 .}{ }^{197}$. In these epithelia, basal cells are also known to play a vital role in the adhesion of the epithelium to the basement membrane ${ }^{191}$.

Basal cells are not the only cell type immunolabeled with anti-keratin 5 and 14 , but parabasal cells are also present in normal human airway epithelium. $7 \%$ of the epithelial cells in the largest airways (i.e., diameter $z 4 \mathrm{~mm}$ ) are parabasal cells, representing $33 \%$ of the proliferation compartment (table 2 and figure 2). In the proliferation compartment of airways with diameters between 2 and $0.5 \mathrm{~mm}$, overrepresentation of parabasal cells is even more apparent: the proliferative fraction of parabasal cells in this area is $8 \%$. Parabasal cells, with an 'intermediate" position between basal and columnar cells, thus have a fair contribution to the proliferation compartment of normal conducting airway epithelium in 
humans despite their relatively modest cell numbers. High proliferative activity of 'intermediate' cells has been noted in previous studies using ${ }^{3} \mathrm{H}$-thymidine pulse-labelling in laboratory animals 92-94. 104. Without immunohistochemical techniques, identification of airway epithelial cells with the light microscope is difficult ${ }^{88}$, resulting in large differences in the definition of the 'intermediate' cell. As a consequence, the putative origin of the 'intermediate' cell has led to considerable controversy. Evans and associates defined the intermediate cell as an undifferentiated columnar cell which, in their opinion, is part of the secretory cell compartment and not a direct descendant of the basal cell ${ }^{89}$. Donnelly and colleagues ${ }^{92}$ employed another definition of the intermediate cell, namely a non-basal non-columnar cell. The compartment of ${ }^{3} \mathrm{H}$-thymidine labeled intermediate cells peaked at one day after the peak in labeled basal cells, followed by a subsequent increase in ${ }^{3} \mathrm{H}$-thymidine labeling of both secretory cells and ciliated cells. This pulse-chase experiment led Donnelly and associates to conclude that basal cells are the progenitor cells of the airway epithelium. with the intermediate cell as their direct descendants. In addition to the criteria of the 'intermediate' cell of Donnelly and colleagues, we defined the parabasal cell by its immunoreactivity of keratins 5 and 14. As basal cells are the only other epithelial cell type in the normal human conducting airways to express these keratins, it is quite plausible to argue that the combined parabasal and basal cell populations belong to a distinct cell compartment. While the design of the present study prohibits the delineation of pathways of cell differentiation, it is quite conceivable that an interrelation between basal cells and parabasal cells exists, one being the progenitor cell of the other. While basal cells are overrepresented in the proliferation compartment in the epithelium of the airways with a diameter of $0.5 \mathrm{~mm}$ and more, parabasal cells contribute even more to the proliferation compartment relative to their modest cell numbers. This difference in a relative contribution to the proliferation compartment of basall and parabasal cells fits with the hypothesis that basal cells are relatively slowly cycling 'stem' cells, giving rise to parabasal cells, which represent a comparatively rapid cycling transient amplifying cell population.

In summary, in normal human conducting airway epithelium the percentage of basal and parabasal cells as defined by immunolabeling of anti-keratin 5 and 14 is $23 \%$ and $3 \%$. respectively. The number of basal and parabasal cells is strongly related to the thickness of the respiratory epithelium, suggesting a role of these cells in the attachment of the airway epithelium to the basement membrane. Basal cells represent over $50 \%$ of proliferating cells in the airways with a diameter of $0.5 \mathrm{~mm}$ or more, with a significant contribution of parabasal cells to the proliferation compartment. The overrepresentation of (para)basal cells to the proliferation compartment of these airway supports the theory that cells at or near the basement membrane are likely to be the progenitor cells of the larger airways.

\section{Acknowledgments}

The authors would like to thank the Department of Pathology of De Wever Hospital, Heerlen, the Netherlands for providing part of the lung material. The technical advice of dr. J.L.V. Broers and dr. F.J. Bot is also greatly appreciated. 



\section{Five}

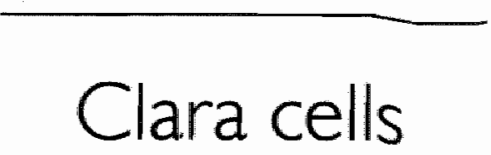

Submitted for publication as

Distribution and proliferation of Clara cells in the normal human airway epithelium James E Boers, Anton W Ambergen and Frederik BJM Thunnissen 


\section{Introduction}

Over 60 years ago, a nonciliated nonmucous cell was described in the human respiratory epithelium of the peripheral conducting airways ${ }^{73}$. The eponymous histologist Max Clara defined these cells by their distinctive cytoplasmic granules indicating a secretory function. Since then numerous electron microscope studies performed in mammals have shown considerable interspecies heterogeneity in both morphology and distribution of these cells 139. An ultrastructural characteristic of Clara cells is the presence of electron-dense membrane-bound granules, which immunolocalize with rat Clara cell $10 \mathrm{kd}$ protein (CCI0), one of the secretory products of Clara cells ${ }^{150}$. Antibodies raised against human $\mathrm{CClO}{ }^{82.17 \%}$ "later also isolated and described as protein $\mathrm{PI}{ }^{222}$, have been used as immunohistochemical markers of Clara cells. CCIO immunoreactive cells are described in the human respiratory epithelium of both peripheral and central conducting airways ${ }^{81 .}$ 171-174. Though the distribution of Clara cells has been examined in the peripheral conducting airways of lung cancer patients ${ }^{76,80,82}$, no comprehensive quantitative study of the Clara cell population has been performed of the entire tracheobronchial tree of normal lungs.

Clara cells contribute to cell renewal in hamster bronchial epithelium in the steady state ${ }^{93}$. The proliferative response of the bronchiolar epithelium after exposure of rats to $\mathrm{NO}_{2}{ }^{87}$ or $\mathrm{O}_{3}{ }^{195}$ gases is predominantly due to Clara cell division. Grafting isolate cell compartments of rabbit bronchiolar epithelium highly enriched in Clara cells onto denuded tracheas results in an epithelium containing both Clara cells and ciliated cells, resembling bronchiolar epithelium ${ }^{200}$. Thus, the Clara cell is an important cell type regarding cell renewal in rodent conducting airway epithelium in both health and disease ${ }^{86}$.

In man, the overall proliferation compartment of normal conducting airway epithelium has been determined ${ }^{304}$, but the extent to which Clara cells contribute to cell renewal is unknown. The architecture of terminal conducting airways shows species-specific variations in addition to a highly diverse epithelial composition prohibiting extrapolation of data obtained in animal models to the human lung ${ }^{119}, 120$. As Clara cells play a plausible if undefined role in both neoplastic and non-neoplastic lung disease ${ }^{76,172.174,216,219,312,313}$ knowledge of Clara cell distribution and proliferation in the normal human lung is of importance when disease is to be defined morphologically and cell-kinetically.

The aim of the present study was to determine in normal human airway epithelium: the distribution of Clara cells; the prolliferation compartment and the contribution of Clara cells to the proliferation compartment. To this end, human lungs obtained by autopsy were fixed by tracheal infusion of formaline and cross-sections from central to peripheral airway were stained secuentially with an antibody to the proliferation-associated protein Ki-67 (MIB-1) followed by a Clara cell marker (CC10 antibody). 


\section{Methods}

\subsection{Material}

In De Wever Hospital, Heerlen, and Maastricht University Hospital, the Netherlands, perfusion fixation of lungs was performed if deceased patients were available for autopsy within $6 \mathrm{~h}$ after death (for details see chapter 2). Perfusion fixation of 275 cases was carried out. After fixation, seven samples were taken from trachea down to peripheral lung tissue and routinely processed. A standard haematoxylin \& eosin (H\&E) stain was used for histological assessment. In order to obtain a more or less normal population all cases with primary or secondary pulmonary diseases were excluded. After these selection procedures, a total pathologic score (TPS) was established for each slide using both H\&E and Elastica - von Gieson stained sections (for details see chapter 3). Seven patients (six nonsmoking, one with unknown smoking history) with a TPS score of less than 100 remained for further study.

\subsection{Immunohistochemistry}

A sequential double indirect immunohistochemical staining procedure followed by the periodic acid-Schiff (PAS) stain was performed. $3 \mu \mathrm{m}$ tissue sections were placed on 3amino propyltriethoxysilane-coated slides (Sigma Chemical CO., St. Louis, MO) and dried overnight in a convection oven $\left(56^{\circ} \mathrm{C}\right)$. Slides were dewaxed in xylene, rehydrated in graded alcohols, and rinsed in distilled water. Subsequently, the slides were placed in plastic jars containing $500 \mathrm{ml}$ of $10 \mathrm{mM}$ citrate buffer in distilled water, $\mathrm{pH}=6$. Two jars were placed in a $650 \mathrm{~W}$ microwave oven, and irradiated until boiling point. Then, $15 \mathrm{~min}$ of uninterrupted boiling was performed using full-power irradiation. After removing the jar from the microwave oven, cooling until room temperature was achieved in about $20 \mathrm{~min}$. The first immunostaining was an incubation with the MIB-I antibody ${ }^{263}$ (Immunotech, Marseille, France; dilution 1:25) for $45 \mathrm{~min}$ at room temperature. Slides were washed thrice with phosphate buffered saline (PBS), incubated with biotinylated rabbit-anti-mouse (Dako, Glostrup, Denmark; 1:500) and subsequently with peroxidase-conjugated streptavidin label (Dako; $1: 1000$ ). As a chromogen diaminobenzidine (Sigma) was used producing a dark brown nuclear immunostain. Subsequently, slides were incubated with $20 \%$ normal swine serum (Dako) in distilled water for $20 \mathrm{~min}$ at room temperature, followed by the second primary rabbit polyclonal antibody $\mathrm{CClO}^{13}$ (a generous gift from Dr. G. Singh, Pittsburgh, Pa.; dilution 1:2500) for $45 \mathrm{~min}$ at room temperature. After washing with PBS, incubation of biotylinated swine-anti-rabbit (Dako; 1:1000) and alkaline phosphataseconjugated streptavidin label (Dako; 1:200) were used as subsequent steps. The slides were rinsed in PBS and incubated with Fast Blue (Sigma) for 10 min, producing dark blue cytoplasmic immunostain. Then, slides were rinsed in PBS, and the PAS stain ${ }^{65}$ was carried 
out which stains neutral glycoproteins bright red. Finally, slides were lightly counterstained with Mayer's haematoxylin and placed in tap water for 15 min. Three drops of Imsol / Mount (Klinipath, Zevenaar, the Netherlands) were applied to the tissue section. Slides were then allowed to dry, and mounted in Entellan (Merck, Darmstadt, Germany).

Negative control slides were stained with the omission of the primary antibodies MIIB-1 and/or CClO. As positive control a slide was used containing several respiratory bronchioles from a pneumonectomy specimen showing many Clara cells, and large bronchi with squarnous metaplasia with readily apparent MIB-I staining ${ }^{304}$. A fixation delay study was performed on a pneumonectomy specimen, showing no impact of fixation delay up to 12 h on either MIB-I or CCIO immunoreactivity.

\subsection{Image analysis and measurements}

An interactive image analysis system consisting of the Quantimet $570 \mathrm{C}$ and a Leitz microscope was used as described in chapter 2 . Only nucleated epithelial cells were counted manually and divided in the following categories: the total number of epithelial cells; the number of Clara cells; the number of goblet cells; the number of indeterminate cells; the number of MIB-I immunoreactive epithelial cells; the number of M|B-I positive Clara, goblet or indeterminate cells. The total number of epithelial cells was assessed by counting all nuclei located at the luminal site of the basement membrane. A cell was identified as a Clara cell when a typical dome-shaped cytoplasm was distinctly immunostained with $\mathrm{CCl} 0$ without PAS-positivity. Goblet cells were identified by a flask-shaped cytoplasm with large PAS-positive cytoplasmic vacuoles and ovoid nuclei below the cytoplasmic vacuoles. A proportion of the goblet cells demonstrated $\mathrm{CCl} 0$ immunoreactivity, and were included as a separate category of epithelial cells. A small proportion of epithelial cells had CCIO immunoreactivity and indistinct PAS-positivity, not fulfilling the criteria of either Clara cells or goblet cells; these cells were designated as indeterminate cells. Epithelial cells with nuclei stained unequivocally dark brown with diaminobenzidine were regarded as MIB-I positive cells. Reproducibility of the number of all airway epithelial cells, Clara cells, goblet cells, indeterminate cells and MIB-I positive cells was $>90 \%$.

\subsection{Data handling and statistics}

Determination of length of basement membrane and cell numbers was performed for a series of subsequent epithelial areas until 400 to 450 epithelial cells were assessed. The total number of epithelial cells per airway required for quantification was based the standard error of proportion method as described in chapter 3.

The airways were classified into four categories in two different ways. The first approach was to classify the airways solely on the basis of internal airway diameter. Four airway diameter groups were created: group 1 (diameter $\geq 4 \mathrm{~mm}$ ), group 2 (diameter $\geq 2$, $\mathrm{mm}$ but less than $4 \mathrm{~mm}$ ), group 3 (diameter $\geq 0.5 \mathrm{~mm}$ but less than $2 \mathrm{~mm}$ ) and group 4 (diameter $<0.5 \mathrm{~mm}$ ). The second approach was based on a combination of airway 
diameter and morphology, and the airways were classified into 4 morphologic categories: category I [labeled as bronchi], airways with a diameter $\geq 2 \mathrm{~mm}$; category II [ membranous bronchioles], bronchioles with diameters $\geq 0.5 \mathrm{~mm}$ but less than two $\mathrm{mm}$ and without respiratory bronchioles in the vicinity; category III [terminal bronchioles], small nonalveolarized bronchioles in the vicinity of respiratory bronchioles; category IV [respiratory bronchioles], alveolarized bronchioles. Only ciliated epithelium was considered for assessment in the respiratory bronchioles. The individual aimays labeled as terminal and respiratory bronchioles (airway categories III and IV) frequently failed to contain a minimum of 400 epithelial cells; the data (i.e., length of basement membrane and the number of the nine cell categories) of several of these small airways in a particular slide were added until 400 to 450 epithelial cells were available for assessment. Such aggregated data were referred to as an 'airway' for the purpose of the present study.

The following calculations were performed for both airway classification systems. The data of the described cell types obtained per airway were grouped per patient and per aiwway category. The number of the individual epithelial cell types were expressed as percentages of total airway epithelial cell count. A mean was calculated for each epithelial cell type per patient and per airway category. This resulted in $7 \times 4=28$ means as is shown for Clara cells in table I. These mean percentages were used to determine a mean per ainway category. The standard deviation (SD) was calculated with the nested ANOVA procedure ${ }^{306}$; this approach not only detects variance between patient means but also between the different observations within a patient per airway category.

Table 1. Calculation of mean percentages of Clara cells per patient and per morphologic airway category.

\begin{tabular}{lcccc}
\hline patient & bronchi & $\begin{array}{c}\text { Airway } \\
\text { membranous } \\
\text { bronchioles }\end{array}$ & $\begin{array}{c}\text { Category } \\
\text { terminal } \\
\text { bronchioles }\end{array}$ & $\begin{array}{c}\text { respiratory } \\
\text { bronchioles }\end{array}$ \\
\hline 1 & 0 & 0.6 & 14 & 22 \\
2 & 0 & 0 & 13 & 26 \\
3 & 0 & 0 & 14 & 19 \\
4 & 0 & 0 & 6 & 34 \\
5 & 0 & 0.3 & 11 & 21 \\
6 & 0 & 0.9 & 10 & 18 \\
7 & 0 & 0.9 & 8 & 17 \\
mean ( \pm SD) & 0 & $0.4( \pm 1,0)$ & $11( \pm 5)$ & $22( \pm 5)$ \\
\hline
\end{tabular}

\section{Results}

Lung material of seven patients was used after a rigorous selection procedure. Five patients were female, two male. Ages were between 24 and 84. The causes of death were: myocardial infarction (three patients); cerebral infarction (one); saddle embolus of the lung 
(one); sudden death with aortic stenosis (one) and sick sinus syndrome (one).

In total, 51,264 epithelial cells and $198 \mathrm{~mm}$ of basement membrane were counted in 111 airways; the number of assessed airways, the range of internal airway diameters and the total number of epithelial cells counted per airway category are presented in table 2.

\subsection{Clara cells}

A total number of 2,950 Clara cells (Figure I on p. 1/8) were counted. Table I shows the number of Clara cells expressed as the mean percentage of airway epithelial cells per patient and per morphologic airway category. Clara cells were absent in the bronchi; $0.4 \% \pm 1.0 \%$ (mean $\pm \mathrm{SD}$ ) of the epithelium of the membranous bronchioles were Clara cells. Clara cells were predominantly present in the terminal bronchioles ( $11 \% \pm$ $5 \%$ ) and in the ciliated epithelium of the respiratory bronchioles (22\% $\pm 5 \%)$. In the respiratory bronchioles a short transitional non-ciliated cuboidal epithelium was frequently observed between the bronchiolar and the alveolar epithelium, consistently lacking CC 10 immunoreactivity.

The number of Clara cells using the airway classification based solely on internal diameter were as follows: airway diameter groups I and II, 0\%; airway diameter group III $(0.5-2$ $\mathrm{mm}), 5 \% \pm 3 \%$, and group $\mathrm{V}(<0.5 \mathrm{~mm}) 18 \% \pm 7 \%$

Table 2. Number of assessed airways, range of internal airway diameters, total number of epithelial cells per $1 \mathrm{~mm}$ of basement membrane (bm); Clara, goblet and MIB-I positive cells expressed as percentage of epithelial cells per morphologic airway category.

\begin{tabular}{|c|c|c|c|c|c|}
\hline & bronchi & $\begin{array}{l}\text { Airway } \\
\text { membr. } \\
\text { bronchioles }\end{array}$ & $\begin{array}{c}\text { Category } \\
\text { terminal } \\
\text { bronchioles }\end{array}$ & $\begin{array}{l}\text { respiratory } \\
\text { bronchioles }\end{array}$ & $\begin{array}{l}\text { total / } \\
\text { mean }\end{array}$ \\
\hline $\begin{array}{l}\text { Number of assessed } \\
\text { airways }\end{array}$ & 45 & 24 & 21 & 21 & 111 \\
\hline $\begin{array}{l}\text { Range of internal } \\
\text { airway diameters } \\
\text { Number of assessed }\end{array}$ & $2-17$ & $0.5-1.8$ & $0.4-0.9$ & $0.2-0.4$ & \\
\hline $\begin{array}{l}\text { epithelial cells } \\
\text { Mean number of }\end{array}$ & 23,018 & 10.102 & 9,388 & 8,756 & 51,264 \\
\hline $\begin{array}{l}\text { epith. cells / mm bm } \\
\text { Clara cells } \\
\text { Goblet cells } \\
\text { MIB I positiwe cells }\end{array}$ & $\begin{array}{c}349 \pm 34 \\
0 \\
11 \pm 6 \\
0.91 \pm 0.73\end{array}$ & $\begin{array}{c}284 \pm 27 \\
0.4 \pm 1.0 \\
10 \pm 5 \\
0.61 \pm 0.91\end{array}$ & $\begin{array}{c}214 \pm 20 \\
11 \pm 5 \\
2 \pm 3 \\
100 \pm 074\end{array}$ & $\begin{array}{c}184 \pm 5 \\
22 \pm 5 \\
0 \\
081+065\end{array}$ & $258 \pm 16$ \\
\hline mean $+5 D$ & $0.71 \pm 0.83$ & $0.61 \pm 0.91$ & $1.00 \pm 0.74$ & $0.81 \pm 0.65$ & $0.83 \pm 0.77$ \\
\hline
\end{tabular}

\subsection{Goblet cells}

A total number of 3,519 goblet cells (Figure I on p. 118) were counted. Table 2 shows the mean percentage of goblet cells per morphologic airway category. The number of goblet cells in the bronchi and the membranous bronchioles were $11 \% \pm 6 \%$ and $10 \%$ 
$\pm 5 \%$, respectively. Goblet cells were infrequently present in the terminal bronchioles $(2 \% \pm 3 \%)$ and absent in the respiratory bronchioles. Using the airway classification based on internal diameter, the number of goblet cells were: group I ( $4 \mathrm{~mm}), 10 \% \pm 6 \%$; group $2(2-4 \mathrm{~mm}), 13 \% \pm 5 \%$; group $3,10 \% \pm 4 \%$ and group $4,1 \% \pm 2 \%$. Coexpression of $\mathrm{CClO}$ was found in 1,014 goblet cells (Figure 1). Relative to the total number of goblet cells, the proportion of CCIO positive goblet cells in the bronchi was $25 \%$, in the membranous bronchioles $34 \%$ and in the terminal bronchioles $45 \%$ using the morphologic airway classilication system. Three different patterns of $\mathrm{CCl} 0$ immunoreactivity were seen (Figure 1): coarse CCID positive granules throughout the PAS positive mucous vacuoles; dense immunostaining on the apical part of the cytoplasm; finely granulated immunostaining of the non-PAS-positive cytoplasm surrounding the goblet cell nucleus.

\subsection{Indeterminate cells}

In total, 130 indeterminate cells were counted in the non-respiratory conducting airways, accounting for $3 \%$ of the total $\mathrm{CCl} 10$ immunoreactive cell population. Indeterminate cells were present in the bronchi ( 72 cells), membranous bronchioles ( 42 cells) and terminal bronchioles ( 16 cells). This pattern resembles the distribution of goblet cells and not Clara cells, suggesting that indeterminate cells are part of the goblet cell population which has extruded its mucins.

\subsection{Proliferation compartment}

The proliferation compartment was defined by the immunoreactivity of the Ki-67 antigen by the MIB-I antibody in airway cell nuclei. 427 airway cells were MIB-I positive. overall proliferation compartment expressed as the percentage MIB-I positive epithelial cells per airway category is shown in table 2.4 of 3,519 goblet cells were MIB-I positive, representing approximately $0.1 \%$ of the proliferation compartment. 38 of 2,950 Clara cells (proliferative fraction: $1.3 \%$ ) were $\mathrm{M} / \mathrm{B}-1$ immunoreactive; the contribution of Clara cells to the overall proliferation compartment was $9 \%$. The contribution of Clara cells to the proliferation compartment is higher in the respiratory bronchioles (44\%) than in the terminal bronchioles ( $(15 \%)$ due to the increase in the total number of Clara cells.

\section{Discussion}

The purpose of the present study was to determine in normal human conducting airway epithelium the distribution of Clara cells and the contribution of these cells to the proliferation compartment. The number of Clara cells in the terminal and respiratory bronchioles was $11 \%$ and $22 \%$, respectively. Clara cells were virtually absent in the proximal airways. The contribution of Clara cells to the proliferation compartment was $15 \%$ in the terminal 
bronchioles, and $44 \%$ of the ciliated epithelium of the respiratory bronchioles.

The presence in the human distal conducting airways of a non-ciliated non-mucous cell with characteristic secretory granules, now commonly known as the Clara cell, has been confirmed by numerous morphological studies following the original description by Max Clara ${ }^{73.77,79}$. The development of antibodies against human CC10 32.171 , a protein localized in the Clara cells granules ${ }^{150}$, and a similar protein $(P I)^{222}$ enabled researchers to employ immunohistochemical ${ }^{1,171,174}$ and $m$ RNA in situ hybridization ${ }^{172,173}$ techniques in human lungs for the detection of Clara cells. These qualitative studies not only reproduced earlier observations that the epithelium of terminal and respiratory bronchioles contains many Clara cells, but also indicated the presence of variable numbers of CCIO/PI immunoreactive cells in the proximal ainways. A proportion of these CC 10 immunoreactive bronchial cells were demonstrated to be goblet cells ${ }^{81}$. 17, a secretory cell commonly found in non-respiratory airways. For the determination of Clara cell numbers throughout the human bronchial tree, we decided to use CCIO immunohistochemistry simultaneously with the periodic acid-Schiff (PAS) stain as an additional marker for goblet cells. Our findings are that the location of Clara cells, defined by morphology and CCIO immunoreactivity lacking PAS positivity is virtually restricted to the distal conducting airways. Using an airway classification system based on airway morphology, the number of Clara cells in the terminal and respiratory bronchioles is $11 \%$ and $22 \%$, respectively, in the membranous bronchioles only $0.4 \%$ of epithelial cells are Clara cells. Clara cells are absent in the bronchi. In contrast, goblet cells were predominantly present in the bronchi (11\%) and membranous bronchioles (10\%), but occasionally found in the terminal bronchioles (2\%). No goblet cells were detected in the respiratory bronchioles. In addition to an morphologic airway classification system (i.e., airway categories), we calculated the number of the individual cell types using an airway division system based on internal diameter (i.e., airway diameter group). As the range of airway diameters per morphologic airway category shows overlap (Table 2), considerable differences in the number of Clara and goblet cells exists between these two airway classification systems. The classification system based solely on intemal diameter obscures the observation that goblet cells are absent in the respiratory bronchioles, and that Clara cells are virtually restricted to the terminal and respiratory bronchioles. Thus, an airway division system based on morphology reflects the organization of the human conducting airways more closely than classification by internal diameter.

In a recent study, Shijubo and colleagues ${ }^{92}$ established the proportion of Clara cells in the peripheral conducting airways of hung cancer patients using a different antibody raised against CC 10. They reported a somewhat higher number of Clara cells (i.e., 27\%) after the examination of a total of 30 bronchioles in the lungs of 10 nonwsmoking subjects: in addition, a significant decrease in the proportion of bronchiolar Clara cells was noted in smoking in contrast to non-smoking patients. A possible explanation for the disparity in Clara cell percentages reported by Shijubo and the present study is the difference in sensitivity of the antibodies directed against CCIO for the detection of human Clara cells. In addition, the selection of the patient group differs, as Shijubo used lung carcinoma resection specimens while the present study is based on lungs without any primary or secondary 
lung disease.

A considerable number of goblet cells, defined by a flask shaped cytoplasm filled with large PAS-positive mucous vacuoles, showed one of three patterns of CC 10 immunoreactivity (Figure 1). The proportion of CC10 positive goblet cells increased with diminishing airway size, reaching $45 \%$ of goblet cells located in the terminal bronchioles. The frequent occurrence of CClO immunoreactive goblet cells puts forward the question whether an intermediate secretory cell exists with characteristics of both goblet cells and Clara cells. Some evidence indicates that the existence of such cells is not unlikely. Uitrastructural examination of rhesus monkey lungs has revealed considerable morphological heterogeneity of goblet cell secretory granules. Plopper and colleagues ${ }^{148,314}$ reported electrondense structures in or adjacent to electron-lucent mucous granules of goblet cells in the terminal and respiratory bronchioles. Secretory cells with this intriguing morphology have also been reported in tobacco-smoke exposed rats and in a human lung resected for carcinoma "43. In man, the existence of an intermediate secretory cell remains speculative awaiting results of detailed studies using ultrastructural CCIO-immunolocalization or alternative research strategies.

in the present study a small number epithellial cells were identified in the non-respiratory conducting airways exhibiting CCIO immunoreactivity and indistinct PAS positivity without the typical morphological features of either goblet cells or Clara cells. A possible explanaton is that indeterminate cells are likely to represent CC 10 immunoreactive goblet cells having discharged virtually all mucin. Whether this immunostaining phenomenon is due to cross reactivity or to the presence of the CCIO protein in goblet cells remains unclear. The distribution of indeterminate cells was found to be similar to goblet cells but not Clara cells.

Plopper concluded that Clara cells are principally located at the centriacinair region in those nonlumman species that have an extensive number of respiratory bronchioles $119,120$. The present study confirms the restriction of human Clara cells to this region which is the junction between the distal conducting airways and the alveoli. In his classic paper, Max Clara described a short transitional epithelial zone in the human respiratory bronchiole between the ciliated conducting airway epithelium and the flat alveolar lining ${ }^{73}$. In our hands, CCIO immunostaining revealed abundant numbers of Clara cells in the respiratory bronchiolar cilliated epithelium (located frequently but not exclusively adjacent to a pulmonary arteriole 119.129 , but no immunoreactivity was found in the nonciliated cuboidal cells of the transitional zone. As these cuboidal cells have been shown to be ultrastructurally and immunohistochemically related to type 2 pneumocytes ${ }^{79}$, negative CCIO immunostaining supports the distinction in cell type in the centriacinair zone in the human lung.

Proliferation in the conducting airway epithelium has been studied predominantly in rodents $46,90,93$. Important differences exist in both the tracheobronchial cell composition and the organization of the centriacinair region between these laboratory animals and man 119. 120. Rodents lack respiratory bronchioles, and nonciliated cuboidal Clara-like cells are found in high numbers in the upper airways. Therefore the results of experimental work performed in hamsters and rats, demonstrating a pivotal role of Clara-like cells in the 
conducting airway epithelium both in health and disease ${ }^{86.90,93}$, should not be extrapolated unwittingly to man. Even species with an extensive branching of respiratory bronchicles are far from an ideal model for the human lung. Castleman and colleagues performed a study of epithelial cell injury and renewal in rhesus monkeys exposed to ozone focused on the respiratory bronchioles of this primate ${ }^{96}$. Type 2 pneumocytes and nonciliated bronchiolar cells (i.e., Clara-like cells) were reported to be the stem cells in cell renewal. The organization and numerical density of epithelial cell populations of the centriacinair region of nonhuman primates is not identical to that of man, in contrast to the speculation of Plopper and colleagues ". The composition of the ciliated epithelium of the rhesus respiratory bronchiole corresponds to its upper airways, with 15\% goblet cells. A large transitional zone situated between the ciliated and the alveolar epithelium is lined almost exclusively by Clara-like cells, ultrastructurally identical to human Clara cells ${ }^{148.314}$. In man the ciliated columnar epithelium of the respiratory bronchiole is situated not only adjacent to a pulmonary arteriole but also between the alveolar sacs. The columnar epithelium is composed of ciliated cells and Clara cells; goblet cells are absent. The cuboidal cells of the transitional zone, located between the columnar epithelium and alveolar lining, represent presumably type 2 pneumocyte-like cells. Thus, important differences are present in airway organization, epithelial cell composition and even Clara cell ulitrastructure between man and all animals examined hitherto. Though animals models do contribute to our understanding of the airway epithelium in health and disease, for better appreciation of the human airways we have to turn to the human lung itself.

The present study shows that 15\% of proliferating airway epithelial cells in human terminal bronchioles were Clara cells, and in the respiratory bronchioles $44 \%$. This finding indicates that Clara celis (where present) contribute substantially to cell renewal in normal conducting airway epithelium of man, and is consistent with results from experimental pathologic studies performed in animal lungs both in the steady state and following induced injury $87,93,95,96$. Supplementary evidence pointing towards a credible role of the Clara (like) cell as a major bronchiolar progenitor cell with limited self-renewal capacity can be inferred from rabbit bronchiolar cell culture experiments 200 . While no information is is railable of the proliferative response to injury, we do know that the number of Clara cells is reduced in smokers $75,76,82$. Furthermone, Clara cell secretory proteins CC 10 and PI detected in serum and bronchialveolar lavage fluids are decreased in patients suffering from bacterial pneumonia ${ }^{312}$, smokers ${ }^{82}$, COPD and lung cancer ${ }^{24 \%}$. As the Clara cell is implicated in the carcinogenesis of adenocarcinoma 124 , examination of the proliferation of this metabolically active bronchiolar cell in human disease may be of help in the determination
of the pathogenesis and biology of lung cancer. The present study provides the number
and proliferation of Clara cells in the normal human and proliferation of Clara cells in the normal human conducting airways, and can be useful
for this research avenue.

In summary, the Clara cell population as detected by the Clara cell $10 \mathrm{kd}$ protein antibody $(\mathrm{CC} 10)$ is virtually restricted to the distal conducting airway epithelium in normal human $22 \%$, respectively. CCIO immunoreactive cells of the proximal airways were found to be 
goblet cells; the proportion of CCIO positive goblet cells relative to total goblet cell number increased towards the penipheral airways. The contribution of Clara cells to the proliferation compartment of normal human conducting epithelium was $15 \%$ in the terminal bronchioles and $44 \%$ in the respiratory bronchioles "indicating a substantial role of the Clara cell in the maintenance of the epithelium of the distal conducting airways in man.

\section{Acknowledgments}

The authors thank Dr. Gurmukh Singh, University of Pittsburgh and the VA Medical Center, for kindly providing the anti-Clara Cell $10 \mathrm{kd}$ protein antibody; the Department of pathology of De Wever Hospital, Heerlen, the Netherlands for supplying part of the lung material. 



\section{Six}

\section{An example of abnormal proliferation in human tracheobronchial epithelium: squamous metaplasia}

Published as

P53 in squamous metaplasia: a marker for risk of respiratory tract carcinoma james E Boers, Guul PM ten Velde and Frederik B/M Thunnissen The American Journal of Respiratory and Critical Care Medicine 1996: Volume 153; pages 411-416 


\section{Introduction}

Squamous metaplasia of the bronchial epithelium is known to be induced by mechanical injury ${ }^{315}$ and chemical substances ${ }^{316}$, and frequently by cigarette smoke $19,317,318$, which contains irritants and carcinogenic substances. The number of squarnous metaplastic lesions, as well as the grade of dysplasia, increases with the number of cigarettes smoked 317,319 . Squamous metaplasia of the bronchial epithelium occurs as a multifocal field change, and may be used to estimate the current "irritant burden" of a particular bronchial tree. Such metaplasia, with progressive grade of dysplasia, is thought to be a preneoplastic condition ${ }^{176,318}$. Textbooks define metaplasia as a reversible change in cell type ${ }^{320}$, and the reversible nature of squarnous metaplastic lesions, even with high grade dysplasia, has been suggested ${ }^{176,321}$.

In studies of squamous metaplastic lesions adjacent to lung carcinoma in resection specimens, concomitant mutations of p53 and other genetic abnormalities have been noted in areas of metaplasia and carcinoma ${ }^{294,322-324}$. Moreover, a positive correlation was found betweens mutations in $p 53$ and the grade of dysplasia ${ }^{322}$. Consequently, the occurrence of irreversible changes is well established in some squamous metaplastic lesions. Recently, Bernett and colleagues ${ }^{325}$ suggested that the $p 53$ gene may be an attractive marker for the early diagnosis of lung cancer.

High proliferative activity in invariably found in squamous metaplastic epithelium ${ }^{116,176 .}$ 294, 326. This hyperproliferative state is regarded as an early event in carcinogenesis in the lung, in analogy to the model of colon carcinogenesis proposed by Vogeistein and associa${ }^{\text {tes }}{ }^{327}$. Prolliferative activity has been found to increase in progressive grades of dysplasia ${ }^{116 .}$ 326

The protein $\mathrm{Bd}-2$, an inhibitor of programmed cell death, or apoptosis, is found in basal cells of normal bronchial epithelium, and has been demonstrated in $25 \%$ of non-small-cell iung carcinomas ${ }^{329}$. No immunohistochemical study has yet been reported of $\mathrm{BCl}-2$ on squamous metaplastic epithelium.

The purpose of this retrospective study was to investigate the grade of dysplasia, immunoreactivity of $\mathrm{p} 53$ and $\mathrm{Bcl}-2$, and proliferative activity in squamous metaplastic lesions obtained by bronchial biopsy, and to determine whether these parameters could identify patients at risk for cancer of the respiratory tract.

\section{Methods}

\subsection{Patients}

Using the PALGA (Dutch national pathology-coding computer network) system, bronchial 
biopsies were retrieved for 102 patients coded as having squamous metaplasia between 1982 and 1993 in the Academic Hospital of Maastricht, and were graded for dysplasia by one of us. (F.B.J.M.T.) with the World Health Organization (WHO) histological typing system ${ }^{329}$. Usually, several biopsies were present on the slides. Follow-up was obtained through the PALGA and patient files.

A malignancy of the respiratory tract was defined as a carcinoma of the lung or larynx proved by histologic or cytologic examination. A synchronous malignancy was defined as a carcinoma diagnosed within a year of the biopsy demonstrating squamous metaplasia, whereas a metachronous malignancy was defined as occurring at least I year afterward. The neutral buffered, 4\% formaldehyde-fixed, paraffin-embedded bronchial biopsies retrieved for the study contained sufficient tissue for the analysis of p53 in 51 cases and for studies of Bcl-2 and MIB-1 in 34.

Smoking habits of each of the patients were retrieved from the files. Ex-smokers was defined as those who had quit smoking more than I month before the time of biopsy. Smokers were defined as patients who smoked at the time of biopsy or in the month preceding it.

\subsection{Immunohistochemistry}

Tissue sections of $3 \mu \mathrm{m}$ thickness were cut, placed on slides coated with gelatinechromium-alum, and dried overnight at $56^{\circ} \mathrm{C}$. The specimens were then dewaxed in xylene and dehydrated in absolute ethanol. Endogenic peroxidase was blocked with $3 \%$ $\mathrm{H}_{2} \mathrm{O}_{2}$ in absolute methanol for $15 \mathrm{~min}$ at room temperature. The slides were rehydrated in decreasing concentrations of ethanol and rinsed in distilled water. Subsequently, the slides were placed in plastic jars containing $250 \mathrm{ml}$ of $10 \mathrm{mM}$ citrate buffer in distilled water, $\mathrm{pH}=6$; placed in a conventional microwave oven and microwaved until the buffer solution boiled; and then microwaved for another 10 min. After removing the jar from the microwave oven, cooling to room temperature was achieved in $20 \mathrm{~min}$. The slides were rinsed in phosphate buffered saline (PBS) and incubated for $45 \mathrm{~min}$ at room temperature with monodonal antibodies to p53 (DO-7. DAKO [Glastrup, Denmark], recognizing both wild and mutant type protein), at a dilution of 1:500 ${ }^{330}$, MIB- I (antibody against the Ki-67 epitope, Immunotech [Marseille, France]) at a dilution of 1:25 264 or Bd-2 (done 124, DAKO) a dilution of 1:50 ${ }^{278}$. A biotin-streptavidine detection system was employed with diaminobenzidine (Sigma, St. Louis, USA) as the chromogen. The slides were washed thrice with PBS and incubated with biotinylated rabbit-anti-mouse antibody (DAKO; 1:500) for $30 \mathrm{~min}$ at room temperature. After rinsing in PBS, the slides were incubated with the peroxidase-conjugated streptavidin label (DAKO; 1:1000) for $30 \mathrm{~min}$ at room temperature, rinsed again in PBS, and incubated with diaminobenzidinefimidazol $(1: 1)$ for 5 min. Subsequently, the slides were counter stained with Mayer's hematoxylin, dehydrated, cleared in xylene, and mounted with Entellan (Merck, Darmstadt, Germany). 


\subsection{Controls}

For the p53 and $\mathrm{BCl}-2$ aritibodies, a squamous cell lung carcinoma was used as a positive control. For the purpose of establishing data of MIB-I immunoreactivity of normal human epithelium, 10 rings of bronchi were obtained by autopsy within $6 \mathrm{~h}$ of the death of patients without pulmonary diseases and/or mechanical ventilation. These were fixed in $4 \%$ buffered formalchehyde for $24 \mathrm{~h}$ and embedded in paraffin.

\subsection{Evaluation}

Immunoreactivity was evaluated in squamous metaplastic epithelium by two of us (I.E.B. and F.B.J.M.T.) on two occasions. Only unequivocally stained nuclei $(\mathrm{p} 53, \mathrm{MIB}-1)$ or cytoplasm ( $\mathrm{BCl}-2)$ were counted; an evaluation of immunoreactivity was done for the entire epithelium of each squamous metaplastic lesion. Scoring of $p 53$ immunoreactivity was done semi-quantitatively: the number of $p 53$ immunoreactive nuclei was counted and expressed as a percentage of all nudei of the entire squamous metaplastic lesion. The squamous metaplastic lesions were then divided into four groups, with nil nuclear staining, $1-5 \%, 5-50 \%,>50 \%$ nuclear staining, respectively. For $\mathrm{Bd}-2$, classification was based on the type of staining, according to the granular staining of basal cells, parabasal cells, or throughout the lesion (diffuse staining). MIIB-I immunoreactivity was quantitated using a ocular $10 \mathrm{~mm} \times 10 \mathrm{~mm}$ grid at a magnification of $\times 250$. The total amount of cell nuclei of the entire squarnous metaplastic lesion was assessed. The proliferative activity was expressed as the percentage MIB-I positive cells and number of mitoses per 1000 nuclei (mitotic index). Both the labelling percentage of MIB-I and the mitotic index were counted twice; the reproducibility was within $5 \%$ limits. The mean of the two values was used for further analysis.

\subsection{Statistics}

The significance of the associations were determined by Pearson's chi-square analysis. Values $<0.05$ were considered significant.

\section{Results}

\section{I. Patients}

The average age of the 51 patients was 67 years (range, 40 to 85 years); $86 \%$ were males. The mean follow-up was 6 years (range, I to 11 years). Carcinoma was detected in 31 of the 51 patients with squamous metaplasia. Of the patients with a malignancy, 17 patients had a squamous cell carcinoma, involving the bronchi in 14 cases and the larynx in three. 
The 14 remaining cases consisted of bronchial carcinomas of which eight were adenocarcinomas, three large-cell carcinomas, and three small-cell carcinomas by histopathologic criteria. In 27 of the 31 cases of carcinoma, the tumor was synchronous (i.e., diagnosed within I year after the biopsy containing the squamous metaplastic lesion was taken). In 15 of the 27 cases of synchronous carcinoma, both the biopsy containing the carcinoma and the biopsy containing squamous metaplasia were taken simultaneously. In four of the 31 cases of carcinoma, the malignancy was metachronous, occurring between 1 and 6 years after the biopsy; these four cases comprised three bronchial carcinomas (one squamous cell carcinoma and two adenocarcinomas) and one squamous cell carcinoma of the larynx. All four patients had current smoking at the time of the diagnoses.

\subsection{Smoking habit}

Smoking habit could be retrieved for 47 of the 51 patients. Eleven of the patients had never smoked, and eight patients had stopped smoking more than I month before the biopsy containing the squamous metaplasia was taken (i.e., from 3 months to 30 years before the biopsy). Both groups were combined into a group of 19 nonsmoking patients. The remaining 28 patients were current smokers.

Of the 19 squamous metaplastic lesions in the nonsmoking patients, $42 \%$ showed p 53 immunoreactivity; of the 28 squamous metaplastic lesions in smoking patients, $46 \%$ were $p 53$ immunoreactive $(p=0.26)$. Hence, no differences were seen in p53 immunoreactivity of the squamous metaplastic lesions in the nonsmoking and smoking patients.

The positive predictive value of current smoking status for the occurrence of a malignancy was $71 \%$, with 20 of 28 smokers having a synchronous or metachronous malignancy. In contrast, only $37 \%$ (7 of 19) of nonsmokers had a symchronous malignancy. The association between smoking status and the occurrence of a malignancy was statistically significant $(p=0.02)$

\subsection{Dysplasia}

The positive predictive value of grade I, II and III dysplasia for the occurrence of a malignancy was $52 \%, 60 \%$ and $80 \%$, respectively. The correlation between grade of dysplasia and the occurrence of a malignancy was not statistically significant $(p=0.3)$.

\section{4. $p 53$}

Twenty-two of the 51 squamous metaplastic lesions showed p53 immunoreactivity. Immunostaining for $p 53$ occurred in epithelial cells only.

Amongst Grade I dysplasias, 29\% showed p53 immunoreactivity; in contrast, $60 \%$ of Grade III dysplasias were p53 positive (table 1). The association between p53 immunoreactivity and grade of dysplasia was not statistically significant $(p=0.2)$. 
Table 1. P53 Immunoreactivity and grade of dysplasia

\begin{tabular}{lrrr}
\hline Grade of dysplasia & p53-negative & $p 53$-positive & Total \\
\hline 1 & $15(71 \%)$ & $6(29 \%)$ & 21 \\
II & $10(50 \%)$ & $10(50 \%)$ & 20 \\
ill & $4(40 \%)$ & $6(60 \%)$ & 10 \\
Total & $29(57 \%)$ & $22(43 \%)$ & 51 \\
\hline
\end{tabular}

Pearson's chi square statistic $=0.2$.

A malignancy occurred in all six patients with lesions showing $>5 \%$ p53 positive nuclei (figure 1), and in 14 of 16 (88\%) patients with lesions containing only scattered immunoreactive nuclei (figure 1). The positive predictive value of 553 for the occurrence of a malignancy was $91 \%$ (table 2).

Table 2. P53 Immunoreactivity and malignancy.

\begin{tabular}{lccc}
\hline p53 & Malignancy & No malignancy & Total \\
\hline Negative & $11(38 \%)$ & $18(62 \%)$ & 29 \\
$1-5 \%$ positive & $14(88 \%)$ & $2(12 \%)$ & 16 \\
$6-50 \%$ positive & $4(100 \%)$ & 0 & 4 \\
$>50 \%$ positive & $2(100 \%)$ & 0 & 2 \\
Total & $31(61 \%)$ & $20(39 \%)$ & 51 \\
\hline
\end{tabular}

Pearson's chi square statistic $<0.002$.

Of the two patients with 553 positivity but no malignancy, one died without a mallignan$c y$ as proved by autopsy 3 months after bronchial biopsy, and the other had interstitial fibrosis at 6 years follow-up. Both patients were current smokers. Immunoreactivity to 553 (and current smoking status) was noted in all four cases of metachronous carcinoma.

The negative predictive value of $\mathrm{p} 53$ was $62 \%$. Immunoreactivity to p53 was not detected only in metaplastic lesions, but also found in accasional single (para)basal cell of adjacent nonmetaplastic epithelium in four cases (i.e. immunoreactivity far below $1 \%$ of all nuclei of nommetaplastic epithelium). The squamous metaplastic lesions of these four cases showed p53 immunoreactivity ( $<5 \%$ immunostaining). All four patients were current smokers and had a synchronous carcinoma.

\subsection{Proliferative activity: MIB-1/ Mitotic index}

In 34 squamous metaplastic lesions, an average of 763 nuclei (range, 280 to 1000) were counted. The mean ( \pm SD) percentage of MIB- labelling was $23 \pm 14 \%$ (range, 5 to $63 \%)$. In most lesions, heterogeneous staining was observed (figure 1C). The mean mitotic index was 3.1 ( \pm 3.3 ). Both proliferative indices were significantly higher than in the control group consisting of normal bronchial epithelium obtained by autopsy (in which the MIB- I labelling percentage $0.8 \%$ and the mitotic index nil; see also chapters 2 to 5). The MIB-I labelling percentage and mitotic index was quite similar for dysplasia Grades I, II and III (figure $2: \mathrm{P}>0.5$ ). For the group of patients with and without a carcinoma, the distribution of MB-1 labelling percentage and mitotic index were almost identical $(p=0.7)$. 
a

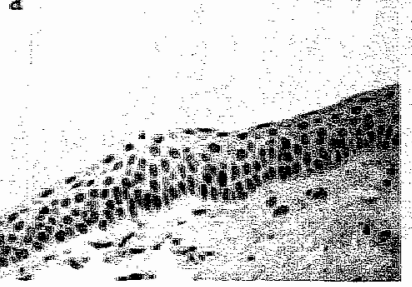

b

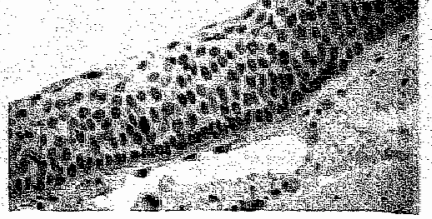

c

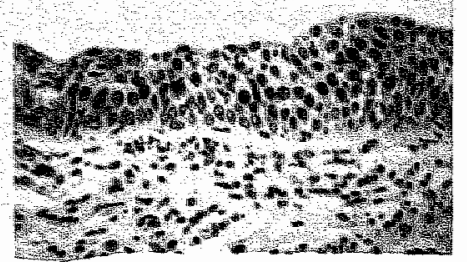

Figure 1.

A. Part of a squamous metaplastic lesion stained immunohistochemically for p53. No preexisting respiratory epithelium is present. Basal and parabasal cells show nuclear p53 immunoreactivity (dark nuclei). The p53 scone for this lesion was more than $5 \%$, but less than $50 \%$ for all nuclei.

B. Squamous metaplasia with only scattered p53 immunoreactivity of nuclei. The p53 score for the entire lesion was less than $5 \%$.

C. Immunostaining of MBB-I in a squamous metaplastic lesion (dark nucle)).

(all photomicrographs, magnification: $\times 250$ )

No significant correlation was present between the proliferative indices and $p 53$ immunoreactivity $(p=0.8)$.

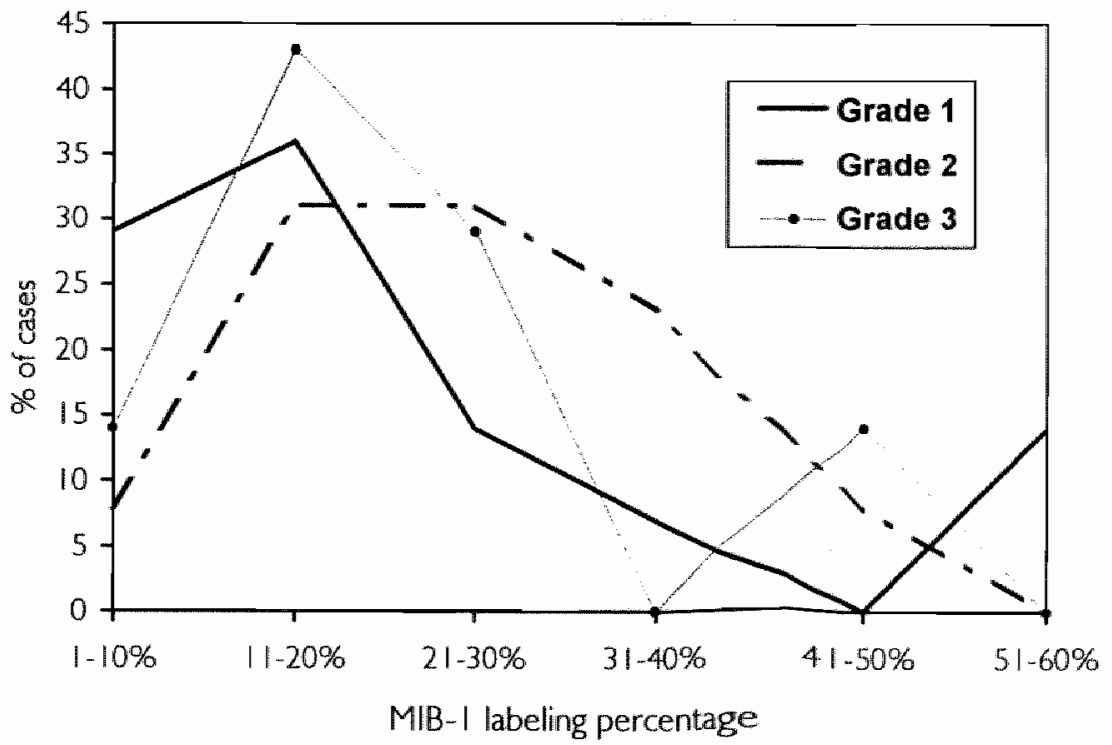

Figure 2. MIB-I immunoreactivity and grade of dysplasia. 


\section{6. $\mathrm{Bd}-2$}

In 34 cases of squamous metaplasia. Bd-2 staining was either normal (i.e., granular immunoreactivity of basal cells with occasional suprabasal staining) or absent. No lesion stained diffusely, in contrast to the non-small-cell lung carcinoma used as a positive controll. Occasionally, a nonciliated columnar cell was immunoreactive in adjacent, histologically normal appearing respiratory epithelium.

\section{Discussion}

The purpose of this study was to investigate the predictive value of histologic and immunohistochemical parameters for the occurrence of a carcinoma of the respiratory tract in patients with bronchial biopsies containing squamous metaplasia of the bronchial epithelium. Sixty-one percent of the patients had or developed a carcinoma in this retrospective study of 51 biopsies. The positive predictive value of p53 immunostaining was $91 \%$; the positive predictive value of high grade of dysplasia was $80 \%$. We found nuclear p53 immunoreactivity in $43 \%$ of the squarnous metaplastic lesions in the studly. Using lung resection specimens, Nuorva and colleagues found p53 immunoreactive lesions in 53\% ${ }^{322}$. In both studies, scattered p53 immunoreactivity was more frequent than nuclear staining of all squamous metaplastic cells.

Although wild type $p 53$ protein is present in nuclei of normal cells, it is not detectable by immunohistochemical techniques at these rather low levels in which it is present. Accumulation of the mutant type of $p 53$ protein is present after most genetic alterations of the p53 gene; this accumulation is detectable with immunohistochemistry in the majority of tumor cells ${ }^{331}$. In six cases of squamous metaplastic lesions in our study, a pattern of diffuse immunoreactivity was noted. This diffuse $\mathrm{p} 53$ immunostaining pattern has been reported in dysplastic lesions with mutations of the p53 gene ${ }^{323.324}$.

After damage to deoxyribonucleic acid (DNA) by various agents, there is a transient elevation of wild type $p 53$ protein levels ${ }^{332.334}$. If anly a few nuclei are immunoreactive for a 553 antibody which recognizes both the wild and mutant types of p53 protein, this pattern of focal immunostaining is probably due to elevation of the normal $p 53$ protein concentration $325,330,335.337$. In our studly, 16 squamous metaplastic lesions showed only scattered p53 immunoreactive nuclei "which may have reflected physiologically increased p53 protein concentration rather than high $p 53$ protein levels due to genetic changes. In four biopsies with p 53 immunoreactive squamous metaplastic lesions, occasional basal cells in adjacent normal respiratory epithelium showed p53 positivity. The patients in these four cases were current smokers with a synchronous carcinoma. This scattered p53 immunoreactivity in normal respiratory epithelium may reflect DNA damage caused by smoking.

In squamous metaplastic lesions, the average positive predictive value of $p 53$ immunore- 
activity for the occurrence of a carcinoma was high $(91 \%)$. In the group with more than $5 \%$ of positive nuclei, the positive predictive value was 100\%. In the group of patients with squamous metaplastic lesions showing only scattered immunoreactive muclei, the positive predictive vallue was $88 \%$. Sensitive immunohistochemical techniques using p 53 seems to identify those patients at risk for cancer of the respiratory tract, irrespective of whether p53 immunoreactivity is due to genetic mutation or not. This supports the emphasis of Bennett and coworkers 325 on 553 as an attractive marker for the early diagnosis of malignancy of the respiratory tract.

Smoking habits were not a confounding variable with regard to p53 immunoreactivity, since squamous metaplastic lesions of both nonsmokers and smokers had almost equivalent percentages of 533 positivity. The positive predictive value of current smoking status for the occurrence of a malignancy was $7 / \%$, representing a significant association between smoking status and malignancy.

A high grade of dysplasia also had a high positive predictive value (80\%) for malignancy. Though a positive association seems to exist between grade of dysplasia and the occurrence of a malignancy, as also does a positive correlation between grade of dysplasia and p 53 immunoreactivity, no statistically significant correlations could be established for these variables $(p=0.3$ and $p=0.2$, respectively).

Several studies have demonstrated high proliferative activity of squamous metaplastic epithelium 116, 176, 294, 326. Hyperproliferative activity of this tissue is thought to precede dysplasia, in analogy to the model of colon carcinogenesils proposed by Vogelstein and colleagues ${ }^{327}$. Moreover, in two studies of squamous metaplastic lesions in bronchial biopsies, a positive correlation was found between the degree of proliferativity using proliferative cell nudlear antigen (PCNA) and the grade of dysplasia 16.326. Of several methods used for assessing cell proliferation, the immunohistochemical detection of cellcycle-related antigens in routinely processed tissues has become very popular. PCNA was the first antibody used for this purpose, but is sensitive to heat and fixation time ${ }^{249}$, and can therefore be used only in carefully controlled conditions. MiB-I has been developed more recently ${ }^{338 .}{ }^{339}$. MIB-I is an antibody against an epitope of the well known Ki-67 antigen. and can also be applied on paraffin material after antigen retrieval. MIB-1 is thought to be a more reliable indicator of cell proliferative activity than is PCNA ${ }^{2 \%}$.

A low but definite percentage of MIB-I labelling was found $(0.8 \%)$ in normal bronchial epithelium, which is similar to an earlier report "17. MIB-\| staining was very heterogenous in squamous metaplastic lesions. As expected, hyperproliferativity was easily established in squamous metaplastic lesions. However, no correlation was found between the percentage MIB-I labelling and grade of dysplasia, in contrast to the work with PCNA of Pendleton and Hirano 116.326 , In addition, MIB- I labelling could not discriminate between the groups of patients with and without malignancy. Therefore, although hyperproliferativity may be an early step in carcinogenesis of the lung, it is not necessarily a marker for the early diagniosis of malignancy.

$\mathrm{BCl}-2$ is an inhibitor of programmed cell death, or apoptosis. The protein is present in many fetal and adult tissues ${ }^{340}$. Bcl-2 is also found in several malignancies, including $25 \%$ of 
non-small-cell lung carcinomas ${ }^{328}$, and is thought to 'immortalize' cells so that tumorous growth ensues. In normal bronchial epithelium, Bd-2 is present in basal cells. The present study showed no increase of $\mathrm{BCl}-2$ immunoreactivity in squamous metaplastic lesions. An increase in the expression of $\mathrm{BCl}-2$ may occur at a late phase in lung carcinogenesis.

In conclusion, p53 immunoreactivity in squamous metaplasia of the bronchial tree is a marker for the early diagnosis of a carcinoma in the respiratory tract. 
Seven

Epilogue 


\section{Introduction}

The distribution and contribution to the proliferation compartment of the individual tracheobronchial cell types was described consecutively in the preceding chapters. A comprehensive account of the composition and the cell type distribution of the proliferation compartment of the normal human tracheobronchial mucosa will be provided in the present chapter, followed by a discussion of squamous metaplasia with dysplasia as an example of abnormal epithelium of the lower conducting airways. Preliminary to this account, the issues of reproducibility, variance of the observations and the efficacy of the quantification procedure are dealt with as these matters are of considerable importance to the reliability of the presented results.

\section{Reproducible and efficacious quantification of the tracheobronchial mucosa}

\subsection{Reproducibility}

If a reliable method of quantification is to be obtained, reproducibility or the level of agreement between replicate measurements ${ }^{305}$ is of major concern. In the field of cell type quantification, reproducibility can be assessed by the determination of intraobserver and interobserver variation, which evaluates the levell of agreement between the repetitive measurements of one or more cell type(s) in a particular slide. An appraisal is carried out how a qualitative definition of a particular cell type is implemented by a researcher between two time points or between two researchers, and the measurements are usually repeated within a short time period. This kind of study also needs to take into account any variation which can occur when cell type quantification is performed in immunohistochemically stained tissue slides cut at different time points from a particular tissue block. In addition, the effect of time on the implementation of cell type definition needs to be evaluated.

In the present study, the quantification of MIB-I positive cells in the lower conducting airway epithelium of a set of patients was performed in four consecutive studies ${ }^{b}$, each of which was focussed on one or two particular tracheobronchial cell types. The time span between the first and the last study was three years. In addition, the proportion of goblet cells was determined in two of these four studies ${ }^{c}$ which were conducted one year apart. As a consequence, it is possible to examine the reproducibility of these quantification

\footnotetext{
a Or in the case of electron microscopical studies, a particular set of electron micrographs.

- See chapter 2 to 5 .

'See chapter' 3 and 5.
} 

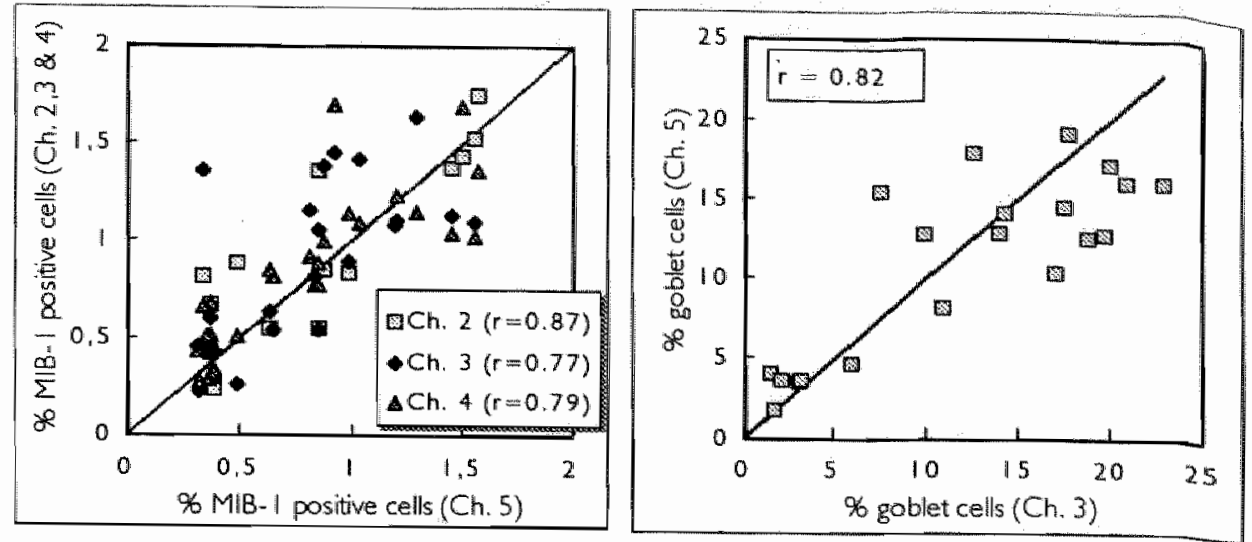

Figure |. Quantification of MIB-I positive cells and goblet cells: correlation between different observations. Left-hand panel: the percentage MIB-I positive cells assessed in chapter 5 vs. the percentages of chapters 2,3 and 4. Right-hand panel: the percentage goblet cells assessed in chapter 3 vs. chapter 5 . The percentages are the means per patient and per airway category.

procedures between different time points using different tissue slides from identical patient material. In figure I, left-hand panel, the percentage of MIB-I positive cells assessed in the study described in chapter $5^{\mathrm{a}}$ is correlated with quantifications carried out at 36 months, 12 months and 5 months before that study (described in the chapters 2, 3 and $4^{\mathrm{b}}$, respective ly). The correlation coefficients are between 0.77 and 0.82 ; the regression coefficients were 0.92 to 1.01 . A similar procedure was performed between the percentages of goblet cells as quantified in the chapters 3 and 5, with a correlation coefficient of 0.82 and a regression coefficient of 0.9 , as is shown in the right-hand panell of figure 1. Although the correlations are not perfect, these data permit the conclusion that a high degree of reproducibility was achieved.

\subsection{When is the composition of the human tracheobronchial epithelium abnormal?}

If results regarding the composition and cell type distribution of the human tracheobronchial epithelium are to be used as reference values, how do we define these results as "normal', and when will a deviant observation be classified as 'abnormal"? To this end, upper and lower confidence limits of normal need to be calculated, using the mean value and a standard deviation. In the present study, variance (and the standard deviation) was not simply calculated from the individual means of the respective cell types of the seven patients, but a statistical approach was used in which the variance between several observati-

\footnotetext{
"The mean percentages per patient and per airway diameter group were taken, calculated as described in chapter 2 to 5 .

- As the classilication of the ainway categories differ between the chapters (see section 3.1.), the percentages of the cell types were recalculated according the airway diameter groups used in chapter 4 .
} 
ons for a given aimay category within a particular patient is also taken into account ${ }^{304}$. The standard deviations calculated with this nested ANOVA approach, allowing variation of cell type proportions with and between patients, were used to compute $90 \%$ confidence intervals of the overall proliferation compartment, and of the goblet, ciliated, (para)basal and Clara cell types. When a proportion of a given cell type in a particular tracheobronchial mucosal specimen is outside the range (as defined by the $90 \%$ confidence intervals), it is reasonable to consider that observation 'abnormal'. Thus, the upper $90 \%$ confidence limits provides numbers for hyperplasia of the various cell types, and vice versa (see Appendix to chapter Seven for the data of the six cell types). This means that basal cell hyperplasia is present when the percentage of basal cells in the airways with a diameter of $2-4 \mathrm{~mm}$ is more than $41 \%$. Hyperplasia of parabasal cells occurs when the percentages of this cell type is $>12 \%$ in the airways with a diameter of $>4 \mathrm{~mm}$, and $>4 \%$ when the airway diameter is between 0.5 and $2 \mathrm{~mm}$. Any qualification of abnormal cell type distribution can only be made when the size or the location of the biopted airway is taken into account, since the number of a particular cell type (and its corresponding $90 \%$ upper confidence limit) is dependent on the airway diameter.

\subsection{Efficacious quantification}

When reproducible (immuno),histochemical staining procedures are employed in a set of tissue specimens from a characterized group of patients and results of the quantification procedure can be described using a comprehensive statistical method, the actual assessment of the composition and cell type distribution of the human tracheobronchial mucosa can start. As the tracheobronchial cell type distribution is described only fragmentarily ${ }^{\mathrm{a}}$, and the proliferative compartment is but a very small proportion of the normal lining epithelium of the lower conducting airways, how do we know the required number of epithelial cells which have to be assessed in each individual airway in order to obtain reliable results? In chapter 2 , the number of neuroendocrine cells and the proliferation compartment were quantified by determination of all the available epithelium of seven lung tissue slides of seven patients, which resulted in the assessment of 326,500 epithelial cells. As this procedure obviously is very time consuming and laborious, three statistical approaches were examined in order to obtain an efficacious quantification procedure. As the proportions of goblet cells are thought to be particularly variable ${ }^{73}$, these approaches were tested using the data of this type (for details see chapter 3).

Firstly, the possible use of progressive means of proportion was investigated. This method is based on the presumption, that the progressive mean of proportion of a series of observations eventually stabilizes around a certain mean after a number of events (i.e., the number of epithelial cells assessed). After a pilot study, the optimal number of events is chosen. This method is suited for regularly distributed cells, but the progressive means of

- See chapter". 
goblet cell proportion showed no optimal number of epithelial cells required for assessment due to uneven distribution. As a consequence, this method was not further considered.

Secondly, the relative standard error of proportion (RSE prop ) advocated by Going ${ }^{300}$. This approach is based on the calculation of the standard error (SE) divided by the proportion. As a result, $95 \%$ confidence intervals of an observed proportion of a given sample drawn from a population are dependent on the magnitude of the proportion. The problem using the RSE $\mathrm{p}_{\text {pop }}$ method was, that an extended data analysis was required in order to select an acceptable value for the RSE

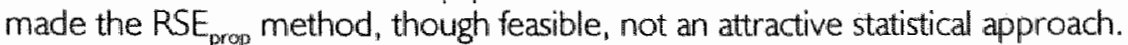

Thirdly, the standard error (SE) of proportion method was investigated ${ }^{307}$. Theoretically, a sample size of 400 epithelial cells is required. $95 \%$ confidence intervals are irrespective of the magnitude of the proportion. This relatively simple statistical approach provided good estimates of the proportion of goblet cells, ciliated cells and the proliferation compartment. Comparison between the pilot data and the results after implementing this method was successfully repeated for the assessment of (para)basal cells (see chapter 4). As a result, only one-third of the epithelial cells originally quantified were required yielling virtually identical cell type proportions. For the determination of Clara cells, this approach was used without preliminary quantification of all the epithelia suited for assessment. As a consequence, only one-sixth of the epithelial cells assessed in the first study (i.e., the neuroendocrine cells) was taken into account.

Therefore, the employment of this statistical approach which comprises the calculation of the standard error of proportion provides an effective tool resulting in an efficacious procedure, significantly reducing the effort of quantification without compromising the reliability of the results.

\section{Composition of the normal human tracheobronchial mucosa}

\subsection{The normal human tracheobronchial mucosa: a comprehensive account}

The composition of the normal mucosa lining the human tracheobronchial tree is presented in figure 2; $90 \%$ or more of the epithelial cells could be classified into six epithelial cell types, though the proportion of these cell types was assessed in four separate studies (described in Chapter 2 to 5; data presented graphically in the Appendix to chapter 7). The airways were dassified using different criteria in the individual studies, reflecting the variation in distribution of a particular cell type along the human tracheobronchial mucosa most accurately. For practical purposes, the airway classification system employed in figure 2 is the best system in which the data of all cell types could be recalculated. However, airway categorization based on a combination of airway morphology and diameter (as used in Chapter 5) is superior as this system adequately reflects the difference in composition of 


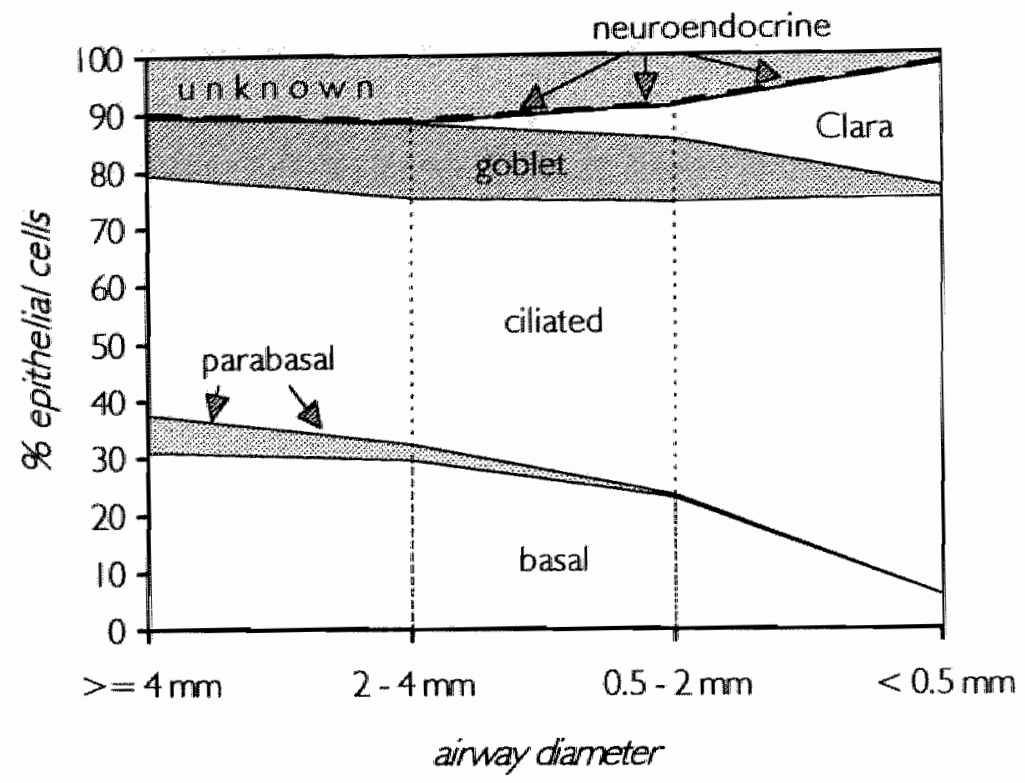

Figure 2. Composition of the normal human tracheobronchial epithelium

the respiratory, terminal and other bronchiolar mucosa. Only Clara and goblet cells were quantified taking this morphological classification system into account, but the occurrence of the other cell types in the mucosa of the terminal and respiratory bronchioles (viewed separately ${ }^{a}$ ) can be described qualitatively. Goblet and parabasal cells are not found in the mucosa of the respiratory bronchioles, and are rare in terminal bronchioles. In contrast, neuroendocrine and basal cells are part of the conducting airway epithelium up to the transitional zone (i.e., the junction between the ciliated columnar epithelium and the alveolar lining; see Chapter 1, section 2).

While the majority of the tracheobronchial epithelial cells could be classified into six epithelial cell types, approximately $10 \%$ of the epithelium lining the conducting airways with a diameter of $0.5 \mathrm{~mm}$ or more remained of indeterminate cell type. One of the explanations for this proportion of unclassifiable cell types in the larger airways is the presence of cells with a position between the basal and luminal cell rows that lack keratin 5 and 14 immunoreactivity, and are not of parabasal cell nature. Another explanation is that the quantification procedure was conducted in four separate studies in which the number of airways assessed varied slightly per patient and per airway category. In addition, up to

\footnotetext{
"As the intternal diameter of a few terminal bronchioles is 0.5 mm or less, the aimay category ' $<0.5$ mm" obscures the difference between terminal and pespiratory bronchioles to some extent.
} 
$3 \%$ of cells present in the normal tracheobronchial mucosa are nonepithelial cells, but are either lymphocytes or Langerhans cells ${ }^{30,233}$ which remain undetected with the (immuno)histochemical methods used in the present study.

\subsection{Cell typing of tracheobronchial mucosa: electron microscopy or immunohistoche- mistry?}

Some significant differences are apparent when the proportions of the respective tracheobronchial cell types presented in figure 2 are compared with previous reports. In the electron microscopical study of Mercer and colleagues ${ }^{17} 25 \%$ less ciliated cells are reported whereas $20 \%$ of the epithellial cells were of indeterminate cell type. Goblet and basal cells were not present in the bronchioles (diam. $<1 \mathrm{~mm}$ ), though the proportion of these cell types in the bronchi (diam. I - $5 \mathrm{~mm}$ ) were virtually identical with the present study. The difference in the number of cillated cells could be due to the dissimilarity in technique between the two studies.

More important is disparity between the proportion of indeterminate cells found in Mercers' report and the present study. The accuracy of cell type determination using ultrastructural characteristics of single micro-photographs would be expected to be higher than immunohistochemical quantification procedures in four consecutive studies. One of the possibilities explaining the disparity in indeterminate cell percentage is the reluctance of Mercer and colleagues to recognize the parabasal cell type (see Chapter 4). The other explication "namely that immunohistochemical cell typing is superior to morphological classification systems, is illustrated by the assessment of basal, Clara and neuroendocrine cells. The absence of basal cells in the electron micrographs of the small airways (diam. < I $\mathrm{mm}$ ) is clearly contradicted to the unequivocal demonstiation of these cells up to the transitional zone using immunohistochemical techniques (see Chapter 4). The number of Clara cells is underestimated if thin plastic tissue sections stained with toluidine blue are studied, probably due to a slightly tangential plane of section (see Chapter 5). Neuraendocrine cell quantification appears to be too cumbersome in electron microscopy, but is readily performed when antibodies are applied (see Chapter 2 ).

Considerable differences in the proportions of a particular cell type using practically identical immunohistochemical techniques can occur, when different antibodies and/or different antigen retrieval procedures are employed. The importance of consistent, elaborate, and reproducible staining protocols is demonstrated in the case of the neuroendocrine cells, in which an antigen retrieval step increased the cell type proportion tenfold (see Chapter 2) in comparison with previous studies.

3.3. The complex composition of the human tracheobronchial mucosa: can structure explain function?

The occurrence of secretory and ciliated cells in the human tracheobronchial epithelium has been noted back in the nineteenth century, and the concept of the tracheobronchial 
mucosa as a mucociliary 'escalator' has become rather stereotypical. The emergence of other cell types (viz. the Clara basal and neuroendocrine cell) has not yet been accompanied by the formulation of new concepts regarding the function of the tracheobronchial epithelium which integrates all identified epithelial differentiation varieties and organizations. Information about airway organization, epithelial cell type distribution and morphology puts forward pertinent questions about the function of the lower conducting airway epithelium. In addition, functional considerations may be inferred from the composition of the tracheobronchial mucosa; in this section, possible roles of the Clara and basal cell will be discussed on the basis of the distribution and morphology of these cell types. The role of the neuroendocrine cell will be briefly mentioned as well.

The function of the ubiquitous basal cell is largely hypothetical according to many authors 33. 71, 123, which might be the reason that the basal cell is almost completely ignored in major publications of lung cell biology ${ }^{2}, 3.41$. Yet, this circumvention is very strange, given the presence of basal cells as responsible for the classification of the tracheobronchial mucosa as a pseudostratified epithelium. Basal cells are not unique to the conducting airway mucosa, but are found im many complex epithelia including stratified squamous, transitional and mixed (glandular) epithelia ${ }^{175,191}$. Not only the presence in complex epithelia but also the unique properties (e.g., hemidesmosome attachments to the basement membrane, expression of keratins 5 and 14) of the basal cell suggest an adhesive role. In addition, the number of basal cells of the tracheobronchial epithelium is not related to the quantity but to the thickmess of the overlying columnar epithelium. Although most authors are reluctant to abandon the old idea of the basal cell as an undifferentiated 'reserve' cell, this cell type could be regarded as a highly differentiated and essential component of the tracheobronchial mucosa.

Mucous-producing goblet cells, with a more or less constant proportion up to the terminal bronchioles, give way to the Clara cells in the distal conducting airway mucosa in man. An explanation of the restriction of the Clara cell to a rather small part of the tracheobronchial tree in humans (and a few other species) could be that mucus would obstruct the small airways ${ }^{\mathrm{a}}$ so that another secretory fluid with different rheological and functional properties is more appropriate at this location in the conducting airways. That airway diameter might affect secretory cell composition could also be inferred from comparative zoology of the tracheobronchial epithelium, which reveals some interesting facts $11,120,145$. Secretory cell composition in the tracheal mucosa of larger species is rather similar to man (i.e., goblet but no Clara-like cells), but this is not the case in smaller animals, where Claralike cells predominate throughout the tracheobronchial tree'. In the terminal bronchioles however, the predominant secretory cell type is the Clara-like cell in virtually all species hitherto examinedc. The observed relationship between airway diameter and Clara cell

\footnotetext{
"Obstruction of small airways by mucous plugs is invariably pathological.

though cat tracheas contain goblet cells, and Gara-like cells occur in rabbit tracheas.

With the noteworthy exception of the ciliated epithelium overlying the pumonary arteries in thesus monkey terminal bronchioles, which contains goblet cells and not Clarawike cells.
} 
distribution may be rather heuristic, but it may serve as an example of attempts to infer functional roles of tracheobronchial cell types from known airway structure.

In the present study, the number of neuroendocrine cells were found to be twelve times more than previously reported. The combination of a relatively high proportion of neuroendocrine cells and the presence of dendritic cell processes implicate a paracrine function (already suggested by Feyrter in $1938^{53}$ ) of this cell type.

\section{Proliferation of tracheobronchial epithelial cells in man}

4.1. The proliferation compartment of normal human tracheobronchial mucosa: a comprehensive account

The overall proliferation compartment of the normal epithelium lining the lower human conducting airways, as defined by nuclear immunoreactivity of the MiB-I antibody ${ }^{203}$, is $0.78 \%$ to $0.93 \%$, with an upper $90 \%$ confidence limit of less than $2.5 \%$ (see Appendix, figure 7). The proportion of the proliferation compartment detected in the present study is quite comparable with the few other reports using different immunohistochemical techniques in bronchial biopsies or lung resection specimens $116,117,265$. We propose to define an increase in tracheobronchial proliferation as abnormal when the proliferative compartment. (i.e., the proportion MIB-I immunopositive cells) is $2.5 \%$ or more.

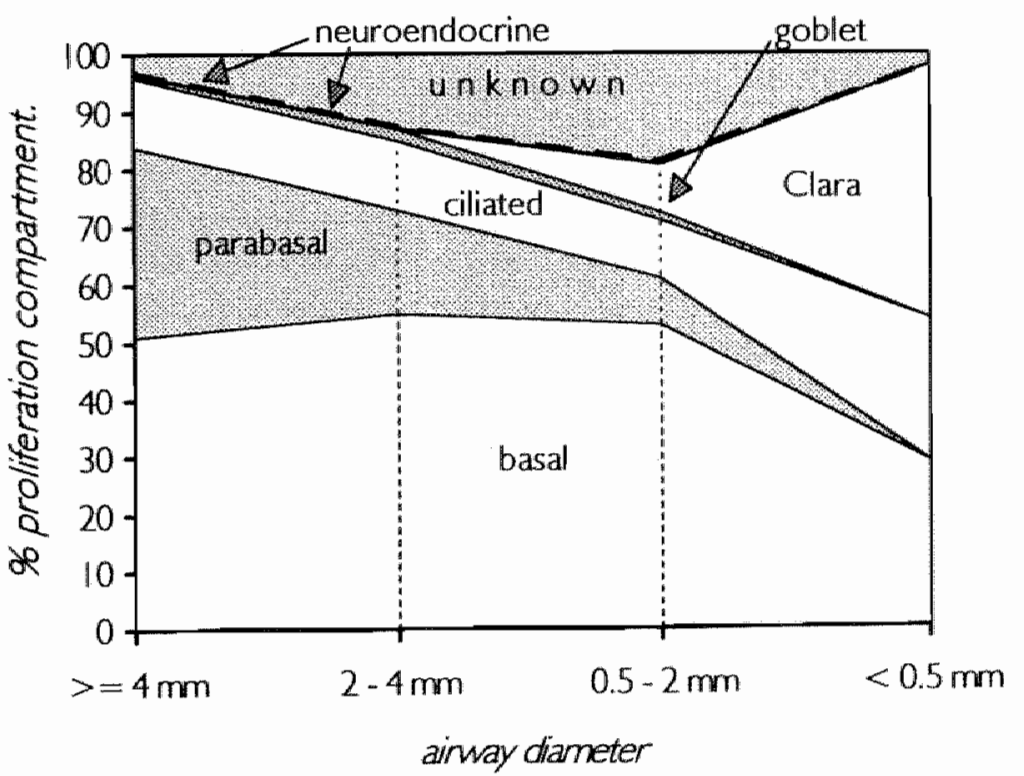

Figure 3. Proliferative cell type distribution of the normal human tracheobronchial epithelium. 
The epithelial cell type distribution of the proliferation compartment in normal human tracheobronchial mucosa is presented in figure 3. Between $81 \%$ and $98 \%$ of the proliferative cells could be classified into one of the 6 major epithelial cell types. Basal and parabasal cells are the predominant proliferative epithelial cells of the ainways with a diameter of 0.5 $\mathrm{mm}$ and more, and in the smallest airways, Clara cells and basal cells are the major cell types contributing to the proliferation compartment. Ciliated cells make up a fairly substantial part of the proliferative compartment throughout the tracheobronchial lining epithelium, while the contribution of goblet cells is very limited. Despite very modest epithelial cell proportions, proliferative neuroendocrine cells were found at all airway levels. Possible explanations for the fact that not all MIB-I positive cell in the tracheobronchial mucosa could be classified are the presence of non-epithelial cells, the slight variation in reproducibility of quantification (see section 2.1.), and a small difference in the number of assessed airways per patient and per airway category between the four separate studies.

The fraction of each of the six individual cell type populations that contribute to the proliferation compartment is shown in figure 4. The proliferation fraction of goblet and ciliated cells is minimal $(0.13 \%$ and $0.25 \%$, respectively). One to two percent of basal, Clara and neuroendocrine cells belong to the proliferation compartment. The fraction of parabasal cells contributing to the proliferative compartment of normal human tracheobronchial mucosa $(5.25 \%)$ is the greatest of all major epithelial cell types.

Figure 4. The fraction of each of the six indiviciual cell types that contributes to the proliferation compartment. (n.e. = neuroendocrine cells)

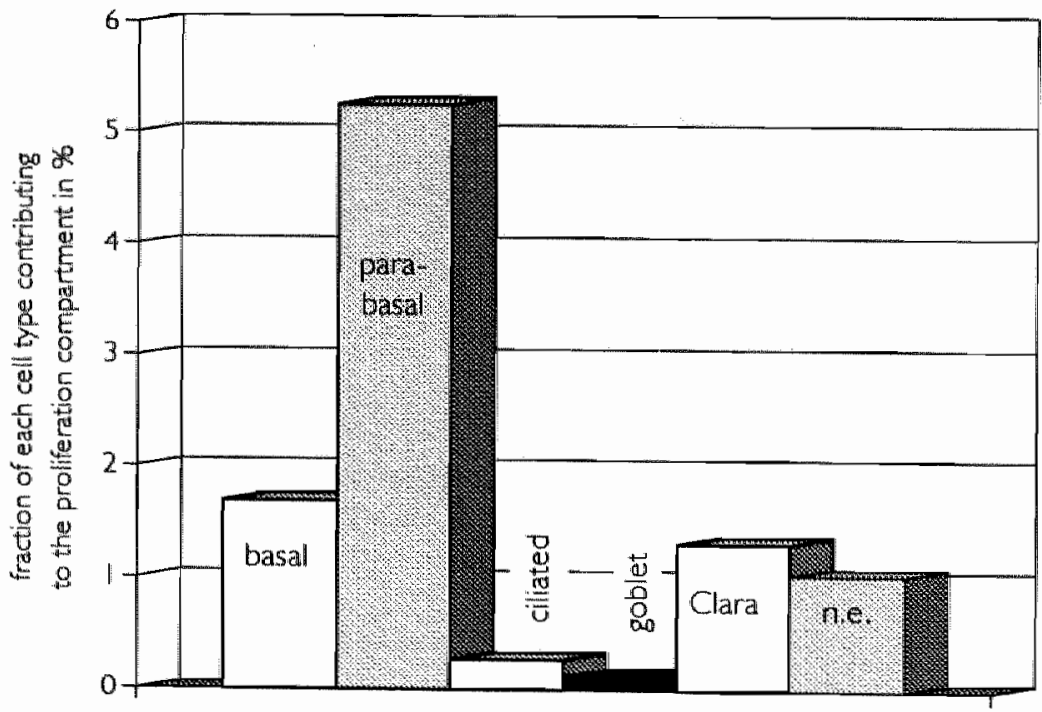




\subsection{Proliferation in the lower conducting airway epithelium: two separate stem cell compartments?}

The basal cell has long been considered to be the sole progenitor cell of the pseudostratified tracheobronchial epithelium. This concept was based on the interpretation of the results of a few cell-kinetic studies performed on young rats ${ }^{35,92,108,248}$, but proved to be untenable. The contribution of luminal cells to cell renewal, later identified to be of the serous or Clara-like cell type, was unequivocal in the lower conducting airway epithelium of rodents in the steady state ${ }^{92-94}$. These secretory cells were even shown to be the major cell types responsible for the proliferative response in experimental pathologic studies, in which tracheobronchial epithelium of non-human species was examined after mechanical or chemical injury ${ }^{88,95,96,98}$. As a consequence, it has become quite customary to completely discard the role of the basal cell in the maintenance of the tracheobronchial epithelium

${ }^{23 .}{ }^{86}$. Reports of the poor colony forming potential of tracheal basal cell suspensions ${ }^{25}$ and studies describing the late appearance of basal cells in fetal lung development ${ }^{31,120}$ were in support of the concept, that secretory cells are the only progenitor cells in the lower conducting airway epithelium.

A position in between the two mutually exclusive concepts has been taken by investigators regarding both cell types (i.e., basal and secretory) as the tracheobronchial progenitor cells ${ }^{200}$. They have stated quite rightfully that an overwhelming part of the human tracheobronchial tree is devoid of Clara cells ${ }^{a}$, and that it is questionable whether human Clara cells are in fact similar to the rodent secretory cells $s^{b}$ examined in experimental studies. In addition, inoculation studies of rodent tracheobronchial cell suspensions indicate a limited differentiation potential of Clara cells ${ }^{227}$ in contrast to the ability of basal cells to repopulate denuded tracheas with a complete mucociliary epithelium ${ }^{195,196,198}$. These observations have resulted in the formulation of the two compartment theory, which states that the major progenitor cell of the bronchial lining epithelium is the basal cell, and Clara(-like) cells represent the origin of the bronchiolar mucosa ${ }^{2000}$.

At a first glance, our findings seem to support the two compartment theory. Yet three observations appear to be at variance with the theory that basal and Clara cells are the progenitor cells of the large and small conducting airway mucosa, respectively. Firstly, the proliferation compartment comprises $10 \%$ to $25 \%$ ciliated cells. Secondly, basal cells are present in and significantly contribute to the proliferation compartment of the mucosa of the smallest airways (diam. $<0.5 \mathrm{~mm}$ ). Thirdly, a cell type defined as the parabasal cells accounts for a considerable part of the proliferation compartment of the larger airways. The parabasal cell exhibits the largest proliferative proportion of all the cell types examined (see figure 4). The first observation induces the question whether the ciliated cell, traditio-

- See figure 2, and section 3.1.

- These secretory cells are referred to as 'Clara-like' cells in this study (see Chapter 1 , section 3.2.5).

"See chapter 1, section 3.2.6., and chapter 4, section 2.3. 
nally regarded as a nondividing terminally differentiated cell ype, might act as a progenitor cell in the human tracheobronchial epithelium. In the present study, the relatively high proportion of ciliated cells in the proliferation compartment (figure 3) was a result of the tremendous size of this cell type population (see figure 2). The fraction of proliferative ciliated cells was small (figure 4), which darifies the common notion that ciliated cells do not divide. A possible explanation for the occurrence of proliferating cilliated cells was put forward by Breuer and colleagues in a report of an experimental pathologic study using an animal model ${ }^{93}$. They hypothesized that some ciliated cells had undergone ciliogenesis but had not yet completely lost their proliferative abilities. The second observation inevitably leads to a correction of the assumption, that the bronchiolar mucosa lacks basal cells, and Clara cells are the only progenitor cells at this airway level. Each of the two cell types appear to play a role in cell renewal of human bronchiolar epithelium. The third observation induces speculations about cell differentiation, since parabasal cells share a major characteristic with basal cells, namely the expression of keratins 5 and 14. It is conceivable that the basal cell might be the progenitor cell of the parabasal cell. Pulse-chase experiments should be performed in the human tracheobronchial epithelium to support this view. In animal models in which cell lineage ${ }^{92,104}$ is examined, it has been suggested that cells with a position in the mucosa intermediate between basal and luminal cells are part of the differentiation pathway of the basal cell. In these reports, ciliated and secretory cell development was thought to be preceded by basal cell division followed by an intermediate cell division. If these 'intermediate cells' in rodents are the counterparts of the human parabasal cells described in the present study, the role of the basal cell in the renewal of normal human tracheobronchial mucosa could be explained in terms in common with the two compartment theory.

Now that it is established that the proliferative state of the (para)basal and Clara cells exceeds that of the other major proliferative cell types, may we presume these cells actually represent the stem cells of the normal human tracheobronchial mucosa? in models which attempt to delineate the cell-kinetics and cell lineage of tissues, high proliferative activity is not typical of cells assumed to be stem cells". Pluripotent stem cells are thought to be relatively slowly cycling cells which produce faster cycling cells exhibiting a more limited self-renewal capacity ${ }^{246}$. This highly proliferative cell compartment, known as the transitamplifying compartment, shows progressive differentiation. Thus, the observation af a particular cell type being exceedingly proliferative is no proof of 'stemness', but, as far as models regarding cell lineage are concerned, it is more likely to indicate that these cells are part of a differentiating or transit-amplifying cell compartment. Our hypothesis is that parabasal cells, with their intermediate position in the tracheobronchial mucosa together with shared characteristics with basal cells and a relatively high proliferative state, are likely to represent a transit-amplifying cell compartment. Basal and Clara cells, the presumed stem cells, may in fact be part of this epithelial compartment too as these cells are differen-

"See chapter , section 4.1 . 
tiated, and represent high proportions of the proliferative compartment. Some authors suggest that absence of recognizable cell differentiation is a conditio sine qua non of "stemness" 246. 252. If this definition of a stem cell is adhered to, there must be a population of more primitive stem cells in the tracheobronchial mucosa which has not been examined in the present study. However, we do not support this assumption. From a practical standpoint, it might be prudent not to exclude the existence of undfferentiated, omnipotent stem cells in the lower conducting airway epithelium completely ${ }^{252}$, but to assume that the basal and Clara cells are at present the most likely candidates for the stem cells of the human tracheobronchial mucosa. An altemative hypothesis might be, that basal cells are the sole stem cells of the lower conducting airway mucosia, and that parabasal and Clara cells represent the transit-amplifying compantment. An argument for this hypothesis is that: the combined proportion of the proliferation fraction of parabasal and Clara cells is more or less constant irrespective of airway site (figure 3). The identification of stern cells in human tissues is not a purely academic issue as these cells of great longevity are thought to be the target cells for carcinogenesis ${ }^{246}$.

\subsection{An example of proliferation in abnormal tracheobronchial mucosa: squamous metaplasia with dysplasia}

Preliminary to the comprehensive examination of the normal tracheobronchial epithelium in autopsy lung samples, a study was performed in bronchial bilopsy specimens containing squamous metaplastic lesions with dysplasia, in order to get acquainted with a new antigen retrieval technique required for $\mathrm{MBB}$ - I immunostaining. We expected a high percentage of MIB-I immuoreactive cells, as squamous metaplasia (with or without dyspiasia) is to exhibit marked typerproliferation $116,176,2944$. In our study, the prolifieration compartment of squamous metaplastic lesions of 51 patients was $23 \% \pm 14 \%$ (mean \pm SD) w with a range of $5 \%$ to $63 \%$. Thus, not a single metaplastic lesion was normal in terms of proliferation compared with the upper $90 \%$ confidence limit of $2.5 \%$ (see section 4.1 ). Interestingly; proliferation in squamous metaplasia with mild dysplasia predominantly occurs in the basal cells, extending to the suprabasal cell layers in moderate and severe dysplasias ${ }^{116,294}$. If we assume that the basal cell is likely to be the stem cell of the upper tracheobronchial mucosa, it is conceivable that hyperproliferation of these cells indicates a dysfunction of cell cycle regulation of the stem cells. In addition, the extension of proliferative activity to increasingly higher suprabasal cell layers when the grade of dysplasia increases might indicate a progressive disorder of the transitumplifying compartment accompanied by a decline of differentiation.

The hypothesis that squamous metaplasia with dysplasia is a process which begins with a deregulation of basal cells, is supported by studies performed with immunohistochemistry of 553 , a tumor suppressor protein. Wild-type 53 protein is a transcription factor that

\footnotetext{
*.e., the pretreatment of tissue slides in boiling organic buffer, heated by a microwawe-oven. This antigen retrieval method had pronounced effects on the detection of meuroendocrime cells too (see chapter 2).
} 
plays an important role in guarding the integrity of the genome. In normal circumstances, wild-type 553 can not be demonstrated by immunohistochemical techniques, but DNA damage stabilizes the $p 53$ protein and also enhances the expression of wild-type $p 53$ to levels than can be detected. High levels of $p 53$ lead to cell-cycle arrest in the GI-phase or S-phase, and induce apoptosis if the DNA damage is not reparable ${ }^{332.342-345}$. Mutations of the $p 53$ gene belong to the most common genetic alterations in cancer ${ }^{331}$, and have also been detected in squamous metaplastic lesions with dysplasia ${ }^{325}$ in the tracheobronchial mucosa. Most anti-p53 antibodies can not distinguish between wild-type and mutant p53 proteins, but $p 53$ immunoreactivity of an individual cell does indicate DNA damage ${ }^{a}$. In squamous metaplasia with mild dysplasia, 553 positive cells are usually located in the basal part of the epithelium ${ }^{294,322,325}$. As the grade of dysplasia increases, p53 immunoreactivity becomes prominent in suprabasal cells ${ }^{325}$. Thus, the pattern of $p 53$ immunostaining closely resembles that of markers which detect the hyperproliferative state of squamous metaplastic lesions with dysplasia. This could indicate that damage to the basal cells is the major event that may lead to progressive grades of dysplasia and, ultimately, carcinoma.

\section{Concluding remarks}

The introduction of the immunohistochemical techniques which elucidate the composition and distribution of the different epithelial cell types as well as of the proliferation compartment of the human tracheobronchial mucosa in the field of pulmonary disease may lead to: (1) more precise description of pathology of the lower conducting airway mucosa in various pulmonary disorders such as asthma, COPD and lung carcinoma, (2) hypothesises on the pathogenesis of lung disease. In addition, new techniques involving combinations of cell type specific markers with other nudear markers than proliferation-associated antibodies can be developed, so that the occurrence of oncogenes, DNA transcription factors and apoptosis may be studied in particular cell types of the lower conducting airway epithelium in man.

\footnotetext{
"In chapter 6,p53 immunor eactivity in squamous metaplasia with dysplasia in bronchia biopsies is shown to have a high positive predictive walue for the occurrence of a carcinoma of the respiratory tract. which may be a result of a thigh degree of chronic irrtation to the laryngeotracheobronchial tree.
} 


\section{Appendix to Chapter Seven}

Cell type composition and the overall proliferation compartment of the normal human tracheobronchial epithelium. Mean values and $90 \%$ confidence intervals. 


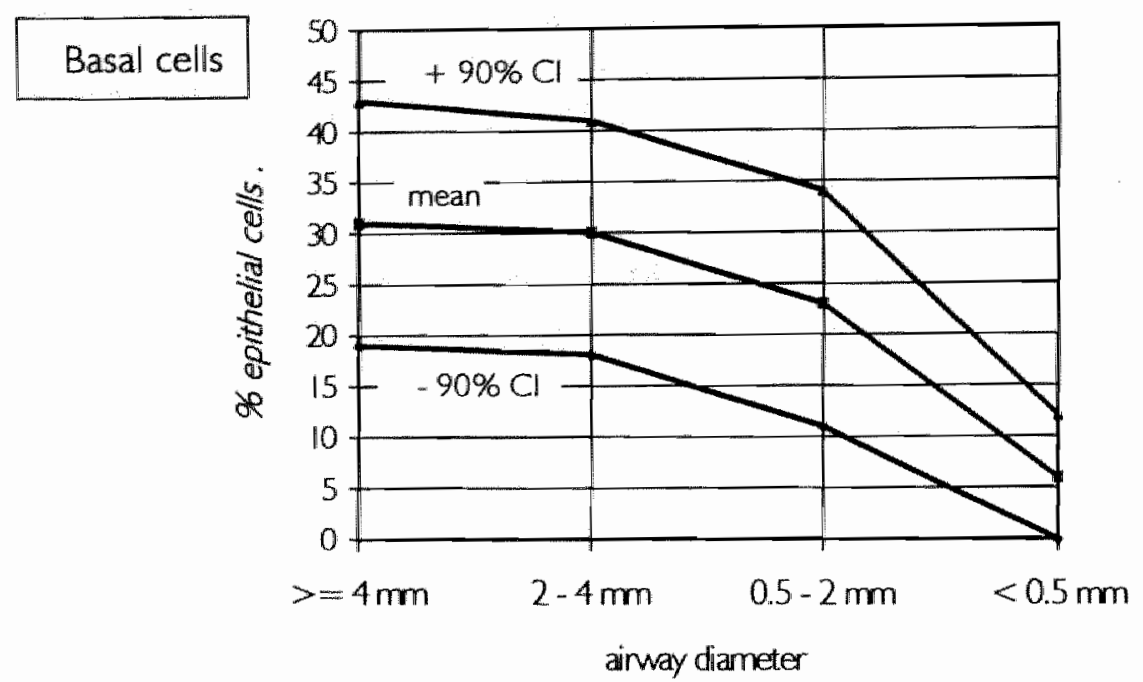

Figure 1. Basal cells (mean $\pm 90 \%$ confidence intervals [C.I.]) per airway diameter category. SD is calculated with the nested ANOVA procedure (see Ch. 4).

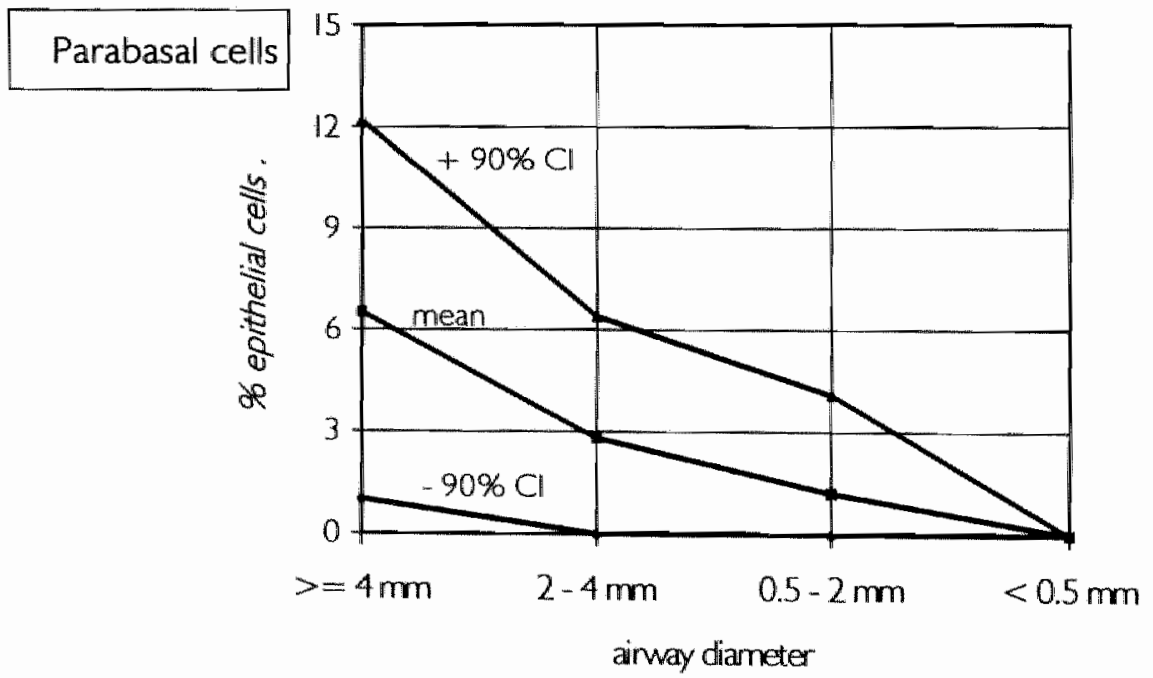

Figure 2. Parabasal cells (mean $\pm 90 \%$ confidence intervals) per airway diameter category. SD is calculated with nested ANOVA procedure (see Ch. 4). 


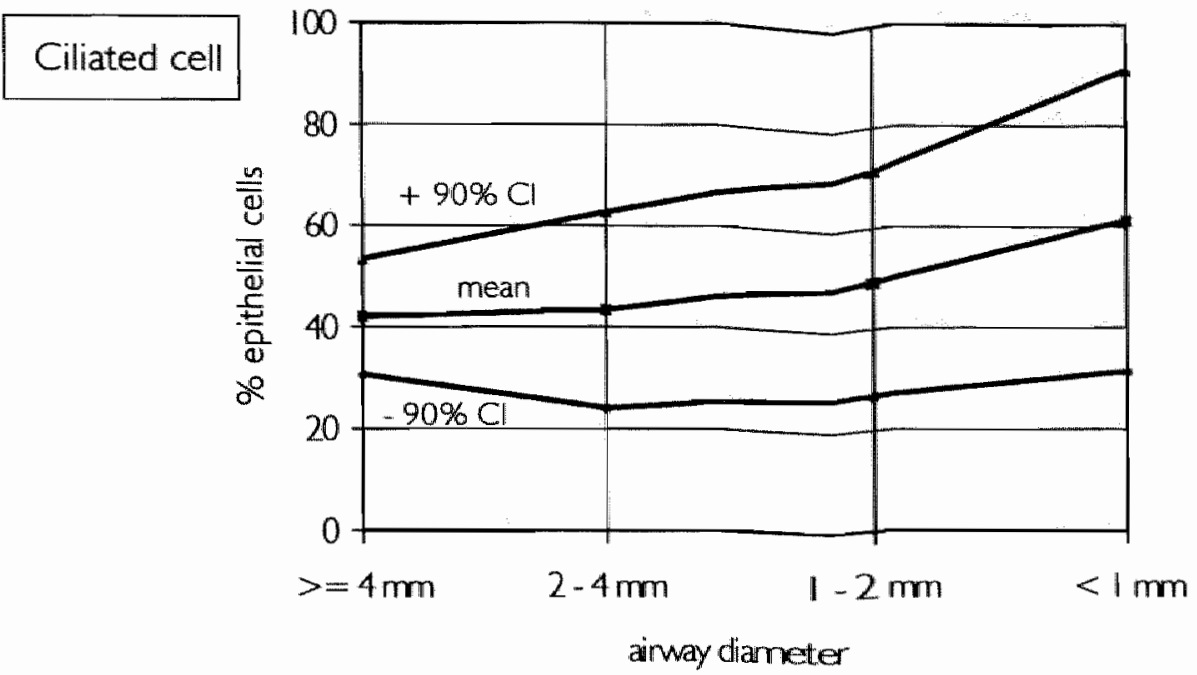

Figure 3. Ciliated cells (mean $\pm 90 \%$ confidence intervals [CI]) per airway diameter category. SD is calculated with the ANOVA procedure (see Ch. 3)

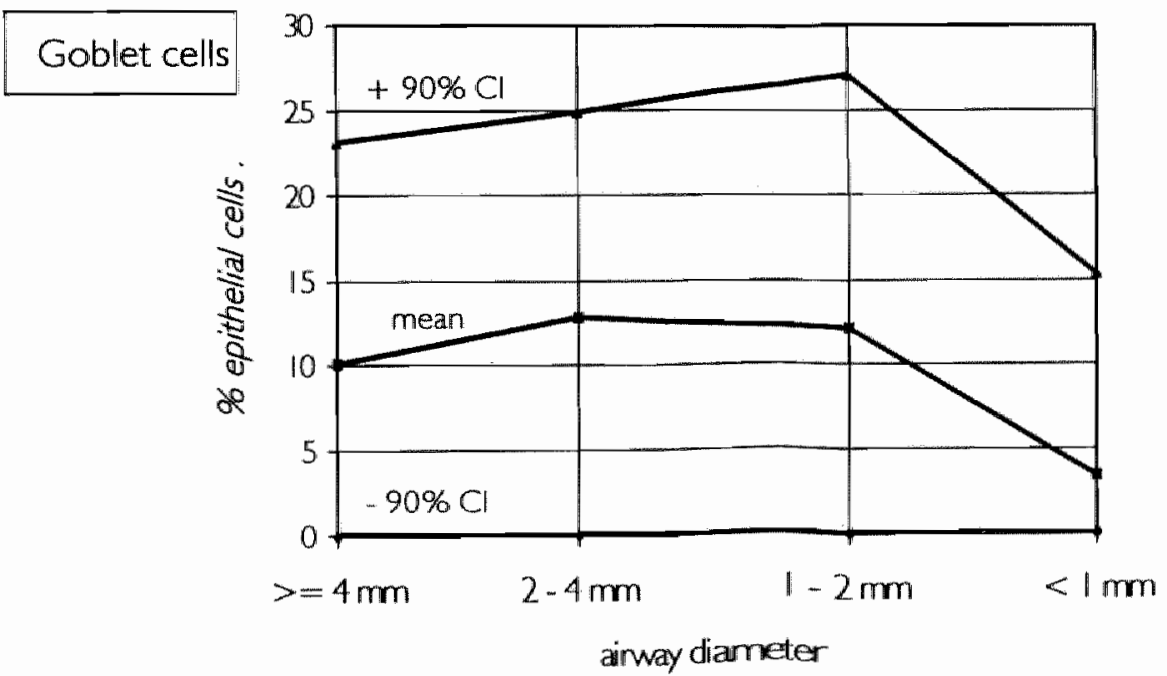

Figure 4. Goblet cells (mean $\pm 90 \%$ confidence intervals [CI]) per airway diameter category. SD is calculated with nested ANOVA procedure (see Ch. 3) 


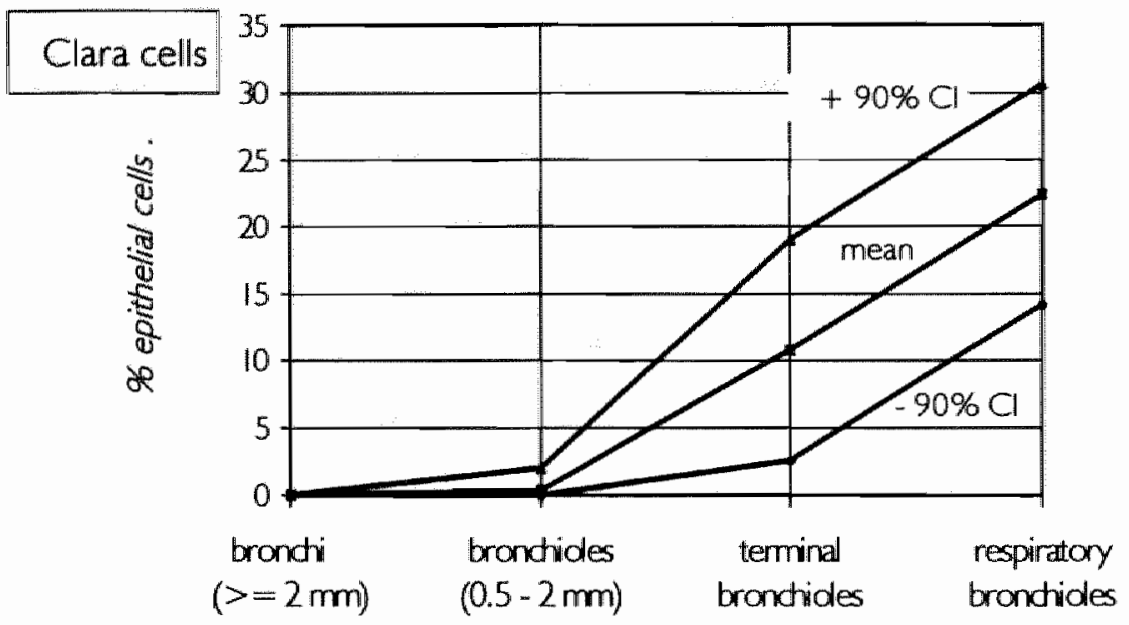

Figure 5. Clara cells (mean $\pm 90 \%$ confidence intervals [Cl]) per morphological airway category. SD is calculated using a nested ANOVA procedure (see Ch. 5)

Neuro-
endocrine
cells

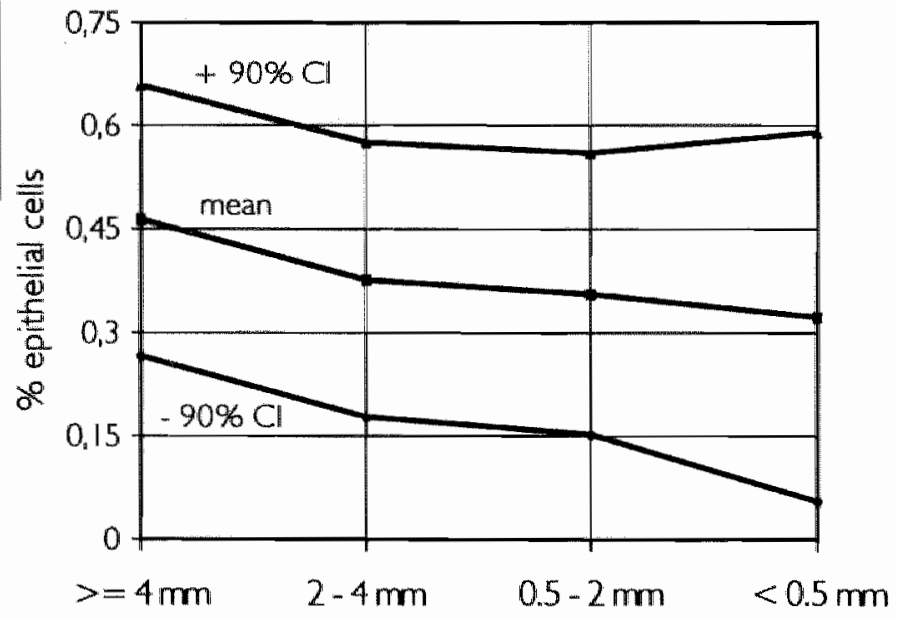

aimay diameter

Figure 6. Neuroendocrine cells (mean $\pm 90 \%$ confidence intervals [Cl] per airway diameter category, recalculated from chapter 2. SD was calculated from patient mean percentages without the nested ANOVA procedure. Neuroepithelial bodies were virtually absent. 


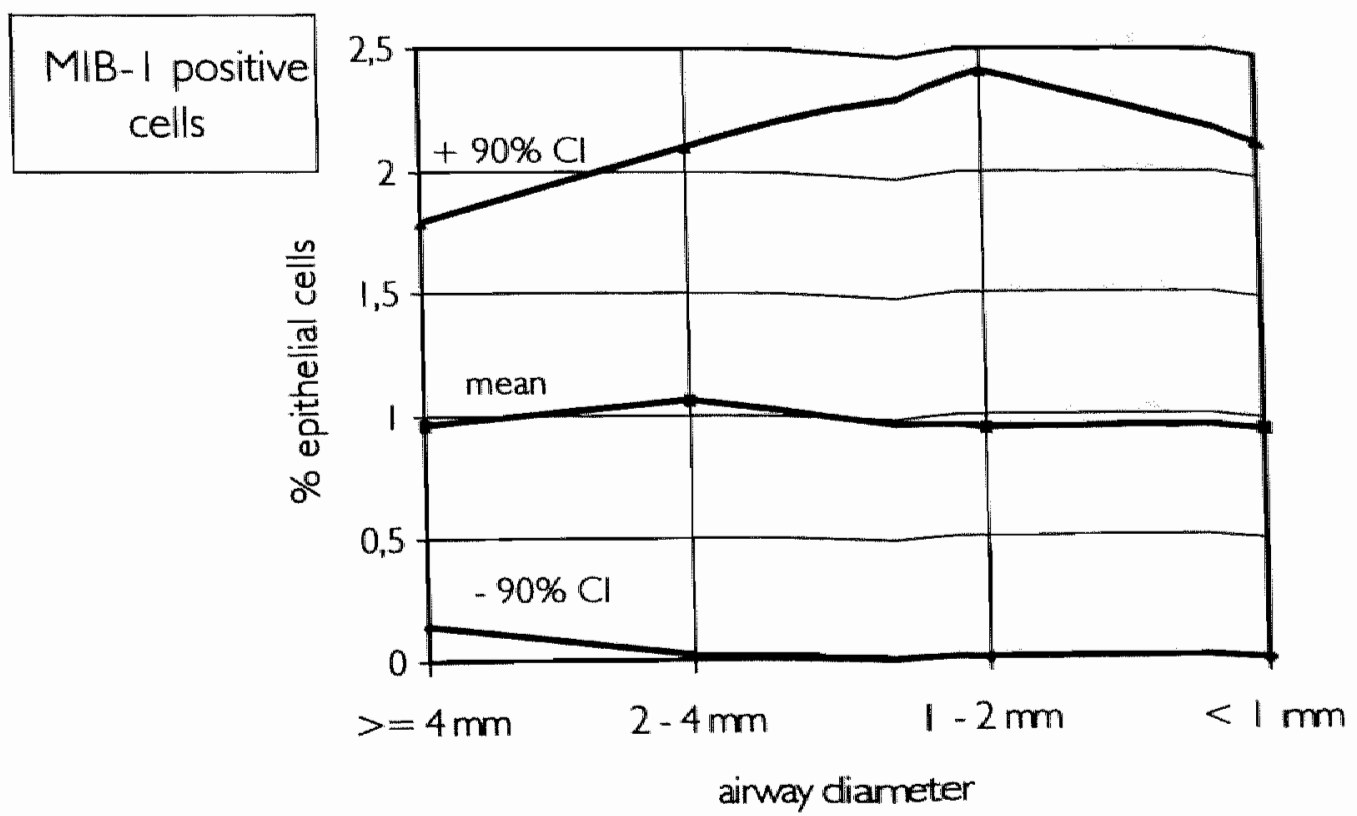

Figure 7. MIB-I positive cells (mean $\pm 90 \%$ confidence intervals $[\mathrm{Cl}]$ ) per airway diameter category, calculated from the data of Chapter 3. 



\section{Eight}

Summary / Samenvatting 


\section{Summary}

Diseases of the lower conducting airways, the air passages between larynx and the alveolar space, are extremely common due to the fact that the mucosal surface is exposed to a considerable number of airborne pathogens. Prerequisites for an adequate description of airway pathology are a comprehensive knowledge of normal histology. A definition of the normal human tracheobronchial mucosa comprising all epithelial cell types at all airway levels has not yet been given. Although many qualitative and quantitative studies of the lower conducting airway epithelium exist, comparison of hitherto acquired quantitative data of cell type distribution with studies of other institutions is virtually impossible due to wide disparity in study design of prior reports.

Morphological alterations of the tracheobronchial mucosa are caused by an aberrant cell cycle regulation of epithelial cell types. Information about the proliferative cell type distribution of the normal conducting airway epithelium may reveal which cell types are involved in the maintenance of the human tracheobronchial mucosa, and may indicate which cell types are probable target cells of injurious stimuli in the pathogenesis of human airway disease. To date, no data is available of the cell type distribution of the proliferation compartment of the lower conducting airway epithelium in man.

The aim of the study was to establish the composition and cell type distribution of the normal human tracheobronchial mucosa using relatively simple immunohistochemical techniques. In addition, squamous metaplastic lesions were examined as an example of proliferation in abnormal tracheobronchial epithelium. Statistical issues, dealing with large scale quantification procedures, are also addressed to.

Chapter One comprises a general introduction to the field of study, and includes a table of all quantitative studies conducted in the human tracheobronchial mucosa.

Chapter Two deals with the neuroendocrine cell type of the human tracheobronchial epithelium. A sequential immunohistochemical staining procedure using MIB-I as a marker for the proliferation compartment and Chromogranin $A$ for the identification for neuroendocrine cells is described. A large scale quantification procedure is carried out involving 326,000 epithelial cells in lungs obtained by autopsy of 9 patients. The percentage neuroendocrine cells (approx. 0.4\%) is twelve times more than previously reported, probably due to a new antigen retrieval technique. Many dendritic neuroendocrine cell processes are seen between non-neuroendocrine epithelial cells adjacent to the basement membrane. The proliferation fraction of neuroendocrine cells is equal to the overall proliferation fraction.

In Chapter Three, the distribution and proliferation of ciliated and goblet cells is established using a sequential immunohistochemical / histochemical staining protocol (MIB-I as a proliferation marker, and a PAS stain as a marker for goblet cells). The group of patients 
selected is even more restricted than in the previous study (chapter two) by application of a histopathological score system of the lung tissue. The feasibility of two statistical approaches (i.e., standard error of proportion and the relative standard error) is evaluated in order to establish a efficacious quantification procedure. Both statistical approaches reduce work effort of cell quantification by two-thirds. Only a very small fraction of goblet and ciliated cells contribute to the proliferation compartment. The share of the ciliated cell in the proliferation compartment is considerable (i.e., one-tenth to one-fourth) due to the enormous size of the cillated cell population.

Chapter Four describes a sequential immunohistochemical staining procedure in order to quantify basal and parabasal cells, the proliferation compartment, and the contribution of (para)basal cells to the proliferation compartment. An antibody directed against keratins 5 and 14 is used as a marker for (para)basal cells. The group of selected patients is identical to the group described chapter three. Evaluation of one statistical approach (the standard error of proportion method) is carried out; quantification using this approach reduced the work load by two-thirds. The number of (para)basal cells per mm of basement membrane is strongly correlated to the thickness of the airway epithelium. Half of the overall proliferation compartment is made up by basal cells. In the smallest conducting airways, onesixteenth of epithelial cells are basal cells representing one-third of the proliferation compartment. Parabasal cells are only present in the airways with a diameter of $0.5 \mathrm{~mm}$ and more, and constituted one-sixth of the overall proliferation compartment. The high fraction of (para)basal cells that contribute to the proliferation compartment supports the theory that cells at or near the basement membrane are likely to be progenitor cells of the normal human tracheobronchial epithelium.

In Chapter Five, the percentage and proliferation of Clara cells is quantified using a triple sequential immunohistochemical / histochemical staining protocol. The $\mathrm{CClO}$-antibody is used as a marker for Clara cells. The group of selected patients was identical to the stuclies described in chapter three and four. Quantification was performed using the standard error of proportion method without prior evaluation. The Clara cell population was virtually restricted to the distal conducting airway epithelium in normal human lungs. In the terminal bronchioles, one-ninth of epithelial cells were Clara cells, and the contribution of Clara cells to the proliferation compartment was one-seventh. In the respiratory bronchioles, Clara cells represented one-fifth of the mucosal epithelium and almost half of the proliferation compartment. Thus, the contribution of Clara cells to the proliferation compartment of normal human tracheobronchial epithelium is substantial, indicating a probable role of the Clara cell in the maintenance of the mucosa of the distal conducting airways in man.

In Chapter Six "squamous metaplasia with dysplasia is examined as an example of abnormal human tracheobronchial epithelium. Immunohistochemical staining is carried out on bronchial biopsy material of 51 patients (with or without a carcinoma of the upper and lower conducting airways). MIB-I is used as a proliferation marker, $\mathrm{p} 53$ and $\mathrm{BCl}-2$ as 
(possibie) markers of cellular injury. All squamous metaplastic lesions invariably show an increase in epithelial proliferation. P53 immunoreactivity is present in almost half of the biopsies, and is found to be a marker for risk of a carcinoma elsewhere in the respiratory tract (occurring at the time of biopsy and/or several years later) regardless of p53 staining intensity. No increase in $\mathrm{BCl}-2$ immunostaining is noted.

In Chapter Seven, the issues of reproducibility, definition of normal values and the evaluation of efficacious quantification procedures are discussed. A comprehensive account is given of the composition and cell type distribution of the proliferation compartment of the normal hurnan tracheobronchial epithelium, integrating the data of the chapters two to five. Possible functions of basal cells and Clara cells are inferred from the distribution of these cell types. In addition, the significance of the ciliated, basal and Clara cell in the maintenance of the normal tracheobronchial mucosa is discussed. Finally, the hypothesis that squamous metaplasia starts with basal cell injury is re-evaluated.

In the Appendix to Chapter Seven, mean percentages with $90 \%$ confidence intervals are presented for each of the epithelial cell types and the overall proliferation compartment. 


\section{Samenvatting}

\section{Opbouw en proliferatie van normaal epitheel van de lagere menselijke luchtwegen}

Aandoeningen van de lagere luchtwegen (d.w.z. de luchtpijp(en) tussen strottenhoofd en longblaasjes) komen veel voor. Dit is mede een gevolg van de blootstelling van het luchtwegoppervlak (dat bekleed wordt door een laag epitheelcellen) aan vele ziekteverwekkers die in de lucht voorkomen. De hierdoor veroorzaakte structurele afwijkingen van de luchtwegen zijn pas goed te beschrijven indien er een grondige kennis van het normale luchtwegepitheel vergaard is.

Kwalitatieve en kwantitatieve karakterisering van dit epitheel is geen simpele zaak omdat het luchtwegepitheel vit tenminste zes verschillende soorten epitheliale cellen is opgebouwd, en wat de opbouw betreft er bovendien verschillen zijn tussen de grote en kleine luchtwegen. Het probleem is echter dat wij gedetailleerde kennis omtrent de opbouw van het menselijk luchtwegepitheel ontberen. De tot nu toe verrichte onderzoeken zijn namelijk zodanig verschillend in opzet dat vergelijking van de beschreven aantallen celtypen ernstig wordt bemoeilijkt. Er is een grote verscheidenheid in de technieken waarmee de cellen worden aangetoond en geteld, en ook zijn er verschillen in de eenheden waarin de aantallen van de diverse celtypen zijn uitgedrukt. Daarnaast is het aantonen van de verscheidene celtypen dermate lastig, dat de meeste onderzoeken zich tot éen of slechts enkele celsoorten beperkt hebben. Tenslotte is het zo, dat dierexperimenteel onderzoek slechts zijdelings toepasbaar is op de mens, nu gebleken is dat de luchtwegorganisatie en opbouw tussen diersoorten onderhevig zijn aan grote verschillen.

Een structurele afwijking van het luchtwegepitheel is in wezen een gevolg van een voorafgaande (en ook nog voortdurende) abnormale celdelingsactiviteit van éen of meerdere celtypen. Kennis van de normale celdelingsactiviteit (d.w.z. de proliferatie) van het normale menselijke luchtwegepitheel ontbreekt nagenoeg geheel. Als gevolg hiervan kunnen speculaties, afkomstig van nauwelijks toepasbaar dierexperimenteel onderzoek, omtrent de identiteit van de celtypen die verantwoordelijk zijn voor de instandhouding van het normale luchtwegepitheel niet worden geëvalueerd. Wat normale en abnormale proliferatie is in het menselijk luchtwegepitheel is dus niet aan te geven. Over de identiteit van de celsoorten die mogelijkerwijs het doelwit zijn wan ziekteverwekkers valt ook geen uitspraak te doen.

Het doel van het onderzoek, waanvan dit proefschrift een beschrijving geeft, was dan ook: de opbouw van het normale epitheel van de lagere menselijke luchtwegen bepalen, en de bijarage van elk celtype aan het proliferatieve compartiment ( $d, w, z$. dat deel van het epitheel dat celdelingsactiviteit vertoont) vaststellen. Het materiaal betrof longen die afkom- 
stig waren van overleden patiënten, en die een bewerking ondergingen die standaard is in de dagelijkse praktijk van een Nederlandse afdeling pathologie. De methode om de celsoorten aan te tonen ging uit van een relatief eenvoudige immunohistochemische en histochemische 'kleurings'- techniek. Ook de statistische methoden die werden toegepast $o p$ de verkregen uitkomsten waren op zich niet ongebruikelijk. Selectie en combinatie van materialen en methoden zijn echter niet eerder toegepast. Tenslotte werd nog onderzoek verricht naar de proliferatie in squameuze metaplasie, een abnormale verandering van het luchtwegepitheel, die aangetroffen werd in biopsie-materiaal van 5 . patiënten.

Hoofdstuk Een bevat een algemene inlleiding in het onderzoeksthema, en zet de doelen van het onderhavig onderzoek uiteen.

Hoofdstuk Twee gaat in op de neuro-endocriene cel in het normale menselijke luchtwegepitheel. Een sequentiële immunohistochemische 'kleuring' wordt beschreven, waarbiij als proliferatie-marker is geselecteerd een antilichaam gericht tegen het proliferatie-geassocieerde antigeen Ki-67 (antilichaam MIB-1); als marker voor neuro-endocriene cellen is genomen een antilichaam gericht tegen Chromogranine A. Een grootschalige kwantificering is uitgevoerd waarbij 326.000 epitheelcellen in longweefsel van 9 patiënten zijn bekeken door de microscoop. De omvang van het proliferatieve compartiment was. $0,76 \%$ van alle epitheliale cellen. Het gevonden percentage neuro-endocriene cellen (ca. 0,4\%) is twaalf maal hoger dan eerder werd beschreven, vermoedelijk als gevolg van een nieuwe weefselvoorbehandeling waarbij gebruikt wordt gemaakt van de magnetron. Het percentage prolifererende neuro-endocriene cellen is vrijwel gelijk aan het percentage epitheelcellen dat celdelingsactiviteit vertoont.

Hoofdstuk Drie behandelt de gecilieerde cel en de slijmbekercel. Beschreven wordt een sequentielle kleuring, waarbij na de proliferatie marker MIB-I gebruikt wordt gemaakt van een histochemische PAS-kleuring voor het aantonen van sljmbekercellen. Als gevolg van PAS-kleuring zijn gecilieerde cellen eveneens goed identificeerbaar. Ditmaal werd gebruikt gemaakt van longweefsel van 7 patiënten. In vergelijking met het vorige hoofdstuk werden de selectiecriteria nog verder aangescherpt doordat het longmateriaal tevens werd gescreend m.b.v. een scoresysteem, waarbij eventuele afwijkingen in het longweefsel ieder afzonderlijk werden bekeken. Het geselecteerde longweefsel werd ook gebruikt voor het onderzoek zoals beschreven in de hoofdstukken vier en viff. $\mathrm{Na}$ de verrichte tellingen werd de toepasbaarheid van een tweetal statistische benaderingen geëvalueerd, teneinde de hoeveelheid te tellen cellen zoveel mogelijk in te perken. Beide benaderingen blijken de tel-arbeid met tweederde te reduceren. Slechts zeer geringe percentages van de gecilieerde cellen en de slijmbekercellen dragen bij aan het proliferatief compartiment. Indien echter de celtypeverdeling van het proliferatief compartiment bezien wordt, is het aandeel van de gecilieerde cel niet onaanzienlijk $(10 \%-25 \%)$ daar dit celtype een groot deel uitmaakt wan het luchtwegepitheel. 
Hoofdstuk Vier handelt over de basale en parabasale cel, die worden aangetoond m.b.v. een antilichaam gericht tegen de keratine-eiwitten type 5 en 14 , in combinatie met de proliferatie marker MIB- 1 . Eén statistische benadering die het tel-werk met tweederde vermindert wordt geëvalueerd. Het aantal (para)basale cellen per lengte-eenheid van de basaalmembraan waarop het epitheel rust blijkt sterk gecorreleerd te zijn met de totale hoogte van het luchtwegepitheel. De helft van het proliferatieve compartiment bestaat uit basale cellen. In de kleinere luchtwegen (diameter minder dan $0,5 \mathrm{~mm}$ ) bestaat het epitheel voor slechts eenzestiende deel uit basale cellen, die echter eenderde van het proliferatieve compartiment voor hun rekening nemen.

Het luchtwegepitheel van de grotere luchtwegen (diameter $0,5 \mathrm{~mm}$ of meer) bestaat voor $1 \%$ tot $6 \%$ uit parabasale cellen, maar de bijdrage van dit celtype aan het proliferatieve compartiment is eenzesde deel. Het relatief hoge percentage (para)basale cellen dat deel uitmaakt van het proliferatieve compartment geeft steun aan de theorie dat celtypen nabij de basaalmembraan belangrijke voorlopercellen zijn van het menselijk luchtwegepitheel.

In Hoofdstuk Vijf komt de Clara cel aan bod, waarbij een antilichaam gericht tegen het Clara Cell $10 \mathrm{kd}$ eiwit (CClO) gebruikt wordt als immunohistochemische marker in combinatie met MIB-I (proliferatie marker) alsook de PAS-kleuring (marker voor slijmbekercellen). De statistische methode die in de hoofdstukken drie en vier is getest (nl. de standaardfout van de proportie) wordt voor het eerst direct gebruikt voor de vaststelling van de minimaal benodigde hoeveetheid te tellen cellen. Clara cellen komen vrijwel alleen voor in de kleinste luchtwegen. Het percentage Clara in de terminale en respiratoire bronchioli bedraagt respectievelijk $11 \%$ en $22 \%$. De bijdrage van Clara cellen aan het proliferatieve compartiment bedraagt in de terminale bronchioli $15 \%$, en in de respiratoire bronchioli $44 \%$. Derhalve speelt de Clara cel in de handhaving van het epitheel van de kleinste luchtwegen een niet onbelangrijke rol.

In Hoofdstuk Zes handelt over abnormaal luchtwegepitheel dat aangetroffen is in bronchusbiopten die zijn genomen bij $5 l$ patiënten (waarbij ongeveer de helft ten tijde van het biopt kanker had van de luchtwegen dan wel in de loop der jaren daarna kanker ontwikkelde). Het betroffen zgn. squameuze metaplastische afwijkingen, waarbij het normale meerrijige trilhaarepitheel vervangen is door meerlagig plaveiselepitheel onder invloed van chronische prikkeling. Op de biopten werden immunohistochemische 'kleuringen' verricht m.b.v. MIB-1 (proliferatie marker), p53 en Bd-2 ([mogelijke] markers van genetische schade). Alle squameus metaplastische afwijkingen vertonen duidelijk toegenomen proliferatie. P53 kon in de biopten van ongeveer de helft van de patiënten worden aangetoond. Indien p53 in welke vorm dan ook aanwezig is in een biopt, blijkt in negen van de tien gevallen dat de patiënt ofwel reeds kanker heeft van de luchtwegen, ofwel dat zich in de loop van de tijd kanker zal ontwikkelen. Bd-2 bleek geen rol te spelen bij squameuze metaplasie.

Hoofdstuk Zeven behelst allereerst een discussie over statistische onderwerpen die 
relevant zijn bij grootschalige tellingen (reproduceerbaarheid, effectief en efficiènt kwantificeren) en gaat kort in op de (statistische) definitie van 'normaal'. Vervolgens worden de gegevens van de hoofdstukken twee tot en met viff geintegreerd: zowel de opbouw als de celtype-verdeling van het proliferatieve compartiment van normaal menselijk luchtwegepitheel wordt gepresenteerd en besproken. Met name wordt ingegaan op de celdelingsactiviteit van de (para)basale en de Clara cellen, en de mogelijke rol die deze celtypen spelen bij de handhaving van het luchtwegepitheel. Voorts wordt de hypothese, dat squameuze metaplasie begint met schade van de basale cel, besproken.

In de Appendix bij Hoofdstuk Zeven worden de gemiddelde waarden met de $90 \%$ betrouwbaarheidsintervallen van elk van de zes epitheelsoorten en van de omvarig van het proliferatieve compartiment grafisch weergegeven. 


\section{Dankwoord}

Het verrichte onderzoek wat de grondslag vormt van dit proefschrift zou niet zijn begonnen, laat staan afgerond, zonder de ideeën, begeleiding en aanmoediging van velen.

Vooraleerst mijn co-promotor, dr. F.B.J.M. Thunnissen. Beste Erik, bezie je geesteskind(eren). Het is mij een voorrecht geweest enkele van je goede vondsten samen met jou te mogen uitwerken. Aan de ene kant bood jij mij zeer veel ruimte, maar aan de andere kant werd altijd een snelle en adequate hulp geleverd, en kritiek goed gedoseerd én psychologisch verantwoord geuit.

Tevens mijn promotor, prof. dr. J.W. Arends. Beste Jan Willem, de goede faciliteiten die het mij mogelijk maakten het onderzoeksproject uit te voeren dank ik aan jou. Voorts was jouw oordeel van de afzonderlijke deelonderzoeken zeer to the point, en heb ik jouw begeleiding en medewerking bij de tot stand koming van het manuscript als zeer plezierig ervaren.

Daarnaast dank ik (in alfabetische volgorde; s.s.t.t.):

Ton Ambergen, die zorgdroeg voor de statistische inzichten (hoezo, verschil van inzicht?) en bewerkingen (co-auteur van de hoofdstukken 3,4 en 5). Cor Beek, die de statistiek verzorgde van hoofdstuk 6 , en voorts vraagbraak was van allerlei computer-sores (was ik de enige maar...). Freek Bot, wiens "afdek-tip' de immunohistochemische techniek van de hoofdstukken 4 en 5 (eindelijk) mogelijk maakte. Jos Broers, 'prince Keratin', die zeer behulpzaam was bij 'the quest of the basal cell'. Jan den Brok, die het computerprogramma van de Quantimet schreef (co-auteur van hoofdstuk 2). Jacques Cleutjens, die menig probleem (van computerprogramma's tot meetoculairen) adequaat wist op te lossen. Mat Daemen, voor al je snelle adviezen - dank! Mijn collega arts-assistenten, die tijdens mijn onderzoekstijd zonder enig morren er een behoorlijk tandje bij moesten zetten. In de eerste fase, Marti Kuizinga, Prapto Sastrowijoto en Ingrid Willems, in de latere fase Leo de Bruijckere, Dennis Rupa, Hedwig Tromp en Nathalie Vandevijver. Miriam Geenen, die haar rappe hand bij allerlei praktische zaken gepaard liet gaan met de laatste update over het leven 'buiten het proefschrift'. Sjaak (de "korte') en Ismène joosten, die weefselstukjes van tig longen doorvoerden en de zooi opruimden. Zonder het verstrekken van longweefsel door Dr. Joh. Koudstad en dr. P. Theunissen, afdeling Pathologie, de Wever ziekenhuis te Heerlen, zou dit onderzoek volstrekt niet tot stand zou zijn gekomen. Roel Kuijer, wiens koene computer-blik mijin periode als digibeet danig verlichtte. Trouwens, weefsel wat op de glaajjes blijft plakken is ook een van de gouden tips geweest. Chris van der Loos, wiens proefschrift over dubbele, driedubbele en ...dubbele immunohistochemische kleuringen inmiddels uit elkaar ligt. Piet $O p$ de beek, die onverstoorbaar elk obductieprobleem oplostte (scherpe schaar graag, Piet!), en tevens de formalineperfusor aan de gang kreeg en hielp. De medewerkers van het histologie-laboratorium, m.n. Jan Smeets, "Lange' Sjaak (Jacques Baltus) en Josien Dear, die vele blokjes aansneden en mij franco HE coupes bezorgden van tig longen. Annick Moors, die subiet elke oververhitting die gepaard ging bij het 'kleuren' bluste met Vaamse nuchterheid. Anniek Peeters en Petra Aarts, die 
mij welwillend een blaw chromogeen ter beschikking steiden voor de Clara cellen. Margriet Pills, met wie ik als egocentrische immuno-beet menige discussie kon voeren over het wel en wee van menig onderwerp. Jouw onverstoorbaarheid op het lab mocht ik menigmaal compenseren als immuno-frustro! Frans Ramaekers, door jou ben ik over de stamcel dieper gaan nadenken. Bert Schutte deed op enkele woor mij belangrijke momenten dienst als biechtvader op het gebied van de psychologie van de (delende) cel. Guvil ten Velde (co-auteur van hoofdstuk 6), die zeer snel met allerlei patiẻnten-gegevens op de proppen wist te komen. Voorts dank ik het personeel van de Universiteitsbibliotheek en de Audiovisuele dienst van het azM voor de uitstekende service. Mijn schoonvader, Cees de Geus, corrigeerde op de valreep de Nederlandse samenvatting - niet alleen Engels blijkt een moeilijke taal te zijn! Het manuscript werd voorgelegd aan de leden van de commissie, die ik mede langs deze weg hartelijk dank voor hun inspanningen. The author of this thesis is flattered by the general remarks made by Dr. Travis, whose detailed criticism of the manuscript was an impressive demonstration of the toill reviewers may incur.

Ter afsluiting een tweetal speciale vermeldingen.

Mischa Selis, co-autrice van hoofdstuk 3 (in de wandelgangen hardnekkig als 'telfeut' aangeduid), jii sleepte het gehele onderzoek door het diepste dal heen door onverschrokker de slijmbekercellen te lijf te gaan - een buitengewoon prijzenswaardige prestatie. Tevens veroorzaakte je onbedoeld ritmestoornissen bij mens en computer. Heel veel succes met de studie \& all het andere - houd je taai!

A en $\omega$ van deze onderneming was mijn wederhelft, Elies de Geus. Als geen ander smaakte zij het genoegen gedurende een periode van ruim 1200 dagen de minder aangename kanten van het onderzoek mee te maken. Elies zal ongetwijfeld de structurele verandering van gespreksonderwerp (en de rest!) op prijs stellen! 
Color plates 

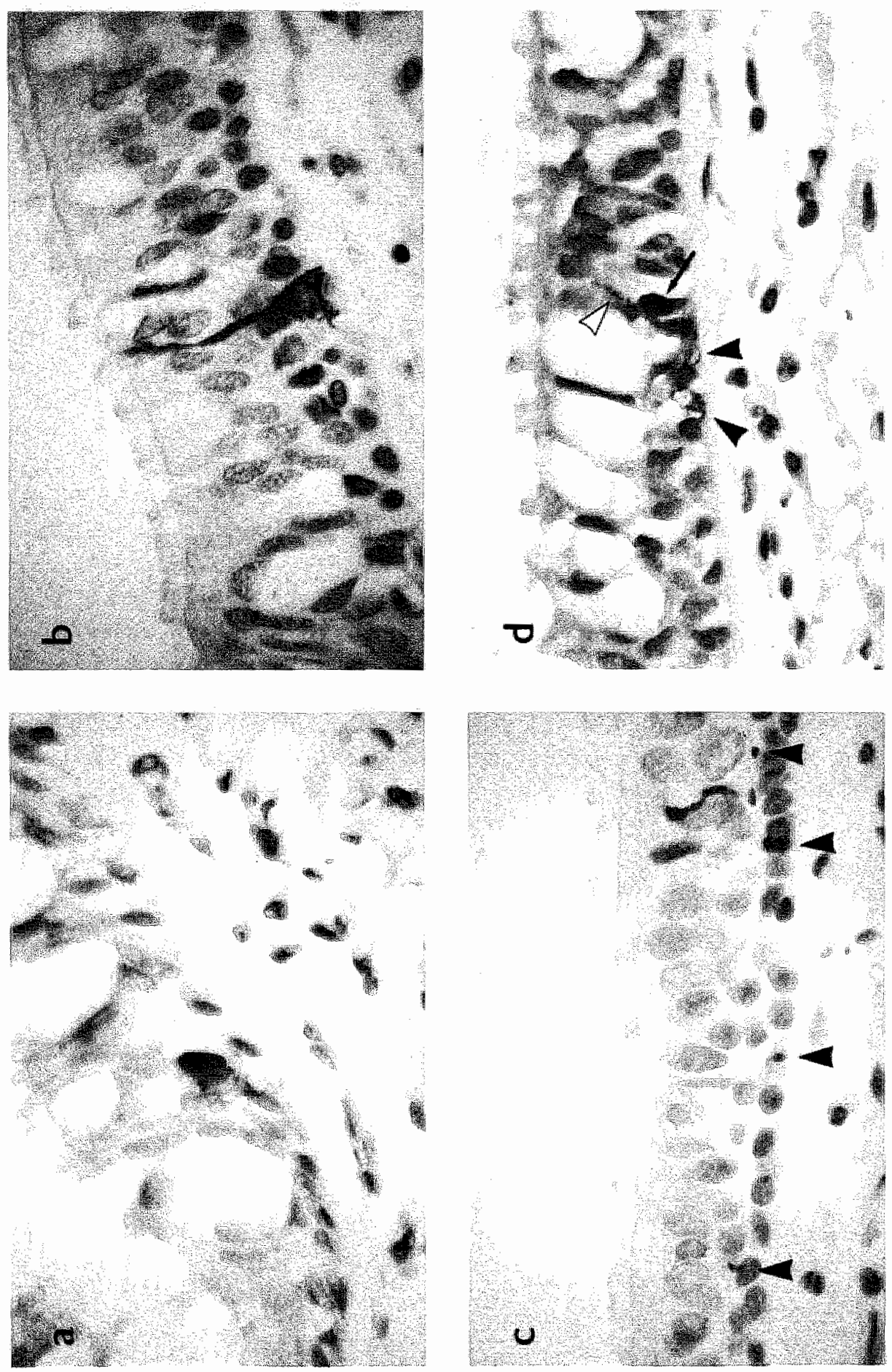


\section{Chapter Two. Neuroendocrine cells}

Figure 2.

A. Airway epithelium double immunostained for both MIB-I (brown nuclear staining) and CgA (red cytoplasmic staining). The PNEC immunostained with CgA lies adjacent to the proliferating epithelial cell immunostained with MIB-I.

B. Airway epithelium immunostained for CgA only. The PNEC with its typical Eiffel Tower-shaped cytoplasm shows dark brown immunostaining. The base of the cell is adjacent to the basement membrane, the tip of the cell is in contact with the airway lumen. C. Airway epithelium immunostained for $\mathrm{CgA}$ only, showing several dendritic neuroendocrine cell processes (arrowheads). CgA does not stain nerve endings.

D. Airway epithelium double immunostained for MIB-I (brown nuclear staining) and CgA (red cytoplasmic staining). The PNEC shows a somewhat curved cytoplasmic tip (open arrowhead) and dendritic cell processes (closed arrowheads). The nucleus of the PNEC is light brown immunostained for MIB-1. Adjacent to the PNEC is a non-neuroendocrine cell also immunoreactive for MIB-I (arrow).

(all photographs, magnification: $\times 1,000$ ) 
Chapter Three. Goblet and ciliated cells
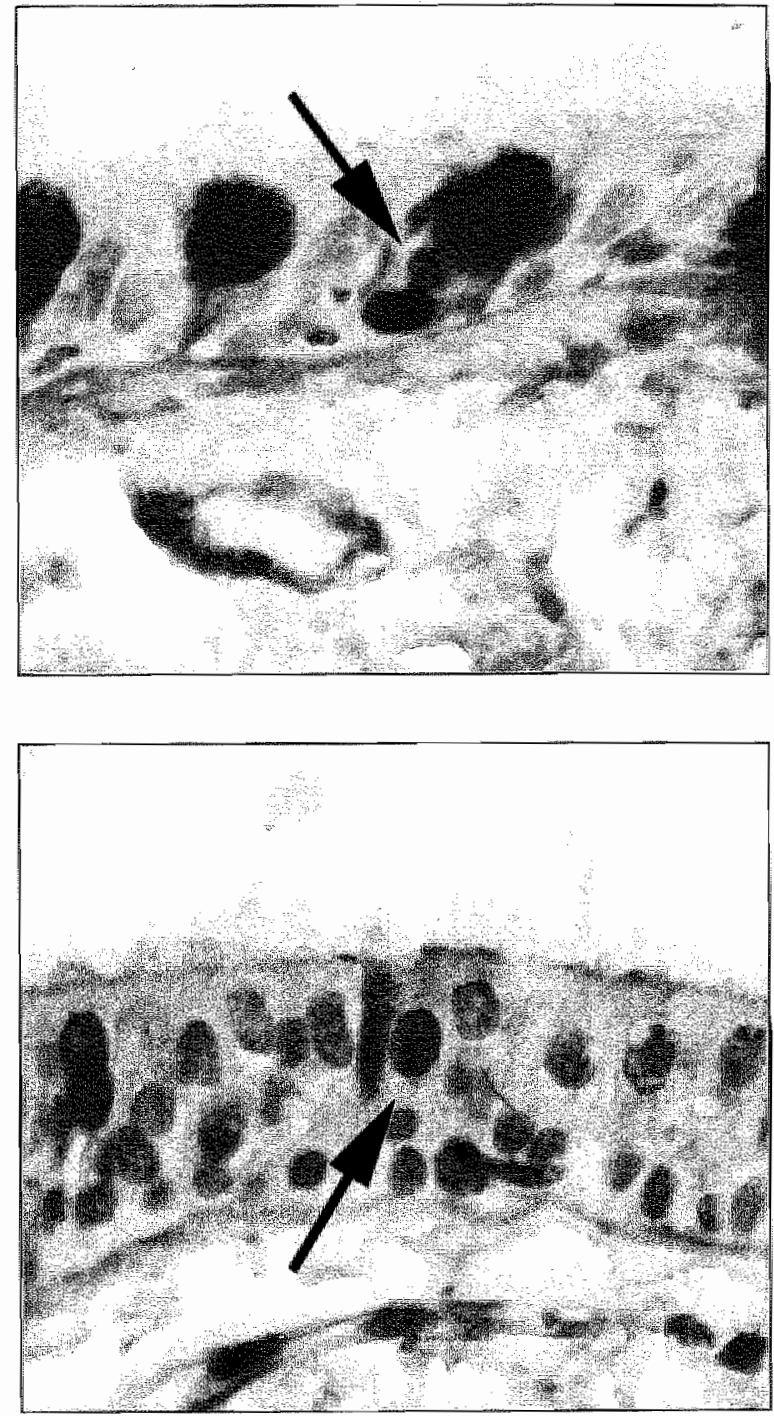

Figure 2.

Upper panel. Several goblet cells with PAS stained flask-shaped cytoplasm (pink color). One goblet cell has a MIB-I immunoreactive nucleus (brown color, arrow). Adjacent to the goblet cell a MIB-I positive basally located cell is seen.

Lower panel. A ciliated cell with a MIB- 1 immunoreactive nudeus (brown color, arrow). (Both photomicrographs, magnification: $x$ 1,000) 
Chapter Four. Basal and Parabasal cells.

Figure 1.

A. Bronchus with 34ßE/2-immunostained basal cells and parabasal cells (red-colored cytoplasm). Brown MIB-1 positive nuclei are seen in two basal

a
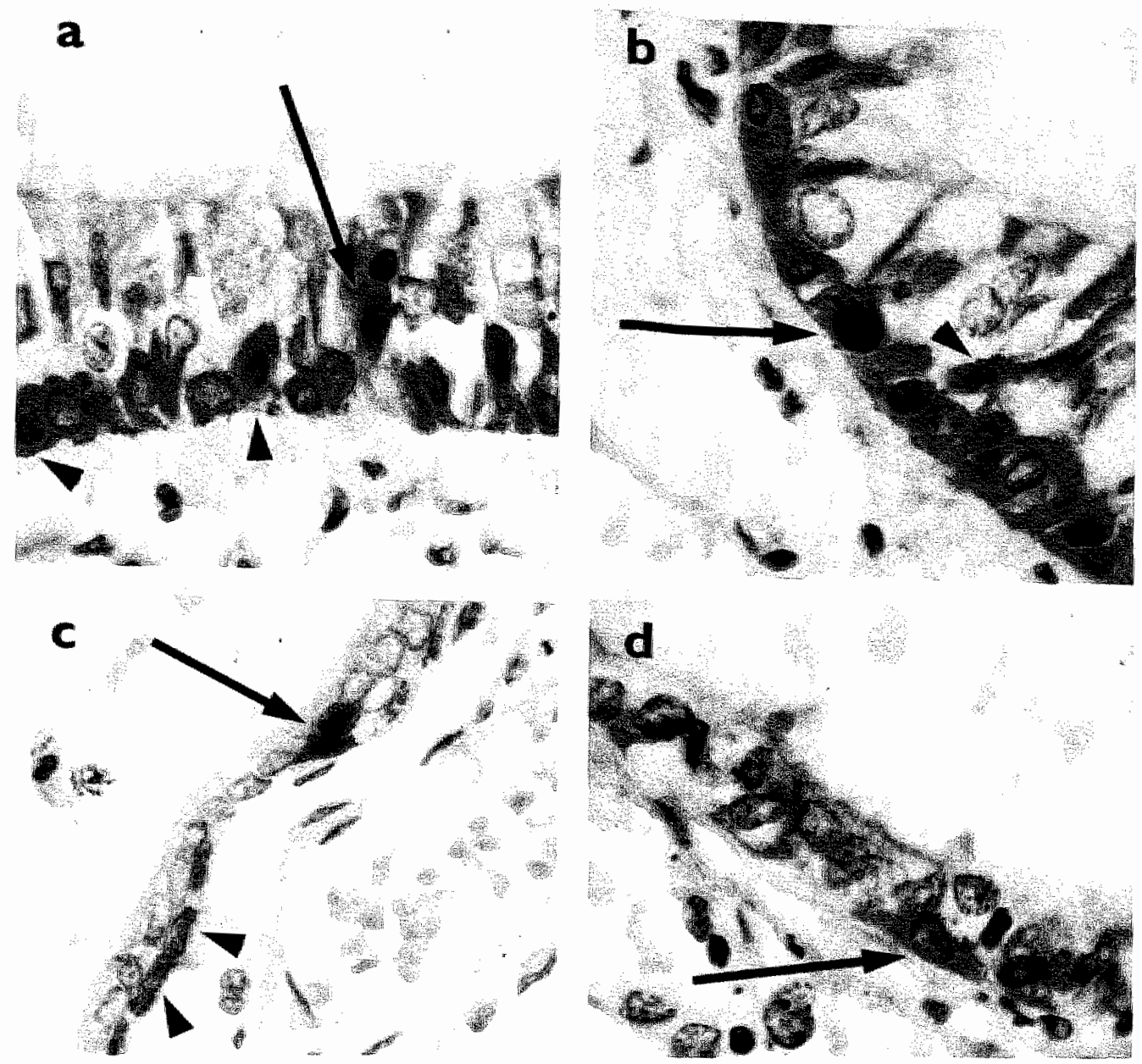

B. Bronchus with immunostained basal cells (red-colored cytoplasm), one with MIB-1 positive nucleus (black-brown color, arrow). In addition, a single parabasal seen is present with MIB - I positive nucleus (arrowhead).

C. Bronchiole with two indistinctly immunostained basal cells in the left-hand corner (arrowheads). Two basal cells with MiB-1 positive ruclei are present in the middle of the photograph (arrow).

D. Bronchiole showing relatively thin epithelium with fewer basal cells (arrow).

(all photomicrographs, magnification: $\times 1,000$ ) 


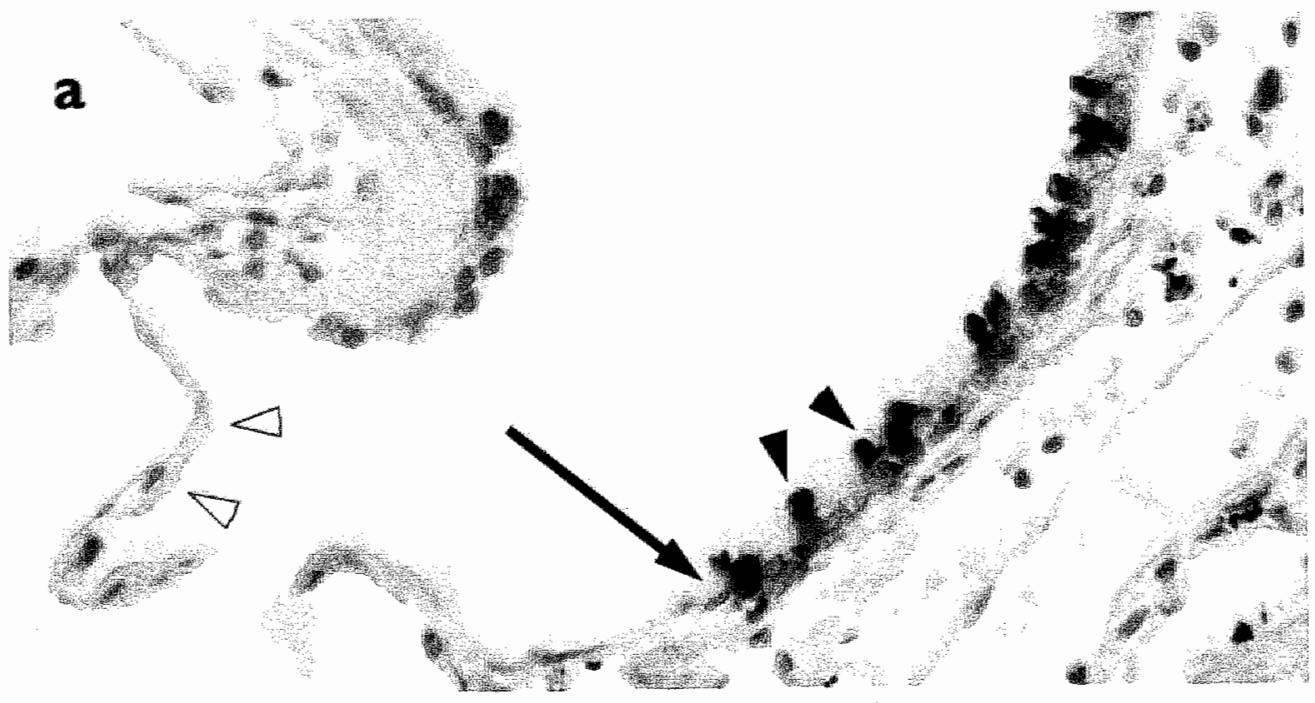

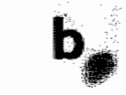
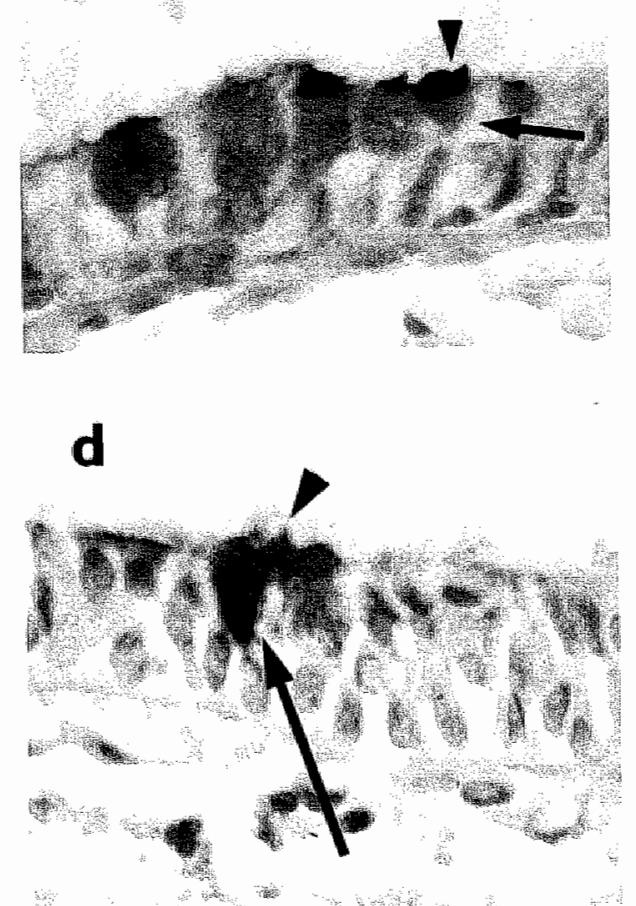

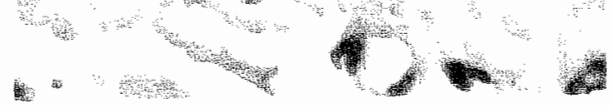

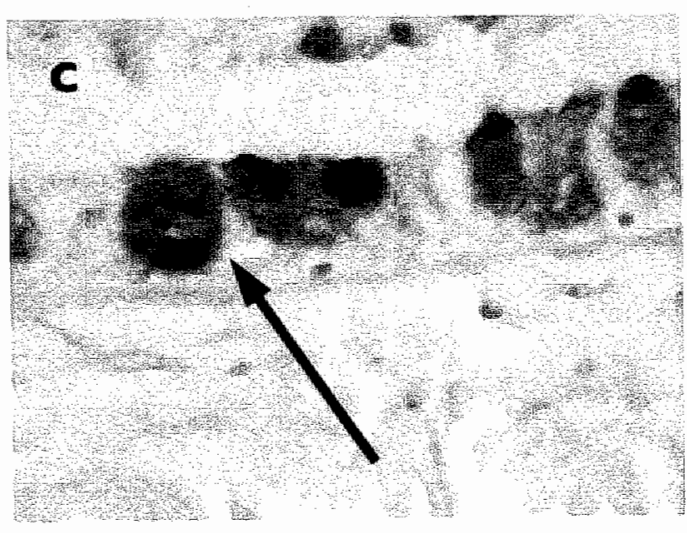

inger:-

e

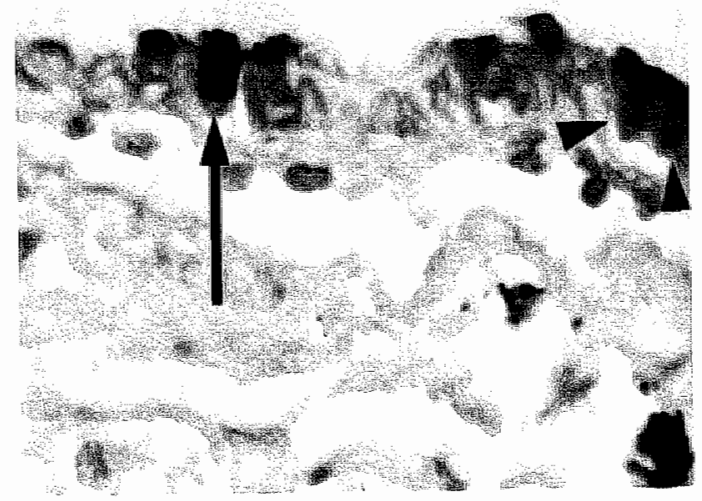


Chapter Five. Clara cells

Figure 1.

A. The right-hand side of the photograph shows the ciliated epithelium of a respiratory bronchicle with CClO immunoreactive Clara cells staining dark blue (black arrowheads). The junction between the ciliated conducting airway epithelium and the respiratory zone is indicated (large arrow). An alveolar wall is present in the left-hand side of the photograph (open arrowheads). (magnification: $\times 500$ )

B. Several goblet cells with PAS-positive cytoplasm (pink color, arrow) with dense CCIOimmunoreactivity of the apical part of the cells (dark blue, arrowhead). (magnification: $x$ $1,000)$

C. Goblet cell (arrow) with PAS-positive cytoplasm (pink color) with coarse CCI0-positive granules (dark blue color). (magnification: $\times 1,000$ ).

D. Goblet cell with perinudear CCl0-immunoreactive cytoplasm (dark blue, arrow) with PAS-positive pink colored apex (arrowhead). (magnification: $\times 1,000$ ).

E. Dark blue immunostained Clara cells in a respiratory bronchiole (arrowheads). One Clara cell with a MIB-1 positive nucleus staining brown (arrom). (magnification: $\times 1,000$ ). 

Bibliography 
1. Scothorne PI. The respiratory system, in: Romanes GI, ed. Cunringham's lextbook of anatomy. 12th ed. Oxford: Oxford Uniwersty Press. $1981,49 !-530$.

2. Robbins SL, Kumar V. The respiratory system. In: Robbins SL, Kumar V: eds. Basic pathology. 4th ed. Philadelphila: W.B. Saunders, $1987 ; 407-456$.

3. Chretien ]. Dusser D. eds. Enwronmental impact on the ainways: from inumy to repar. Lung Biology in Heath and Disease ed. v. 93 New York: Marcel Dekker, 1996.

4. Cotran RS, Kumar $V$, Robbins SL. The respiratory system, In: Cotran RS, Kumar V, Robbins SL, edis. Pathologic basis of disease.. Philiadelphia.: W.B. Saunders, 1989.755 .810 .

5. Wouters EFM. Resonanties in de pulmonologie. Maastricht: Universitudre pers Maastricht, 1993.

6. Same JM, ed Epidemiology of Lng cancer. New York: Marcel Dekker, 1994(Lentant C. ed. Lung biology in heaith and digease, vol. 74).

7. Cotran RS, Kumar V, Robbins SI. Cellu/er injury and adaptation, In: Cotran RS, KLmar V, Robbins. SL, eds. Pathologic basis of disease. 4th ed. Philadelphia: W.B. Saunders, $1989.1-38$.

8. Virchow RC. Die Celluarpathologie in ihrer Begruendung auf physiologische und pathologische Gewebentehre. Berlin: Verhag August. Hirschwald, 1858.

9. Anonymous. Webster's encyclopedic unatridged dictionary. New rewsed edition ed. New York: Gramercy Books i 1994.

10. Barnes P. Greening AP. Crompton GK. Glucoconticoid resistance in asthma. Am I Respir Crit Care Med $1995 ; 152: 5125 \% 5142$.

11. Harkema IR, Mariassy A, St.George I. Hycle DM, Plopper CG. Epithedial cells of the conducting airways. A species comparison. In: Farmer $\$$ G, Hay DWP, eds. The airway epithelium. Physiology, pathofysiology and pharmacology. New York: Marcel Dekker. 1991;3-39.

12. Crystal RG, West JB. eds. The lung. Scientific foundations. New York: Raven Press, 1991.

13. Sorokin SP. The respiratory system. In: Weiss $L$, ed. Cell and tissue biology. Gth ed. Baitimore: Urban \& Scharzenberg, $1988,751-814$.

14. Ide G, Suntzeff V. Cowdry EV. A comparison of the histopathology of tracheal and brionchial epithellum of smokers and nonsmakers. Cancer 1959:12:473-484.

15. MeDowel EM, Beals TF. Diopsy pathology of the bronchi Cambridge: University Press Cambridge, 1986.

16. Breeze RG, Wheeldon EB. The cells of the putmonary arinays. Am Rew Respir Dis 1977;1 16:705-777.

17. Mercer RR, Russell ML, Roggli VL, Crapo JD. Cell number and distribution in humah and rat ainways Am J Respir Cell Mol Biol 1994:10:613-624.

18. Jeffery PK, Gaillard D. Moret S. Human airway secretory cells dung development and in mature ainway epithelium. Eur Respir ] 1992;5:93-104.

19. Auerbach O. Stout AP, Hammond EC, Garfinkel $\mathbb{L}$. Changes in bronchial epithelium in retation to cigaretie smoking and in relation to lung cancer. N Engl I Med 1961:265:2531267.

20. Auerbach O, Fetrick TG, Stout AP. Statsinger AL, Muehsam GE, Forman JB, Brewster Gere I. The anatornical aporoach to the stidy of smoking and bronchogenic carcinoma. Cancer 1956;976-83.

21. Auerbach $O$. Brewster Gere J Forman JB, Petrick TG, 5moln H. Muehsam GE, Kassouny DY, Stout AP Changes in the bronchial epithelum in retation to smoking and cancer of the rung. N Engl I Med $1957,256.97$. 104.

22. Auerbach O, Stout AP, Cuyler Hammond $E_{i}$ Gartinkel L. Changes in the bronchiat epithefium in relation to sex: age, residence, smoking and preumonia. N Engl| Med 1962,267:11!1-1125.

23. Auerbach O. Stout AP, Cuyler Hammond E. Garfinel L. Smoking habits and age in retation to pumonary changes. N Engl) Med 1963;269:1045-1054.

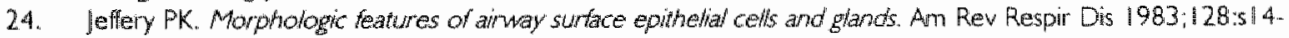
$\$ 20$.

25. Reid L. Jones R. Expermental chronic bronchitis. Int Rev Exp Pathol 1983;24335-382.

26. Grapo JD, Barry BE, Gehr P, Bacholen M, Weibel ER. Cell number and cell characteristics of the normal human hung. Am Rev Respir Dis 1982:125:332-337.

27. Spicer SS, Chalkn LW, Wardell JR, Kendrick W. Histochemistry of mucosubstances in the canine and human respiration tract lab Inwest 1971:6:483-490.

28. Watson JHIL, Brinkman GL. Electron microscopy of the epthelial cets of nomat and bronchitic human bronChus. Am Rew Respir Dis 1964,90:851-855.

29. McDowell EM. Barrett LA, Glawn F. Harrs CC. Trump BF. The respiratory epithelium. 1. Human bronchus. I Natl Cancer inst 1978:61:539-549.

30. Danel C. Erzurum SC, MCElvaney NG. Crystal RG. Quantitative assessment of the epithellat and intanmaton cell populations in large aimwass of nomal and indinduals with cystio fibrosis. Am I Respir Crit Care Med 
$1996 ; 153: 362-368$

31. Broers ILV, Lei L de, Kein Rot M, Har A ter, lane EB, Leigh M. Wagenaa 55 , Voolis GP. Ranaekers FCS.

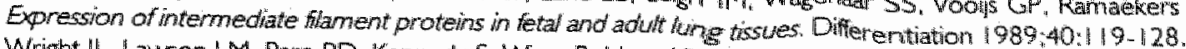

32. Wright $L$, Lawson LM, Pare PD. Kennedy S. Wiggs B. Hoge IC. The detection or small amways disease: Am Rev Respir Dis 1984:129:989-994.

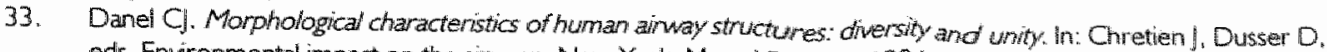
eds. Enwronmental impact on the arways. New York: Mancel Diekker, 1996;19-42.

34. Soderberg M. Mellstrom S. Sandstrom T. Lundgren R. Bergh A. Structural chatacterisation of bronchial mucosal

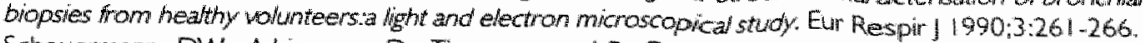

35. Scheuermann DW, Adriaensen D. Timmermans IJP, DeGroodt-Lasseal MHA. Comparative histologrical owernew of the chemical coding of the pumonary neuroepithelial endocrine system in heath and olisease. Eur! Morphol 1992;30:101-112

36. Sorokin SP, Hoyt RF, Pearsall AD. Comparative biology of small granule cels and newropithelial bodies in the respiratory system. Short rewew. Am Rev Respir Dis 1983;128:s26-531.

37. Gosney IR. Sissons MG. Alibone RO. Neuroendocrine cell populations in normal human hngs: az quantiative study. Thorax 1988;43:878-882.

38. Gosney JR Sissons MCJ. OMalley JA. Quantitative study of endocrine cells immonoreactive for cakcitonin in the normal human adut tung. Thorax 1985:40:866-869.

39. Gubbelmans HLL. Maesen BLP, Koudstaal J. Thumissen FBMM. Newroendocrine cells in anthracosilicotic Mungs. Eur Respir \& 1991:4:824-828.

40. Lauweryns IM. Van Ranst L. Leu-7 immunoreactivity in human, monkey, and pig bronchopumonary neuroeptthelial bodies ard neuroendowne cells. H Histochem Cytochem 1987;35:687-69:

41. Hage $E_{x}$ Juel $G$. Endocrine-like cells of the pumonary epithelium of the human adult hung. Call Tissue Res $1977: 178: 39-48$

42. Sorokin SP. Hoyt RF. Newroepithelial bodies and solitary small-granule cells. In: Massaro D, ed. Lung Cell Biology. New York: Dekker, 1989:191-343.

43. Tateishi R. Distribution of argynophil cells in adult tuman Jungs. Arch Pathol 1973,96:198-202.

44. Bonikos QS, Bensch KG. Endocrine cells of bronchid and bronchiolar epithelium. Am J Med 1977:63:765-771.

45. Feyrter F. Zur pathologie des argyrophilen Melle-Zelle. Organes im Bronchialbaun des Menschen. Virciluows Archiv $1954: 325: 723-732$.

46. Gould VE. The endorrine Lung. Editorial. Lab Invest 1983;48:507.509.

47. Madden BP. Gosney J, Coghlan JG, Kamalvand K. Castin AW. Smith P, Yacoud M, Heath D. Pretransplant chicopathological correlation in end-stage primary pumonary hypertension. Eur Respir J 1994:7:672-678.

48. Wison NJ, Gosney JR, Mayall F. Endocrine cels in difuse putmonay whoris. Thor ax 1993;48:1252-1256.

49. Heath D. Yacoub M. Gosney JR. Madden B, Caslin AW. Smith P. Fumonary endocrine cells in hypertensive pulmonary vascular disease. Histopathology 1990;16:21-28.

50. Gould VE, Limnola R. Memoli VA, "Warten WH. Neuroendocrine components of the bronchopumonary tract: Myperplasias, dysplasias, and neoplasms. lab invest 1983:49:5.19-537.

51. Johnson DE Georgieff MK. Pumanary neuroendocrine cels. Their secretory products and their potemtal roles in heath ard chronic hung disease in infancy. Am Rev Respir Dis $1989: 140: 1807$ 18:12

52. Sunday ME Kaplan LM, Motoyamä E Chin WW. Spindel ER. Biology of disease. Gastrin releasing peptide (mammalian bombesine) gene expression in health and disease Lab Invest 1988:59:5-24.

Gosney JR. Pulmonary endocine pathology. endocine cells and endowine tumours of the tung. Oxford: Butterworth-Heinemann Lid. 1992.

54. Scheuermann DW. Morphology and chtochemistry of the endocine epithevial system in the hug. Int Rev Cytol $1987: 106: 35-88$.

55. Gosney JR, Sissons MCl. Alibone RO, Bakey AF, Pumonary endocrine cels in chroric bronchitis and amphyse ma. IPathol $1989: 157: 127-133$.

Ellefren P. Tos M. Goblet cells in the human trachea. Arch Otolaryng, 1972:95:547.555

57. Thurtheck WM. Malaka D. Murphy K. Goblet cells in the peripherat airways in chronic bronchitis. Ami Rev Respir Dis $1975 ; 112.5569$.

58. Basbaum CB. Finkbeiner WE Mucus-produchng cells of the awways. In: Massaro D, ed. Lung cell biology. (Lung biology in health and disease. Yol. 41). New York: Marcel Dekker, Inc., 1989,37-79.

59. Saldana MI wed. Pathology of pulmonary disease. Philadelpthia: JB Lippincott Compary. 1994:288

Reid L. Pathology of chronic bronchits L ancet 1954:1:275-278.

D Reid L. Quartitative distribution of various types of acrid gycoproten in mucous cells of human bronchy. Histochem $1972,4,91-102$. 
62. Wright L, Lawsor LM, Pare PD. Wiggs B. Kennedy S. Hogg JC. Morphology of peripherat anways in current smokers and ex-5mokers. Am Rev Respir Dis 1983:127:474-477.

63. Florey H, Cartetcin HM. Wells AQ. Murous secretion in the trachea Brit I Exp Path 1932:13:269-284,

64. Rogers DF. Arway goblet cels: responsiwe and addpiable tront-line defenders. Eur Respir 1 19947:1690-1706.

65. Spicer 55, Schulte BA. Thomopoulos $G N$. Histochemical properties of the respiratory tract epithelium in diferent species. An Rew Respir Dis 1983:128:520-526.

66. Aikawa T. Shmura S, Sasakik H. Takishima T. Yaegashi H, Takahashi T. Morptrometric analysis of intratuminat mucus in airways of COPD. Am Rew Respir Dis 1989:140:477-482.

67. Jeffery PK. Wardiaw Al. Nelson FS, Collins JV. Kay AB. Bronchial biopsies in asthma. Am Rev Respir Dis $1989,140: 1745 \cdot 1753$.

68. Karpick R. Pratt.PC, Asmundsson T, KJburn KH. Pathological findings in respiratony failure. Ann Intern Med $1970,72: 189.197$

69. Laitinen LA, Laitinen A, Hathitela T. A comparative study of the effects of an inthaled conticosteroid, budenoside, and a b2 agonist, terbutaline, on ainwa inflammation in newh diagrosed asthma: a randomized, double blind, parallelgroup controlled trial. Allergy Cin lmmunal 1992,90:32-42.

70. Sturgess JM. Chlated celts of the Mngs In: Massaro $D_{\text {n }}$ ed. Lung cell biology. (Lung biology in heaith and disease Wol. 4) New York: Marcel Dekker" Inc. 1992,115-151.

71. Baldwin F. Basal cells in human bronchial epithelium. Anat Rec 1994;238:360-367.

72. Evans MI, Moller PC. Brology of airway basal cells. Exp Lung Fues 1991:17:513-531.

73. Claura M. Zur Histobiologre des Bronchialepithets. Z milkrosk-anat Forsch 1937:4:321-347.

74. Cutz E, Conen PE. Uhrastructure and cytochemistry of Clara cells, Am J Pathol 1971:62:127-134.

75. Ebert RV, Terracio My). The tronchiolar epithelium in cigarette smokers. Am Rev Respir Dis 1975;111:4.11.

76. Lumsden AB, Mclean A, Lamb D. Goblet and Clara cells of human distal arinays: evidence for smoking induced changes in their numbers. Thor ax 1984;39:844-849.

77. Plopper CG, Hill LH. Mariassy AT. Ultrastructure of noncitated bronctiofar epithelial (Chara) cell of mammalian Jung. III. A study of man with comparison of 15 mammatian species. Exp Lung Res $1980 ; 1: 171-180$.

78. De Cario Massaro G. Noncilated bronchiolar epitheliaf (Clara) cells. In: Massaro D, ed. Lung cell biology, Lung biology in health and disease ed. New York: Marcel Dekker, $1989,81-114$.

79. Ten Hawe-Opbroek AAW, Otto-Verberne CJM, Dubbeldam J. Dikman JH. The proxinat border or the human respiratory unit, as shown by scanning and transmission electron microscopy and light miscroscopical cytoche-

(201;229:339-354.

Rogers AW. Dewar A, Corrin B. Jeffery PK Identifcation of serous-/ke cells in the surice epithefium of human
bronchioles. Eur Respir 1 1993:6:498-504.

81. Nomori H, Morinaga S, Kobayashi R, Torikata C. Protein / and Clara cell 10-kOa protein distribution in normal

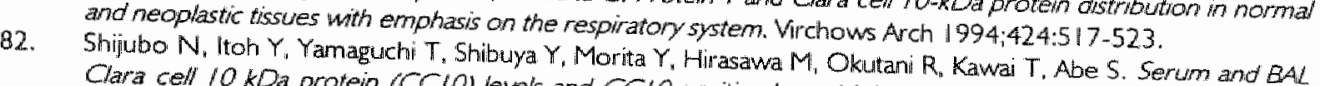

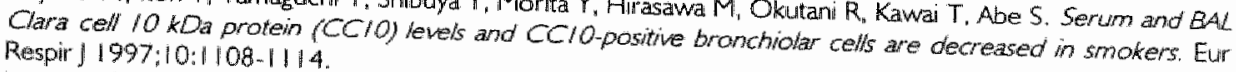

83. Leblond CP. Walker BE. Renewal or celf populations. Physiol Rev 1956;36:255-276.

84. Shorter RG, Titus JL. Dixertie MB. Cell furnower in the respiratory tratci. Diseases of the chest $1964: 46: 138$.
142 .

85. Blenkinsopp WK. Protheration of respinatory tract epithelium in the fat Exp Cell Res 1967:46:144,154. 37 .

37. Evans M). Cabral-Anderson 4. Freeman G. Role of the Clara cell in the renewal of the bromchotar ep the

88. Evans M. Shami SG, Cablat-Anderson U, Dekker NP Role of nonched

89. Kathelum of rats exposed to NO2. Am I Pathol $1986 ; 123: 126-133$.

90. Ayers MM. Jeffery PK. Proweraton and diferention int Rev Exp Pathol $1980 ; 22: 131-191$. 80.

anway ephthefum. Eur Respir' | 1988;1:58. SD. Hesketh P), eds. Lung cancer differentiation: implications for diagnosis and treatment eputhelial cels. In: Bernal and disease; wol, 58). New York: Marcel Dekker inc. 1992;3-43.
Donnelly GM. Hack DG. Heird CS. Trachead epithes and treatment (Lung biology in health

93. Cell Tissue Knet 1982;15:119-130. Tracheat epithelum: Gell kinetics and differentiation in nomal rat tissue.

Breuer Rajicek G, Christensen TG. Lucey EC. Snider GL. Cell knetios or normal adut hamster bronchial 
epithelium. Am ] Respir Cell Mol Biol 1990,2:51.58.

94. Bindreiter M. Schuppler 1. Stockinger L. Zellprolfferation und differenzierung im trachealeaithef der ratte. Exp Cell Res 1968;50:377-382.

95. Lum H. Schartz LW, Dungworth DL, Tyler W5. A comparative study of cell renewal anter exposure to ozone or oxygen. Am Rev Respir Dis 1978:1 18:335-345.

96. Castleman WL, Dungworth DL, Sctrwatz LW. Tyler WS. Acute respiatory bronchiohtis. Am I Pathol $1980 ; 98: 8+1-840$.

97. Keeman KP. Cell injury and repair of the tracheobronchial epithelium. Im: McDowell EM, ed. Lung carcinomas. Edinburgh: Churchill Liwingstone, 1987;74-93.

98. Keenan KP. Combs JW. McDowell EM. Regeneration of hamster tracheal epithelium after mechanical injury. I. Focal lesions: quantitative morphologic study of cell prolferation. Virchows Archiv B CP 1982:41:193-214.

99. Keenan KP. Combs IW. McDowell EM. Regeneration of hamster tracheal epithelium after mechanical injwiry. M. Mutitocal lesions." stathmokinetic and autoradiographic studies of cell proliferation. Virchows Archiv B CP $1982 ; 41: 215-229$.

100. Keenan KP, Combs. WW, MicDowell EM. Regeneration of hamster tracheal epithelium atter mechanical injury. Wh. Large and small lesions. comparative stathmokinetic and single pulse and continuous thymidine labeling autoradiographic studies. Virchows Archiv B CP 1982:41:231-252.

101. Keenan KP., Wilson TS, MCDowell EM. Regeneration of hamster tracheal epithelium after mechanical injury. W. Histochemical, immunocytochemical and ultrastructura' studties. Virchows Archiv B CP 1983;43:2 $13-240$.

102. Plopper CG. Dungworth DL. Structure, function, cell injury and cell renewal of the bronchiolar-atveolar epithelium. In: MCDowell EM, ed. Lung carcinomas. Edinburgh: Churchill Livingstone, 1987;94-129.

103. Ji CM. Plopper CG. Pinkerton KE. Olara cell heterogeneity in differentiation: correlation whith proliferation. ultrastructural composition, and cell position in the rat bronchiole. Am J Respir Cell Mol Biol 1995:13:144-151.

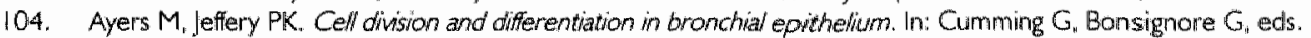
Cellular biology of the lung. New York: Plenum Press, 1982,33-204.

105. Reid L. Evaluation of model systems for study of airway epithethum, cilla, and mucus. Arch Intern Med 1970:126:428-434.

106. Harkema JR, Hotchkiss JAS. In wiwo effects of endotoxin on intraepithelial mucosubstances in rat pulmonary ainways. Am I Pathol 1992;141:307-317.

107. Wright $A$, Alison M. Celf proliferation in respiratory epithellia. $\ln$. The biology of epithellial cell populations. New York: Oxford University Press, 1984;1068-1078.

108. Bolduc P, Reid L. Mitotic index of the bronchial and alveolar lining of the normal rat lung. Am Rev Respir Dis 1976;1 14:112!-1128.

109. Otani EM. The basal progenitor of the tracheabronchial epithelium: fact or folkfore? In: McDowell, ed. Lung carcinomas. Edinburgh: Churchill Livingstone, 1987;410.

110. Lamb $D$, Reid L. Mitotic rates, goblet cells increase and histochemical changes in mucus in rat bronchizl epithelium during exposure to sulphur dioxide. I Pathol Bacteriol 1968:96:97-111.

111. Hoyt RF. McNelly NA, Sorokin SP. Oynamics of neuroepithelial body (NEB) formation in hamster Lung: hight microscopic autoradiography after 3H-thymidine labelling in wiv. Anat Rec 1990:227:340.350.

112. Montuenga LM, Springall DR. Winter RJD, Gaer J, Zhao L, McBricte JT, Taybor KM, Barer G, Polak JM. GGRP. immunoreactive endocrine cell proliteration in normal and hypoxic rall Iung studied by immunocytochentical detection of incorporation of 5-bromodeoxyuridine. Cell Tissue Res 1992:268:9-15.

113. Puchelle $E_{1}$ Zahm J.M. Repair processes of the ainway epithelium. In: Chretien J. Dusser D, eds. Environmental impact on the airways. New York: Marcel Dekker, 1996;157.183.

114. Jeffery PK. Gigarette smake-induced damage of arway mucosa. In: Chretien J, Ousser D. eds. Environmental impact on the airways. New York: Marcel Dekker, 1996:299-35.3.

115. McDowell EM. Lung Carchornas, Edinburgh: Churchill Livingstone, 1987.

116. Pendleton N. Dixon GR. Burnett HE, Occleston NL. Myskow MW. Green JA. Expression of protiferating cey nuclear antigen (PCNA) in dysplasia of the bronchial epithelum. I Pathol 1993:170:169-172.

117. Demoly P. Simony-Lafontaine J, Chanez P, Pujol JL, Lequeux. N. Michel PB, Bousquet. I. Cell profiferation in the bronchial mucosa of asthmatics and chronic bronchitics. An J Respir Crit Care Med 1994:1502:4-217.

118. Fjellbirkeland L. Bjerkvig R, Steinsvag SK, Laerum OD. Nonadhesive stationary organ culture of humath bronchial mucosa Am I Respir Cell Moll Biol 1996:15:197.206.

119. Plopper CG. Hyde DM, Buckpitt AR. Clara cetts. In: Crystal RG, West JB, eds. The lung: scientific foundations. New York: Raven press, 1991.215-228.

120. Plopper CG, St. George I. Pinkerton KE, Tyler N, Mariassy A, Wison D, Wu R. Hyde DM, Evans M. Tracheobronchial epithelium in wo: composition, differentiation and response to hormones. In: Thomassen DG. 
Wettesheim P, eds. Bology toxjcology and carcinogenesis in the respiratory epithelum. New York: Hemisphe* re, 1990,308 .

121. Weibel ER. Design of arways and blood vessels considered as branching trees In: Crystail RG. West JS. eds. The lung: Scientific foundations. Mew York: Raver Press ltd., 1991.711 .727 .

122. Tyler WS. Comparative subgross anatomy of hng: pleura, interobular septas and distal aumays Am Rev Respir Dis $1983: 128: 3325-36$

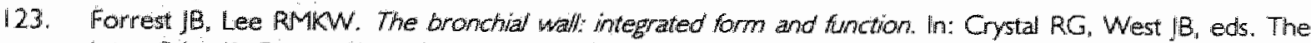
Lung: Scientific Foundations. Naw York: Raven Press, $1991: 729-739$.

124. Kuhn II C. Nomal anatomy and histology. ln: Thurlbeck WM. Churg AM, eds. Pathology of the lung. 2nd ed. New York: Thieme, 1995; 1-36.

125. Fraser RG. Pare JP. Anatomy of the anways. In: Fraser JG. Pare JP, eds. Diagnosis of diseases of the chest. 3 rd ed. Philadelphia: WB Saunders, $1988,3-17$.

126. Cosmey JR Pumonary endocrine pathology: endocrine cells and endocrine tumours of the tung. Oxtord: Butterworth. Fiteinemann Ltd, 1992.3.

127. Jasis JR. Origins of mucin staining. I Clin Pathol 1996:49:787-790.

128. Plopper CG. St. George IA. Nishio SI. Etchison IR. Nettesheim P. Carbobydrate cytochemistry of the tracheobronchial ainw epithelium or the rabbit. $\mathrm{j}$ Histochem Cytochem $1984,32: 209-218$.

129. Hayashi M, Sornberger GC. Huber GL. A morphometric anaflusis of the male and temale tracheal epithelium after experimental exposure to marjuana smoke. Lab inwest 1980;42,65-69.

130. Jones R, Reid L. Secretary cell hyperplasia and modification of intracellular glycoprovein in rat ainways induced by short period of exposure to tobacco smoke, and the effect of the antintarmatory agent phenymethoxytdazo1e. Lab Invest $1978: 41: 41-49$.

131. Lamb. D. Reid L. Goblet cell increase in rat bronchial epithelium after exposure to cigarette and cigat tobacco
smoke. Br Med I 1969:1:33 35. 132. Matsuba K, Shirakusa T. Kuwano K, Hayashi S, Shigematsu N. Small ainways disease in patients whthout othronic
air-Now limitation. An Rev Respir Dis 1987;136:11 106-1111.

133. Cosio M. Ghezzo H, Hogg JC. Corbin R. Loweland M. Dosman J. Marklem PT. The relationship between structural changes in small aimways and pulmonary-function tests. N Engl」 Med $1978 ; 298: 1277-1281$.

134. Glymn AA, Michaels L. Bronchial biopsy in chronic bronchitis and asthma. Thorax 1960:15:142-153.

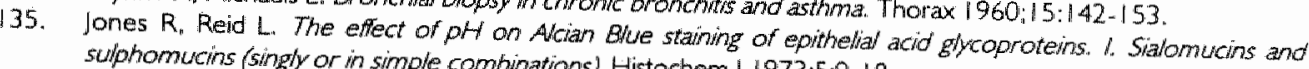
sulphomucins (singly or in simple combinatrons). Histochem j 1973;5:9-18. 136. Hayashi M. HUber GL. Quantitative differences in goblet cells in the tracheal epithelium of male and female rats.
Am Rev Respir Dis 1977; 11 15:595-599. 137. Wright JL, Cosio M. Wiggs B, Hogg, JC. A morphologic grading scheme for membranous and respiratory
bronchioles. Arch Pathol Lab Med 1985:109:163-165.

138. Hale KA, Ewing $S L$, Gosinell BA, Niewohner DE. Lung disease in long-term ciganette smokers with and without chronic air-1how obstruction. Am Rev Respir Dis 1984:130:716.721.

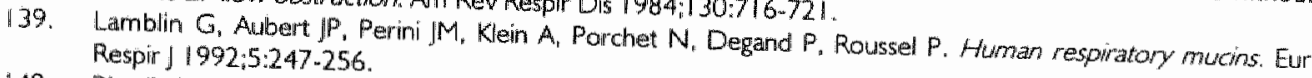

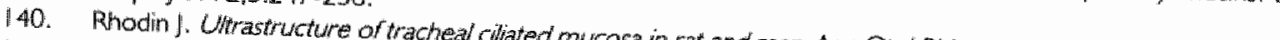

141. Rhodin J. An attas of utrastructure. Philadelphia: W B 5aunder man. Ann Otol Rhin Laryng 1959:68.964968.

142. Gould VE, Yarnopoulos AD, Sommer SC, Thia: W. Saunders, 1963.

ral obserwations and quantitative anghtsic "Terzakis JA. Neuroendocrine cells in dysplastic bronchi. Uhtrastructu56.

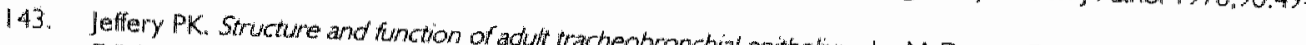
Edinburgh: Churchill Limingstone, 1987,42-74.

144. Jeffery PK, Reid N New obsenaton, or

situdy. J Anat 1975:120:295-320.

145. Ploppei CO Mariasy AT.

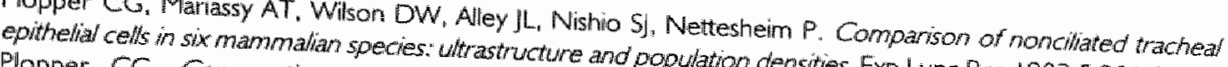

146. Plopper CG. Comparathe morphologic teatures of bopulation densities. Exp Lung Res 1983;5:281-294. 1983:128:537.541.

147. Becci BJ. MCDowell EM. Trump BF. The respiratory epithelism. H. Hamster trachea, bronchus, and bronchioles.

148. Plopper CG, Hoidsiek Al St

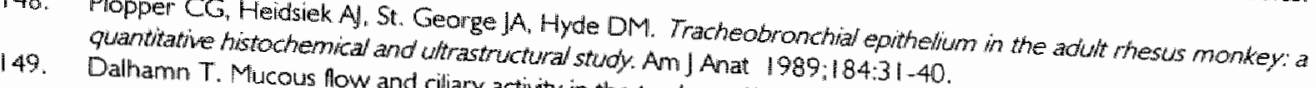


gases (SO2, H3N, HCHO). 1956. Ph.D. Dissertation, Karolinskay Institutet, Stockholm, 160 p.

150. Bedetti CD, Singh 1, Singh G, Katyal SL, Wong-Chong ML. Uhrastructural localization of rat Oara cell $10 \mathrm{kd}$ secretory protein by the immunogald technique using polyclonal and monochonal antibodies. IHistochem Cytochem 1987;35:789-794.

151. StahIman MT, Gray ME. Colocalization of peptide hormones in neuroendocrine cells of human setat and newborn hungs: an electron microscopic study. Anat Ree 1993:236:206-212.

152. Taylor CR. Immunomicroscopy: aliagnostic tool for the surgical pathologist. 2nd ed. Philadelphia: WB Saurnders, 1994.

153. Rindi $G$, Buffa $R$, Sessa F, Tortora $O$, Solcia E. Chromogranin $A, B$ and C immunoreactivities of mammallan endocrine cells. Distribution, distinction from costored hormonesprohormones and relationsthip with the argyrophis component of secretory granules. Histochemistry 1986;85:19-28.

154. Lauweryns JM, Ranst $L$ van, Lloyd RV, O'Connor DT. Chromogranin in bronchopulnonary neuroendocrine cells. Immumachemical detection in human, monkey and pig respiratory mucosa. I Histochem Cytochem 1987;35: $113-118$.

155. Sunday ME, Willett CG, Patidar K, Graham SA. Modulation of oncogene and tumor suppressor gene expression in a hamster model of chronic lung injury with varying degrees of pulmonary neurcendacrine hyperphasiat. Lab Invest 199:4:70:875-888.

156. Aguayo SM, Schuyler WE, Murtagh JI. Roman I. Regulation of lung branching morphogenesis by bombesin-ike peptides and neutral encopeptidase. Am I Respir Cell Mol Biol 1994:10:635-642.

157. MCDowell EM. Hoyt RF. Sorokin SP. Ontogeny of endocrine cells in the respitatory system of Syrian golden hamsters. Hi. intrapuimonary airways and aheoli. Cell Tissue Res 1994;275:157-167.

158. Roncalli M, Springall DR, Maggioni M, Moradoghli-Haftwani A, Wirter RJ, Zhao L, Coggi G, Polak MM. Eariy changes in the calcitonin gene-related peptide (CGRP) content of pulmonary endocrine cells concomitant with vascular remodelling in the hypoxic rat. Am I Respir Cell Mol Bial 1993:9:467-474.

159. Kleinerman J. Marchevsky AM, Thornton J. Quantitative studies of APUD cells in ainways of rats. The effect of diethynitrosamine and NO2. Am Rev Respir Dis 1981:124:458-462.

160. Willey JC, Lechner JF, Harris CC. Bombesin and the c-terminal tetradecapeptide of gastrin-releasing peptide are growth factors for normal human bronchial epithelizal cells. Exp Cell Res 1984;153:245-248.

161. Tsutsumi $Y$, Osamura RY, Watanabe K, Yanaihara N. Immunohistochemical studies on gastrin releassing peptideand adrenoconticotropic hormone-containing cells in the human lung. Lab Invest 1983:48:623-632.

162. Polak JM, Bloom SR. Regulatory peptides and neuron-specific enolase in the respiratory tract of man and other mammals. Exp Lung Res 1982:3:3|13-328.

163. Springall DR, Bloom SR, Polak JM. Neurad, endocrine, and endothelial regulatory peptides. In: Crystal RG. West JB, eds. The lung: scientific foundations. New York: Raven Press, 1991:69-90.

164. Senden NHM. Timmer EDJ, Boers JE, van de Velde HJK, Roebroek A.M. van de Ven WJM, Broers JLV, Ramaekers FCS. Neuroendocrine-specific protein C MSP-C): subcellwar localization and differential expression in relation to NSP.A. Eur J Cell Biol 1996;69:197-213.

165. Johnson;DE, Anderson WR. Burke BA. Pulmonary neuroendocrine cell in pediatric lung diseaser adterations in airway structure in infarts with bronchopulnonary disease. Anat Rec 1993;236:115-119.

166. Hoyt RF, Sorokin SP, MCDowell EM, MCNelly NA. Neuroepithelial bodies and growth of the aimway epithelium in developing hamster hung. Anat Rec 1993:236:15-22.

167. Chen MF. Kimizuka G, Wang NS. Human retal Iung changes associated whth maternal smoking during pregnancy. Pediatr Pulmonol 1987:35:51-58.

168. Aguayo SM, King TE, Waldron IA. Sherritt KM, Kane MA, Miller YE. increased pulmonary neuroendocrine celts with bombesine-like immunoreactivity in aduft patients with eosinophiftr granuloma. I Clin Irvest 1990;86:838. 844.

169. Gillan JE, Canalane SF. Distinctive patterns of pulmonary neuroendocrine cells in sudden intant death syndrome. Ann NY Acad Sci 1988;533:4644466.

170. Aguayo 5M. Pulmonary neuroendocrine cells in tobacco-related /ung disonders. Anat Rec 1993:236:122-127.

171. Singh G, Singh J, Katyal SL. Brown WE, Kramps IA, Paradis UL, Dauber JH, Macpher son TA, Squeglia N. Identifcation, cellular focalization, isolation, and characterization of human clara cell-specific $10 \mathrm{kd}$ protem. $\mathrm{J}$ Histochem Cytochem 1988;36:73-80.

172. Jerisen SM, Jones JE, Pass H. Steinberg SM, Linnoila Rl. Olara cell IO KDa protein mRNA in norrtal and atypicat regions of thuman respiratory epithelum. Int I Cancer 1994;58:629-637.

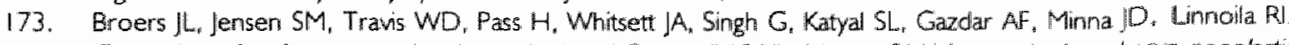
Exoression of surfactant associated protein-A and Clara cell 10 kilodalton m RNA in neoplastic and non-neoplastic human iurng tissue as detected by in situ hybridization. Lab Invest 1992,66:337-3466. 


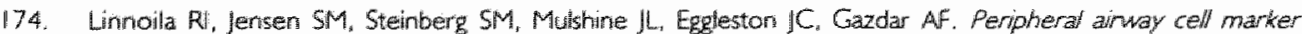
expression in non-small cell lung carcinoma. Association with distinct dincopathologic features. Am I Clin Fathol 1992,97233243

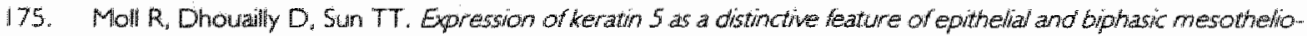
mas. Wirchows Archin B CP 1989-58:129.1.45.

176. Leube RE Rustad T). Squamous metaplasia in the human Rng: molecular characteristics or epithelial stratitication. Virchows Archiv B CP 1991:61:227-253.

177. Ramaekers F, Huijsmans A, Schaart $G$, Moesker $O$, Wooijs. P. Tssue distribution of keranin 7 as monitored by a monoclonal antibody. Exp Cell Res 1987;170:235-249.

178. Bernal S. Weinberg K, Kakefuda M. Stathel R, OHara C. Wong YC. Membrane antigens of human bronchial epithellia' cells identified by monoclonal antibodies. in Vitro Cellular \& Developmental Biology 1988:24:117-125.

179. Montuenga LM, Springall DR, Gaer J. McEride JT, Polak JM. Sinuthaneous immunostaining method for locatisation of bromodeoxyuridine and calcitonin gene-related peptide. IHistochem Cytochem 1992;40:1121-1128.

180. Gosney JR. Pulmonary endocrime pathology: endocrine cells and enciocrine tumours of the tung. Oxtord: Butterworth-Heinemann Lto., 1992:11.

181. Johnson DE. Puhonary Neuroendocrine cells. In: Farmer SG. Hay OWP, eds. The airway epithellum: physiology, pathophysiology and pharmacology. New York. Marcel Dekker, 1990;335-397.

182. Lauweryns JM, Goddeeris P. Neuroepithelliat bodies in the human chifo and aduh lung. Am Rev Respir Dis $1975: 111: 469-476$

183. Gould VE, Limoila RI. Pumonary neuroepithelial cells, neuroendocrine cells, and pulmonary tumors. Hum Pathol 1982:13:1064.1066.

184. Hagn C. Schmid KW. Fischer-Kobrie R, Winkler H. Chromogranin A. B, and C in human adrenäl medulia and endorine tissues. Lab Inwest $1986 ; 55: 405-411$.

185. Wilson BS, Lloyd RV. Detection of chromogranin in neuroendocrine cels whit a monoclonat antibody. Am I Pathol $\| 984 ; 115: 458-468$.

186. Facer P. Bishop AE, Lloyd RV, Wilson BS, Hennessy R. Polak M. Chromogranin: a newly recognized" marker for endoerine ciells or the human gastrointestinal tract Gastroenterology 1985;89:1366 1373.

187. Gosney JR. Pumonary endocrine pathology" endocrine cells and endocrine tumours of the lung. Oxford: Butterworth-Heinemanin Ltd. $1992: 18$.

188. Gosney JR. Pulmonary endocrine pathology: endocrine cells and endocrine tumours of the lung. Oxford: Butterworthintheinemann Ltd, $1992: 46$.

189. Evans MJ, Cox RA, Shami SG. Wilson B, Plopper CG. The role of basal cells in attachment of columnar cels to the basal lamina of the trachea. Am J Respir Cell Mol Biol 1989:1:463-469.

190. Ewans MJ. Piopper CG. The role of basal cells in adhesion of columar epithelim to ainway basement membra. ne. Am Rev Respir Dis $1988_{n}^{\prime 1} 38: 481-483$.

191. Purkis PE, Steel JB, Mackenzie IC, Nathrath WBI. Leigh IM, Lane EB. Antibody markers or basal cells in complex opithelis. I Cell SC: 1990,97:39-50.

192. Cooper D, Schermer A, Sun TT. Classication of human epithelia and their neoplasms using monoclonat antibodies to keratins: strategies applications, and hmitations. Lab invest 1985:52:243-256

193. Gown A.M. Vogel AM. Monodonal antibodies to humam intermediate fhament proteins. It. Oistribution of fhament proteins in nomal human tissues. Am J Pathol $1984,114: 309.31$ |

194. Moll $\mathrm{R}_{\mathrm{i}}$ Franke WW. Schiller DL. The catalog of human cytokeratins: patterns of expression in nomal eothelia. tumars and cuttuned cells. Cell 1982;31:11:24.

195. Randell 5H, Comment CE. Ramatkers FCS. Netteshem P. Properties of rat tracheal epithelia/ cells separated based on expression celi sulface a-galactosyl end groups. Am I Respir Cell Mol Biol 1991:4:544-554.

196. Shimizu T. Nettesheim P. Ramaekers FCS, Randell SH. Expression of cell-type-specitio markers ouring rat

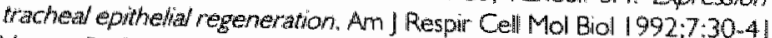

197. Vassar $R_{x}$ Rosenterg M. Ross $S_{1}$ Tyner A, Fuchs E. Tissue-specific and difierentiation-spectic expression of a human Kl keratingene in transgenic mice. Proc Natl Acad Scl U S A 1989;86:1563-1567.

198. Inayama $Y$, Hook GER, Brody AR, Cameron GS, Jetten AM, Gilmore LB, Gray T. Wettesheim P. The diferentation potential of tracheal basal cells. Lab Inwest 1988;25:706-717.

199. Inayama $Y$. Hook GE, Brody AR, Jetten AM, Gray T. Mahlear J. Nettesheim P. In witro and in wwo growth and diferemtiation of clones of tracheal basal cells. Am I Pathol 1989;134:539-549.

200. Nettesheim P. Jetten AM, Inayama Y, Brody AR, Gray TE Mahller JF. Hook GER. The rote of Clara cells and basal cells as opithelhit stem cells of the conducting ainways. ln: Thomassen DG. Nettesheim P, eds. Biology, toxicology and carcinogenesis in the respiratory epithelium. New York: Hemisphere, 1990,99-111.

201. Sleigh MA. Mucus propusion. In: Crystal $R G_{i}$ West JB, eds. The Lung: Scientific Foundations. New York: Raven 
Press, 199!:189-196.

202. Thurlbeck WM, Churg AM, eds. Pathology of the lungy. 2nd ed. New York: Thieme, 1995:739-780.

203. Leuchtenberg C. Leuchtenberg R. Zebrun W. Shaffer S. A comelated histologial, cytological ank chochemical study of the tracheobronchial tree and hungs of mice exposed to cigarette smoke. Cancer 1960;13:721-732.

204. Wright JL. Small arways disease: its role in chronic aiffow obstruction. Sem Resp Mied 1992:13:72-84.

205. Nagai A, West WW, Thurlbeck WM. The National institutes of Heath intermittent positive pressure breathing trial: pathology studies. H. Correlation between morphologic tholings, olnical findings, and evidence of expiratory air-flow abstruction. Am Rev Respir Dis 1985; 132.946-953.

206. Jeffery PK. Structural changes in asthma. In: Airways and Vascular remodelling. Academic Press, 1994;3-19.

207. Aikawa T, Shimura S. Sasaki H. Ebina M, Takishima T. Market goblet celt hyperplassiat w w th mucus accumulation in the airways of patients who died of severe acute asthma attack. Chest 1992;101:916-921.

208. Lee RMKW, Forrest JB. Structure and tunction of cilia. In: Crystal RG, West JB, eds. The Lung: Scientific Foundations. New York: Rlaven Press, 1991:169-181.

209. Sheppard MN. Thurlow NP. Distribution of the cytoskeletal protein $\beta$-twoulin in normal hing cryptogenit fibrosing alveolitis and lung tumours. Histopathology 1992:20:42 1-425.

210. Dixon PM. Respiratory mucocitiary dearance in the horse in heath and distease, and its pharmaceutical modifica. tion. The Veterinary Record 1992;131:229-235.

211. Widdicombe JH. ion transport by airway apitheira. In: Crystal RG. West JB, eds. The Lung: Scientific Foundlations. New York: Raven Press, 1991;263-271.

212. Pavia D, Sutton PP, Angew JE, Lopez-Vidriero MT, Newman SP, "Clarke SW. Lung mucociliary transport in man. In: Cumming $G$, Bonsignore $G_{n}$ eds. Cellular biology of the llung. New York and London: Plenum press, 1982;205-218.

213. Laitinen LA, Heino M, Laitinen $A$, Kava $T$, Haahtela T. Damage or the airway epithelum and bronchial reactivity in patients with asthm: Am Rew Respir Dis 1985; 131:599-606.

214. Widdicombe IG, Pack RI. The Clara cell. Eur I Respir Dis 19:82:63:202-220.

215. Hook GER, Gilmore LB, Gupta RP, Patton SE, Jetten AM, Nettesheim P. The role of pumonary Clara cels, in: Thomassen DG, Nettesheim P. eds. Biology, toxicology and carcinogenesis in the respiratory epithelium. New York: Hemisphere, 1990;38-59.

216. Bernard A, Marchandise $F X$. Depelchin S, Lauwerys R, Sibille Y. Oara cell protein in serum and tronchoalveolar lavage. Eur Respir J 1992:5:1231-1238.

217. Milier RR, Nelems B. Ecwans KG, Muller NL. Ostrow DN. Glandular neoplasia or the lung. Canneer 1988:61:1009-1014.

218. Bernard A. Lawwerys R. Low-molecular-weight proteins as markers of organ toxicity with special reference to Clara cell protein. Toxicology Letters 1995;77:145-1151.

219. Massaro GD, Singh G, Mason R, Plopper CG, Mailkinson AM, Gail DM. Biology or the Clara cell. Conference report. American journal of Physiology 1994;266:L101-106.

220. Ray MK, Wang G. Barrish J. Finegold MJ, DeMayo Rl. mmumotristochemical locatization of mouse Clara cell 10 ko protein using antibodies raised against the recombinant provewn I Histochern Cytochem 1995:44:919.927.

221. Bernard A, Roels H, Lauwerys R, Witters R. Gielens $C$, Soumillon A, van Danme 1, de Ley M. Protein I is a secretory proteir of the respratory and urogenital tracts identical to the Clara celf proteirs. Clin Chem $1992 ; 38: 434-435$.

222. Bernard $A$, Roels $H$, Lauwerys $R$, Witters. $R$, Gielens $C$, Soumillion $A$, van Damme J, de Ley M. Human urinary protein t:evidence for identity with the Clava cell protein and occurrence in respiratory tract and uncgenvitat secretions. Clin Chim Acta 1992:207:239-249.

223. Plopper CG, Macklin F. Nisho SI. Hyde DM, Buckpitt AR. Relationship of cytochrome p-450 activity to clara cell cytotoxicity. Ml. Morphometric analysis of changes in the epithellial populations of terminal bronchioles and lobar bronchi in mice. hiamsters, and rats after parenteral admmistration of naphtalene. Lab irvest 1992;67:553-565.

224. Azzopardi A, Thurbeck WM. The histochemistry of the noncliated bronchiolar eputhelial cell. Am Rev Respir Dis 1969:99:516-525.

225. Kikkawa $Y$. Diverse role of pumonary cytochrome $P$-450 momooxygenase [editorial]. Lab invest 1992:67:535. 539.

226. Plopper CG, Nishio SJ, Alley J, Kass P, Hyde DM. The role of the nonciliated bronchiolar epithelial (Clarall cell as the progenitor cell during bronchiotar epithelial differentiation in the perinatal rabbit lung. Am I Respir Cell Mol Biol 1992;7:606-613.

227. Brody AR. Hook GER, Camerion GS, Jetten AM, Butterick $G$. Nettesheim P. The differentiation capacity of Clara cells isolated from lungs of rabbits. Lab linvest 1987,57:219-22\%.

228. Berend N. Wright $\mathfrak{l}$. Thurlbeck WM. Marlin GE. Woolcock A. Small amways disease: reproducibility of 
measurements and correlation with Hug tunction. Chest $1981,79: 263-268$.

229. Mullen JBM. Wright JL, Wiges BR, Pare PD, Gogg IC. Reassessment of intammation of ainways in chronic arways. Ar Med I 1985:291:1235-1239.

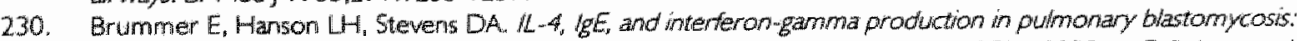
comparison in mice untreated, inmunized, or treated with an antitungat (SCH 39304 ) Cell immunol $1993 ; 1499258 \cdot 267$

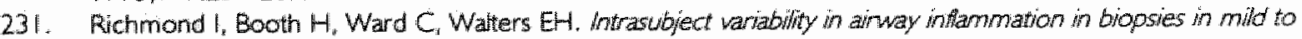
moderate stable athma. Am I Respir Crit Care Med $1996: 153.899 .903$.

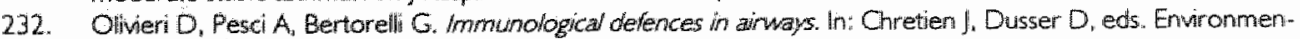
ial impant on the airways. New York: Marcel Dekker, 1996,43-69.

233. Soler P. Moreau A. Basset F. Hance A. Gigarette smoking-induced changes in the number and differentiated state of pulmonary dendritic Langerhains ceils. Am Rew Respir Dis 1989;139:1112-1117.

234. Korm SH, Wouters EFM, Wesseling G. Arends JW. Thunnissen FBM. In wiro and in wo modulation of a- and bghcoconticoid receptor mRNA in human bronchial epithelium. Am I Respir Crit Care Med 1997:155:1 |117. 1122.

235. Gosiney JR Neuroendocrine cell populations in posthatal human lungs: minimal variations from thildhood to old age. Anat Rec 1993:236:177-180.

236. Shimura $S$, Andoh $Y$, Haraguchi $M$, Shirato $K$. Continuty of airway gotiet cells and intraluminal mucus in the airways of patients with bronchial asthma. Eur Respir J 1996,9:1395 i $40 \%$.

237. Sanger JW, MCGilvay Sanger J. Cell division. In: Weiss L, ed. Cell and tissue biology. Gth ed. Baltimore: Urban \& Scharzenberg, 1988;69-92.

238. Lodish Het al. Regulation of the eukayotic cell cycle. In: Lodish H. Batimore D. Berk A, Zipursky SL, Matsudajra P. Darnell J, eds. Molecular cel biology. 3rd ed. New York: Scientific American books, 1995; 1201\%1245.

239. Auberts B at. Differentiated cel/s and the maintenance or tissues. In: Alberts. B. Bray D. Leiws J. Raff M. Roberts K. Watson JD, eds. Molecular biology of the cell, 2nd ed. New York: Garland, 1989:952-1000.

240. Steel $5 G$. Growth kinetics of tumours. Oxfird: Oxtord universify Press, 1977.

241. Hall PA. Watt FM. Stem cells: the generation and maintenance of cellukar diversity. Development 1989:106:619-633.

242. Aherne WA, Camplejohin RS, Wright NA. An introdution to cell population kinetics London: Edward Arnold. 1977.

243. Leblond CP. Cassification of cell populations on the basis of their proviferative behawour. Nati Cancer Inst: Monogr 1964:14:1 19-! 48.

244. Hall PA, Ansari B. The kinetic organisation or tissues. In: Hal PA, Lewison DA, Wright NA, eds. Assessment of ceil proliferation in clinical practice. Berlin: Springer Verlag, 1991 "45-62.

245. von Wangenheim KH. Cell death through differentiation. Poteritial immonta/ity of somatic cells: a teilure in control of difterentration. In: Potten CS, ed. Perspectives on mammalian cell death. Oxford: Oxford Univer sity Press: $1987 ; 129 \cdot 294$.

246. Lajtha LG. Stem cell concepts. In: Potten $\mathrm{SC}$ ed. Stem cells. Edinburgh: Churchill Livingstone. 1983;1 -11.

247. Potten CS, Morris R. Epithelial stem cel/s in wivo. I Cell Sci Suppl 1988; $110: 45-62$.

248. Wells AE. The knethes of cell probleration in the tracheobnonchital coithelia of wats with and without chronic respiratory disease. Cell Tissue Kinet $1970,3,185-206$.

249. Hall PA, Levison DA. Review. assessment of celf proliteration in histologic materia. IClin Pathol 1990;43:184192.

250. Dover R. Basic methods for assessing cellatar prolieration. In: Hall PA, Levison DA, Wright NA, eds. Assessment of call proliferation in dinical practice. Berlin: Springer Verlag, 1991:63\%81.

251. Johnson NF. Hubbs AF. Thomassen DG. Epithelial progenitor cells in the rat respiratory trat. In: Thomassen DG. Nettesheim P, eds. Biology, toxicology and carcinogenesis in the respiratory epithelium. New York: Hemisphere, 1990:88-98.

252. Mason RI. Williams MC. Moses HL. Mohla S. Berberich MA. Stem cells in hung development, disease, and therapy. Anu J Respir Cell Mol Biol 1996;16:355.363.

253. Grazner WI. Monockonal antibody to 5-bromo and 5-kododeoxyridine: a new reagent for the detection of DNA replication, Science 1982:218:474,475.

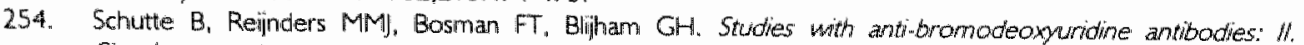
Simultaneous immunocytochemical detection of antigen expression and ONA symthesis by in who labeling of mouse intestinal mucosa. I Histochem Cytochem 1987,35:371-374.

255. de Bruine AP. Dinjens WNM. Zilema HH. Lenders MH. Bosman FT. Renewal of enterochromatin ce/s in the rat caecum. Anat Rec 1992:233:75-82. 
256. Tinnemans MMF, Schutte $B$, Lenders MHIH ten Velde GPM, Ramaekers FCS, Bligham GH. Crtoknetic analysis of hung cances by in wivo bromodeoxyundine labeling. Bif Cancer 1993:67:1217-1222.

257. Tinnemans MMF], Lenders MHIH, ten Velde GPM, Wagenaar SS, Blijham GH, Ramaekers FCS, Schutte $B$. Evaluation of prolferation parameters in wo bromodeoxpuntine kabeded ing cancers. Virchows Archiv
1995:427:295-301.

258. Kubben FGM, Peeters-Haesevoets A, Engels LG]B, Baeten CGMI, Schutte B. Arends MW, Stockbrugger RW. Blijham GH. Prolferating cell nuclear antigen. (PCNA): a new marker to study human colonic cell prodiferation. Gut 1994:35:530-535.

259. Yu CCW, Woods AL, Levison DA. The application of immunohistochemistry in assessment of cellhar prolteration. In: Hall PA, Levison DA, Wright NA, eds. Assessment of cell prolifer ation in elinical practice. Berlin: Springer Verlag, $1991 ; 141-159$

260. Yu CCW. Woods AL, Levison DA. The assessment of cellulam proifteration by immunohistochemistiry: a review of currently avalable methods and their applications. Histochem / 1992:24:121-131.

261. Cattoretti G. Becker MH, Key G. Duchrow M, Schluter $C$. Galle $\|_{n}$ Gerdes 1. Monoclonal antibodies against

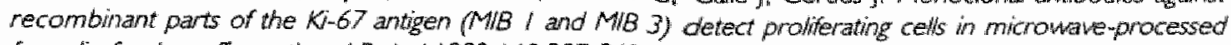
formalion-fxed parafin sections. J Patho! 1992; 168:357-363.

262. Scott Ry. Hall PA, Haldane IS, Noorden S van, Price Y, Lane DP, Wright NA. A comparison of inmmunohistochemical makkers of cell prolfieration with experimentally ctetermined growth fraction. I Pathol 1991:165:173-178.

263. Key $G$. Becker MH, Baron B, Duchrow M, Sehluter $C$. Flad HD. Gerdes J. New Ki-67-equivalent munine monocional antibodies (MB 1-3) generated against bacterially expressed parts of the Ki-67 CONA containing three 62 base pair repetitive elements encoding for the KJ-67 epitope Lab Invest 1993:68:629.636.

264. Munataka S. Hendricks JB. Effect of fixation time and microwave heating time on retrieval or the Ki-67 antigen from parafin membedded tissue. J Histochem Cytachem 1993;41:1241-1246.

265. Lee J5, Hong WK. Biology of preneoplastic lesions. In: Cox JD. Hong WK, eds, Lung Cancer. Cambridge. Massachusetts, USA: Blackwell, inc., 1993;34-56.

266. Hall PA, Levison DA, Woods AL, Yu CCW, Kellock DB, Watkins JA, Barnes DM, Gillett CE, Camplejohn R. Dover $\mathrm{R}$, Waseem NH. Lane DP. Prolferating cell nuclear antigen (PCNA) immulocalization in parafins sections: an index of cell problteration with evidence of deregulated expression in some neoplasms. I Pathol 1990;162:285-294.

267. Bulten J, van der Laak JAWM, Gemmink JH, Pahlplatz MMM, de Wilde PCM, Hanselaar AGJM. MIB I, a promising marker for the classification of cervical intraepithelial neoplasia. I Pathol 1996:178:268-273.

268. Lynch DAF, Clarke AMT, Jackson P. Axon ATR, Dixon MF, Quirke P. Comparison of labelling by bromodeaxysridine, MBB-l, and PCNA in gastric mucosal biopsy specimens. I Clin Pathol 1994;47:122-125.

269. Gerdes J, L I I, Schlueter C. Duchrow M. Wohlenberg C. Gerlach C. Stahmer I, Kloth S, Brandt En Flad HD. immunobiochemical and molecular biologic characterization of the cell prodiferation-associated nuclear antigen that is defined by monoclonal' antibody $K j-67$. Anv J Pathol 1991;138:867-873.

270. Gerdes J. Lemke H. Baisch H. Wacker HH, Schwab U, Stein H. Cell cycte analysis of a celf proliferationassociated human muclear antigen defined by the monoclonal andibody Ki-67. I limmunal 1984:133:1710-1715.

271. Brown DC, Gatter KC. Monoclonial antibody Ki-67: its use in histopathology. Histopathology 1990:17:489-503.

272. Braun N. Papadopoulos T. Mueller-Hermelink HK. Cell cycle dependent distribution of the proditetion associated Ki-67 antigen in humarn embryonic hung celts. Wirchows. Archiv B CP 1988;56:25-33

273. Verhejen R, Kujpers HIH, Driel R van, Beck JLM, Dierendonck JH varn, Brakenhoff G. Rarmaekers FCS. KitG? detects a nuclear-associated proiferation related antigen. W. Localization in mitotic cells and association with chromosomes. J Cell Sci 1989:92:531-540.

274. Verhejien R, Kujpers HJH, Schllingemann RO, Boehmer ALM, Driel R van, Brakenhoff G], Ramaekers FCS. Ki67 detects a nuclear matrix-associated prolferation-related antigen. I. Intracellular locakization during interphase: 1 Cell Sci 1989;92:123-130.

275. Guillaud P. Manoir S du. Seigneurin D. Quantihcation and topographical description of Ki-67 antibody labeling during the cell Cycle of nomal fibroblastic (MRC-5) and mammary tumour cell hines. (MCF-7). Analyticall Cellular Pathology 1989:1:25-39.

276. Sasaki K. Murakami $\pi$, Kawasaki M. Takahashi M. The cell cycle associated change or the Ki-67 reactive nuclear antigen expression. J Cell Physiol 1987:133:579-584,

277. Hall PA, Levison DA. Wright NA. eds. Assessment of cell proliferation in chinical practice. London: SpringerVerlag, 1992.

278. Cattoretti G, Pileri S, Parrancini C. Becker MHG, Poggi S. Bifulco C, Key G, Dismato, Sabattini E. Feudale E. Reynolds F. Gerdes ]. Rilke F. Antigen unmasking on formalin-fixed" paraffin-embedded tussue sections. ] Pathol 1993:171:83-98. 


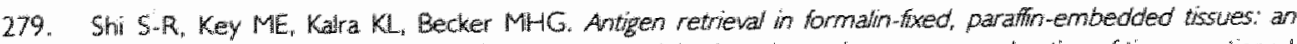
enhancement method tor immunohistochemical staining based on microwave oven heating of tissue sections. I Histochern Cytochern 1991:39:741 -748.

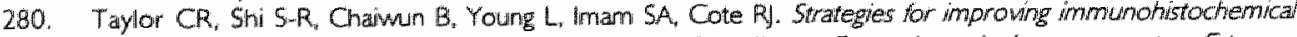
staining of various intranuclear prognostic markers in tormalin-paraffin sections. Androgen receptor. Etrogen recepior, Progesterone receptor, 553 protein, Prohterating Cell Nuclear Antigen, ano ki-67 antigen reveated by antigen retrieval techriques. Hum Pathol $1994: 25: 263 \times 270$.

281. Norton Al. Jordan $\$$ Yeomans: P. Brief, high temperature heat denaturation (pressure cooking) a simple and effective method of antigen retrieval for routinely processed thsives. I Pathol 1994:173:37|1-379.

282. Miller $K$, Auld J. Jessup E, Rhodes A, Astiton Key M. Antigen unmasking in tornalin fixed routinely procexsed paralfin wax wembedded sections by presisure cooking: a comparison whith microwave oven heating and traditional methouls. Advances in Anatomic Pathology 1995:2:60-64.

283. Cattoretti $G$, Sulumeijer AjH. Antigen unmasking on formalin fixed paraflin-embedded tissues using microwaves: a revew Advances in Anatomic Pathology 1995:2:2-9.

294. Hazelbags HM, van-den-Broek L, van "Dorst EB. Offerhaus G. Fleuren G., Hogendoom PC. Immunostainmg of chawispecific keratins on formalin fixed, parath-embedded tissues: a companison of various antigen retreval systems using wicrowave heating and proteolytic pre treatments. I Histochem Cytochem 1995:43:429.437.

265. Suurmeifer AH Boon ME. Optimizing keratin and wimentin retrieval in formatin fixed, parafin-embedded tissue with the use of heat and metal salts. Appl Immunohistochem 1993:1:143-148.

286. Leong AS-Y, Milios J. An assessment of the efficacy of the microwate antigen-retrieval procedure on a range of tissive antigens. Appl Immunohistochem 1993;1:267-274.

287. Gown AM, de Wever $N_{1}$ Battifora H. Microwave-based andigen unmasking. Appl Immunohistochem $1993+1: 256-266$

288. Dapson RW. Fixation of the 1990s: a review of needs and accomplishments. Biotechnic \& Histochemistry $1993: 68: 75-82$.

289. Shi SR, mam SA, Young L, Cote R. Taylor CR. Antigen retrieval immunotwistochemistry under the infuence of pH using monoclonal antibodies. J Histochem, Gytochem 1995:43:193-201.

290. Shi SR, Chaimun B, Young L, Imam A, Cote R., Taylor CR. Antigen retrieval using pH 3.5 glycine-picl buffer or urea solution for immunohistochemical localization of Ki-67. Biotech Histochem 1994;69:213-215.

291. Weerden WM van, Moerings EPCM, Kreuningen A van, Jong FH de, Steenbrugge G] van, Schroeder FH. Ki-67 expression and BrdUrd incorponation as markers of prollerative activity in human prostate tumour models. Cell Prolff 1993;26:67-75.

292. Sasaki K. Matsumura K. Tsuji T. Shinozakj F. Takahashi M. Rabationship between labeling indices of $K i-67$ and BrdUrdin human malignant tumors. Cance! $19888 ; 62999-993$.

293. Tsujihashi H, Nakanishi $\mathrm{A}_{1}$ Matsuda H, Uejima S, Kurita T. Cell prokferation of human bladder tumors determined by Erdurd and Ki-67 immunostaining J Urol 1991:145:846-849.

294. Kein N. Vignaud IM. Sadmi M. Plenat $F$. Borelly $\downarrow$, Duprez A. Martinet $Y$. Martinet N. Squamous metaplasia expression of proto oncogenes and P 53 in hung cancer patients. Lab Invest 1993;68:26-32.

295. Sabatini E, Gerdes J, Gherlinzoni F, Pogeg S, Zucchini L, Melill G, Grigioni F, Vecchio M del, Leoncini L, Falini B. Pileri SA. Companison between the monoctonal antibodies $k / 67$ and PCHO in 125 malgnant hmphomas. I Pathol 1993:169:397-403.

296. Brambilla E, Veale D. Moro D. Morel F. Dunois F, Buambilla C. Neuroendocrine phenotype in lung cancers. Comparison of immumohistochemistry with biochemical determination of enokse isoenzymes. Am . Clin Pathol $1992,98: 88-97$

297. Bhatnagar M. Springall DR, Ghatei MA, Burnet PW. Hamid Q. Graid A, lbrahim NBN, Cuttitta F, Spindel ER, Penketh R. Rockek C. Bloom SR. Polak IM. Localisation of mRNA and co-expression and molecular forms of GRP gene products in endocrine cells of teat human hung. Histochemistry 1988;90:299-307.

298. Aguayo SM. Determinants of susceptibulty to cigarette smoke. Potential roles for neuroendocrine cells and

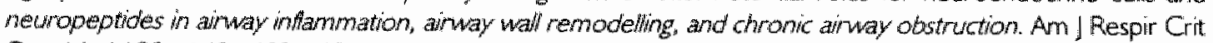
Care Med 1994:149:1692-1698.

299. Sorokin SP. Hoyt RF. Grant MM. Development of neuroepithelial bodies in tetal rabbit hung. I. Apoearance and Anctionat maturation as demonstrated by high-resolution light microscopy and formaldehyde-induced Auorescence Exp Lung Res 1982:3:237-259.

300. McDougall I. Endocrine like celts in the terminal bronchioles and saccules of human fetal tung: An ultrastructural study. Thorax 1978;33:43-53.

301. Weiss: DL, Tweeddale DN. Intation-fixation of Iungs: we of a smple inexpensive apparatus. Am Rev Respir Dis $1966,94: 629-631$. 
of lung tumours; 2nd edition. Am J Cin Pathal 1982;77:123-136.

330. Lambkin HA, Mothersill CM, Kelehan P. Variations in immunohistochemical detection of p53 protein overexpression in cervival carcinomas with different antibodies and methods of detection. I Pathol 199:4:172:13-18.

331. Harris CC. Holistein M. Oinical implications of the p53 tumor-suppressor gene. N Engl I Med 1993:329:1318. 1327.

332. Hall PA, Mckee PH, Menage $H$ du, Dover $R$, Lane DP. High levels of 053 protern in UNimradialed noman human skin, Oncogene 1993;8:203-207.

333. Fritsche M, Hatessler $C$. Brandiner $G$. Induction of nuclear accumulation of the tumor-suppressor protein 0.53 by DNA-damaging agents. Oncogene 1993;8:307-318.

334. Kastan $M B$, Onyekwere $O$, Sidransky D, Vogelstein $B, C r a i g, R$. Participation of $p 53$ protein in the cellutar response to DNA damage. Cancer Res 1991:51:6304-6311.

335. Baas 1O, Mulder JWR, Offerhaus: GIA, Vogelstein B. Hamilton SR. An evaluation of six antibodies for immunohistochemistry of mutant $\rho 53$ gene product in archival colorectal neoptasms. Pathol 199.4:172:5-12.

336. Wyntord-Thomas. D. $\rho 53$ in tumour pathology; can we trust immunohistochemistry? (editorial). I Pathol $1992 ; 166: 329-330$

337. Bosari S, Roncalli M, Viale $G$, Bossi $P_{9}$ Coggi G. p.53 immunoreactivity in intlammatory and neophastic disease of the uterine cerwix. J Pathol 1993:169:425-430.

338. Cattoretti $G$, Becker $M H G, K e y, G$, Duchrow M, Schiueter $C$, Galle J. Gerdes J. Monocional antibodies against recombinant parts of the $K-67$ antigen (MBB I and MB 3) detect profferating cells in microwawe-processed formalin-fixed parathin sections. I Pathol 1992;168:357-363.

339. Key G, Becker MHG, Baron B, Duchrow M, Schiueter C. Flad HD, Gerdes J. New Ki-67 equivalent murine monoclonal antinodies (M/B 1-3) generated against bacterially expressed parts of the KI-67 CONA containing three 62 base pair repetitive elements encoding for the Ki-67 epitope. Lab Invest 1993:68:629-636.

340. Lu Q.L. Poulsom R. Wong L, Hanby AH. BCi-2 expression in adult and emoryonic non-hematopotetic tissues. I Pathol 1993:169:431-437.

341. Massaro D. ed. Lung cell biology. New York: Marcel Dekker, 1989.

342. Harris CC. p.53: At the crossroads or molecular carcinogenesis and risk assessment. Science 1993:262:19801981.

343. Lowe $5 W$, Schmitt EM, Smith $5 W$, Osborne BA, Jacks $T, 053$ is required for radiation induced apoptosis in mouse thymocytes. Nature 1993;362:847-849.

344. Lane DP. The regulation of 053 function: Steiner award lecture. Int / Cancer 1994:57:623-627.

345. Smith ML., Fornace A. The two faces of tumor suppressor p53. Am \ Pathol 1996; 48:1019-1022.

For an invaluable description of multiple immunohistochemical staining methods the reader is referred to:

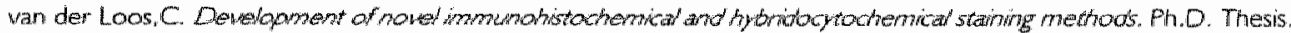
WU University Press Ansterdam, 1992. 


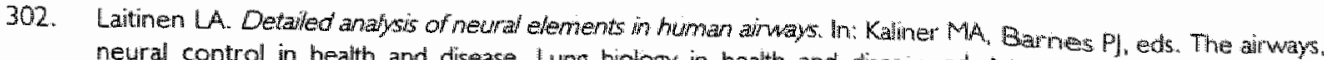
neural contral in heath and disease. Lung biology in health and disease ed. New York Marcal Dekker.
$1988 ; 35-56$.

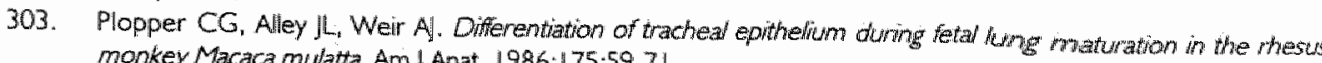
monkey Macaca mulatta. Am I Anat 1986:175:59-71.

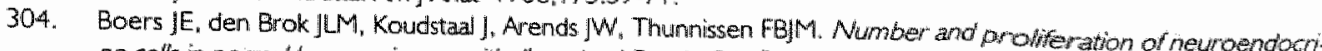
ne cells in normal human ainway epithelium. Am, Respir Crit Care Med 1996:154:758-763

305. Silcocks PBS. Measuring repeatabithty and wallity of histological diagnosis - brier mewiew with some pacticas examples. ] Clin Pathol 1983,36:1269:1275.

306. Kuehl RO. Statistical principles of research design and analysis. Belmont. Ca, USA: Duxbury Press, 1994

307. Neter J. Wasserman W, Whitmore GA. Interences for population proportion. In:. Applied Statistics. 3ro ed. Newton. MA: Alyn and Bacon, 1988;367-397.

308. Going ll. Techniques of mitasis counting Detterl. Hum Patho 1993;24:113-114.

309. Thurbeck WM, Churg AM, eds. Pathology of the kug 2nd ed. New York: Thieme, 1995.

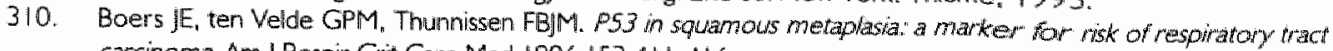
carcinoma. Am J Respir Crit Care Med 1996:153:411 4/6.

31. Taylor CR. Immunomicroscopy: a diagnostic tool for the surgical pathologist. 2nd ed. philadelphia: WB Saun. ders, $1994: 326$.

312. Nomori $H_{11}$ Horio $H_{1}$ Fuyuno G, Kobayashi R. Morinaga S, Hirabayasini $Y$. Protein (Clara Cell Protein) serum levels in healthy subjects and patients wh bacterial pneumonia. Am J Respir Crit Care Med 1995:152746-750.

313. Rehm S, Takahashi M, Ward JM. Singh G. Katyal SL, Hennemun JR, Immunohistochemical demonstration of Clara cell antigen in hung tumors of bronchiola origin induced by N-nitrosoctiethywarnine in syman golden hamsters. Am I Pathol 1989;134.79-87.

314. Tyler NK. Plopper CG. Morphology of the distal Conducting awways in thesus monkey lungs. Anat Rec $1985.211: 295-303$.

315. Trump BF. MCDowell EM. Glain F, Barrett LA. Becci PJ, Schuerch W, Kaiser HE, Harris CE. The respiratory epithelium. IIt. Histogenesis of epidermoid metaplasia and carcinoma in situ in the human. I Natl Cancer Inst $1978 ; 61: 563-575$

316. Ura H. Nowak P. Litwin S. Watts P, Bonfi! RD, Klein-Szanto JP. Effects of formalidefynde on nommat xenotransplanteol human tracheobronchial eprithelium. Am ) Pathol 1989:13499-106.

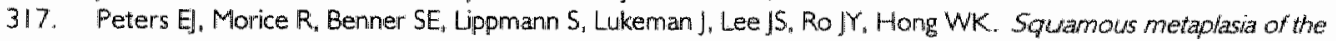
bronchial mucosa and its relationship to smoking. Chest $1993 ; 103: 1429 \% 1432$.

318. Saccomanino G, Archer VE, Auerbach O, Saunders. RP. Brennam $L M$. Development of carcinoma of the Aung ats reflected in exfoliated cells. Cancer 1974,33:256-270.

319. Auerbach $O$, Cuyler Hammond $E_{k}$ Gartinkel L. Changes in bronchial epithelium in retatron to cigarette smoking, 1955-1960 w 1970-1977. N Engl I Med 1979:300:381-386.

320. Cotran RS, Kumar V. Robbins 5L. Pathologic basis of disease 4th ed. Phitadelphia: Wh. Saunders Conpary. 1989.

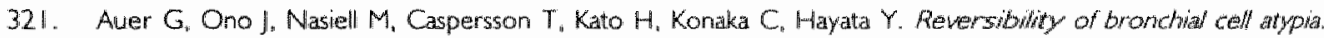
Cancer Res $1982 ; 42: 4241-4247$

322. Nuorva K, Soini Y, Kamel D. Autiontarmainen H. Rustell L, Ristejil Vahakangas K, Paakko P. Coneurrent p53 expression in bronchial dysphasias and squamous cell lung carcinomas. Aun / Pathol $1993,142.725-732$.

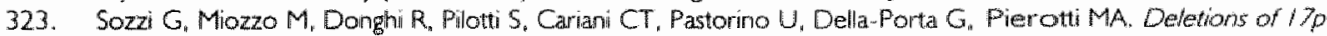
and 053 mutations in preneoplastic lesions of he hung. Cancer Res $1992.52 .6079-6082$.

324. Sundaresan $V$. Gandy $P$. Hasteton P. Rudd R, Sinha G. Bleehen NM, Rabbitts P. p53 and chromosame 3 abnomatities, characteristic of malignant hung wmours, are detectable in premwasine kesions of the bronchus. Oncogene 1992;7:1989-1997.

325. Bennett WP, Colby TV, Traws WD. Borkowski A, Jones RT, Lane DP Metcal RA. Samet M, Takeshima Y. Gu 1R. Wahakangas KH. Soini Y, Paako P. Welsh JA. Trump BF. Harris CC. p53 Profern accurnulates thequewhtly in early bronchial neoplasia. Cancer Res $\$ 993,53: 4817-4822$.

326. Hirano T, Franzen B. Kato H, Ebihara Y. Auer G. Genesis of squamous cell lung carchoma. Sequential changes of prolferation, ONA Ploidy, and p53 expression. Am J Pathol $1994: 144: 296-302$.

327. Vogetstein B. Fear on ER, Hamilon SR, Kern SE. Presinger AC, Leppert M, Nakam wrat Y, White R, Smits AMM. Bos. J. Genetic atterations during coloreatat-"umor development. N Engl J Med 1988;319:525-532.

328. Pezzela F. Turley H, Kuzu I, Tungekar MF, Dunnill MS, Pierce CB. Harris A, Gatter KC. Mason DY. bC-2 Protein in non-small-cell lung carchoma. N Engl I Med 1993:329:690-694.

329. Shisomato $Y$, Sobin LH, Spencer H, Yesmer R. The Wort'Heath Organisation Organisation Histological typing 


\section{Curriculum vitae}

De schrijver van dit proefschrift werd op 20 april 1959 geboren in Calgary, Canada. Hij emigreerde in 1963 naar Nederland, en deed in 1977 eindexamen WO-B op het Chr. Lyceum-HAVO te Gouda. Alhoewel vrijgesteld van militaire dienst ("lichting "59") kon hij pas in 1978 de studie Geneeskunde aan de Erasmus Universiteit te Rotterdam aanvangen vanwege het lot; in april 1986 werd het arts-examen behaald. Aan dezelfde Universiteit werd in 1977 de studie Nederlands recht gestart; eind 1987 werd het doctoraal examen (privaatrechtelijke en bedrijfjuridische afstudeerrichtingen) afgelegd.

In 1988/9 was hij arts-assistent niet in opleiding (AGNIO) Cardiologie, en in 1989/91 AGNIO Interne Geneeskunde in het Bergweg ziekenthuis te Rotterdam (deze instelling ging met het Eudokia ziekenhuis op in het IJsselland ziekenhuis te Capelle a/d IJssel). In het eerste kwartaal van 1992 heeft hij het voorrecht gehad AGNIO pathologie te mogen zijn bij P. Spaander, patholoog, verbonden aan het Rode Kruis ziekenhuis te Den Haag; aldaar werd een onbetaalbare 'spoedcursus pathologie' doorlopen. Daaropvolgend werd in de periode 1992-1997 de opleiding tot patholoog gevolgd in het Academisch ziekenhuis Maastricht (opleider: Prof. Dr. J.W. Arends), alwaar hij in de gelegenheid werd gesteld het onderzoek te verrichten wat de grondslag vormt van dit proefschrift.

Per \| juli 1997 werd hij als patholoog aangesteld aan het Laboratorium voor Pathologie te Zwolle, dat organisatorisch onderdeel uitmaakt van ziekenhuis. De Weezenlanden, doch tevens werkzaamheden verricht t.b.v. het Sophiaziekenhuis en de huisartsen / verpleeghuisartsen in de regio Zwolle.

Hij is getrouwd met Elies de Geus, verloskundige, en vader van Sarah, Heleen en David. 